\title{
Abflussverzögerung - wie Abfluss gebremst werden kann
}

6.1 Flächige, schlaginterne Maßnahmen zur Erhöhung der Oberflächenrauheit - 115

6.2 Grünstreifen - 121

6.3 Begrünte Abflussmulden (Grassed Waterways) - 124

6.4 Kleinstrückhaltebecken in der landwirtschaftlichen Flur - 129

6.5 Flurgliederung und Flächenarrangement - 137

6.6 Abflussgeschwindigkeit in Gräben und Rohren - 146

6.7 Wege- und Wasserführung - 150

Literatur - 153 
In diesem Kapitel werden Maßnahmen zur Minderung der Abflusskonzentration und zum Bremsen des Abflusses zwischen Wasserscheide und Gewässern III. Ordnung beschrieben. Ansatzpunkte dafür sind in allen Abschnitten des Fließpfades vorhanden. Vorweg sei dabei betont, dass Maßnahmen zum Schutz vor Erosion nicht mit Maßnahmen zur Abflussminderung verwechselt werden dürfen. Dafür gibt es drei wesentliche Gründe:

Der erste Grund ist, dass die Mechanismen verschieden sind. Das fängt bereits beim Regen an: Niederschläge, die Abfluss fördern, müssen nicht zwingend im gleichen Maß Abtrag fördern. Beispielsweise hatte der Regen, der die katastrophale Sturzflut von Simbach auslöste, zwar eine hohe, aber keinesfalls außergewöhnliche Erosivität [1]. Ebenso muss eine Maßnahme, die Erosion verringert, nicht zwangsläufig den Abfluss verringern oder umgekehrt. Deutlich wird das zum Beispiel an Filterstreifen, die transportierte Feststoffe aus dem Oberflächenabfluss herausfiltern, dabei aber nur einen vernachlässigbar kleinen Einfluss auf die Abflusssumme oder die Fließgeschwindigkeit im Mittel des Gesamthanges haben.

Der zweite Grund liegt darin, dass Abtragssumme (Erosion) und Abflussscheitel von verschiedenen Komponenten bestimmt werden. Erosion ergibt sich aus dem Produkt (Abflusssumme · Sedimentkonzentration). Da sich beides, und dabei vor allem die Sedimentkonzentration, vermindern lässt, wird häufig angenommen, Erosion sei leichter beeinflussbar als der Abfluss, wobei unter dem unspezifischen Wort Abfluss meist die Abflusssumme verstanden wird. Der Hochwasserscheitel resultiert aber aus dem Produkt (Abflusssumme · Scheitelanstiegszeit). Auch die Scheitelanstiegszeit lässt sich, und zwar stark, über die Fließgeschwindigkeit beeinflussen. Damit ist Hochwasser in der ländlichen Flur ebenso stark beinflussbar wie Erosion. Die begrenzte Beeinflussbarkeit von Erosion und Hochwasser allein über die Abflusssumme zeigt sich schon darin, dass bei sehr langanhaltenden Regen (z. B. wie bei dem
Ereignis von Simbach) selbst die Infiltrationsleistungen von Grünland oder Wald natürlicherweise an ihre Grenzen kommen. Der Feststoffaustrag bleibt dort aber trotzdem gering, weil die Sedimentkonzentration im Abfluss unter Grünland oder Wald gering bleibt. Der Hochwasserscheitel kann auch gering bleiben, wenn die Fließgeschwindigkeit gering bleibt. Dazu muss der Abfluss in der Fläche z. B. durch eine dauerhafte Bodenbedeckung $>30 \%$ und entlang der kompletten Fließwege durch breite und hydraulisch raue Gerinne gebremst werden.

Ein analoges Beispiel im Ackerbau ist die Mulchdirektsaat, die den Bodenabtrag stark senken kann, die Abflusssumme aber weit weniger. Betrachtet man nur die Abflusssumme, erscheint diese Maßnahme zunächst weniger effektiv als hinsichtlich der Abtragssumme (• Abb. 6.1). Der Effekt auf den Abtrag ist so stark, weil zusätzlich zu Abflusssumme auch die Sedimentkonzentration zurückgeht. Da Abflusssumme und Sedimentkonzentration multipliziert werden, um den Abtrag zu errechnen, senkt Bedeckung die Abtragssumme quadratisch ab. Die Abflusssumme sinkt dagegen nur linear ab. Allerdings führt Mulchdirektsaat wegen der erhöhten Bodenrauheit und der längeren Strecke, über die schichtförmiges Fließen erfolgt, auch zu einer ausgeprägten Verminderung der Fließgeschwindigkeit. Da sowohl Fließgeschwindigkeit als auch Abflussvolumen im Mittel proportional zum Abflussscheitel sind, ist durch Mulchdirektsaat ebenfalls mit einer quadratischen Verminderung des Abflussscheitels am unteren Feldrand zu rechnen. Der Einfluss von Mulchdirektsaat auf Abflussscheitel und Bodenabtrag dürfte daher ähnlich groß sein.

Bei der Beurteilung einer Maßnahme, insbesondere bei solchen, die hier nicht beschrieben sind, sind daher immer zwei Fragen zu stellen: Wie stark beeinflusst die Maßnahme die Abflussbildung? Wie stark beeinflusst die Maßnahme die Fließgeschwindigkeit? Um wie viel, kann mit den hier angebotenen Planungsansätzen 

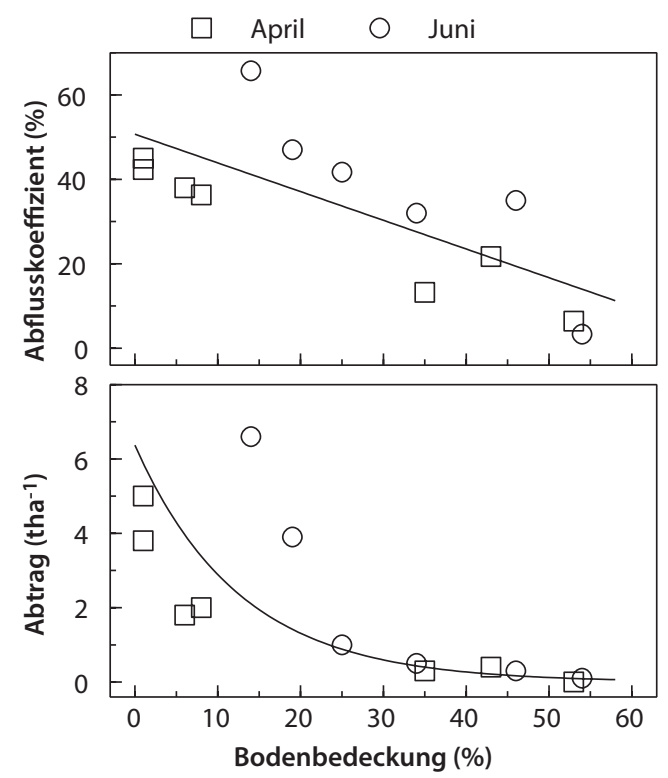

- Abb. 6.1 Mit zunehmender bodennaher Bedeckung geht der Abflusskoffizient linear zurück (oben), der Bodenabtrag aber überproportional (quadratisch) (unten), sodass mit $20 \%$ bis $30 \%$ Bedeckung schon ein sehr guter Erosionsschutz erreicht werden kann. Die Daten stammen von Beregnungsversuchen mit $65 \mathrm{~mm} \mathrm{~h}^{-1}$ auf Zuckerrübenfeldern [2]. Die Unterschiede in der Bedeckung beruhen auf unterschiedlichen Anbauverfahren und darauf, dass im Juni auch Zuckerrüben und Unkräuter zur Bedeckung beigetragen haben. Diese ganz unterschiedlichen Bedingungen neben der Variation in der Bedeckung erklärt die Streuung. Dadurch ist aber auch die Übertragbakeit auf einen weiten Bereich von Bedingungen gewährleistet

abgeschätzt werden. Exemplarische Beispiele zur Wirkung unterschiedlicher Maßnahmen werden im Folgenden dargestellt. Ein umfangreicheres Planungsbeispiel befindet sind in - Kap. 7.

Der dritte und letzte wesentliche Unterschied zwischen Erosion und Hochwasser besteht darin, dass sich Erosion grundsätzlich nur auf der erodierenden Fläche, im Normalfall auf der Ackerfläche, verhindern lässt. Die Verantwortung liegt daher ausschließlich beim Landwirt. Im weiteren Verlauf des Fließweges kann man höchstens eine Wiederablagerung und damit einen Schutz unterhalb liegender Systeme erreichen (Verringerung von sogenannten off-site Schäden), aber nicht den eigentlichen Erosionsschaden in der Fläche verhindern (on-site Schäden). Im Gegensatz dazu lässt sich beim Abfluss die Fließgeschwindigkeit entlang des gesamten Fließpfades beeinflussen. Verantwortung für den Hochwasserscheitel haben daher viele Akteure. Das fängt beim Landwirt in der Fläche an, setzt sich über die Gemeinde (und deren ausführende Organe), die beispielsweise für die Pflege und Unterhaltung von Straßen und Gräben oder die Gewässer III. Ordnung zuständig ist, fort und geht bis zur Wasserwirtschaftsverwaltung, die für die größeren Gewässer verantwortlich ist. In Wäldern stehen Forstwirte in der Verantwortung und bei größeren Projekten wie Flur- oder Bodenneuordnungsverfahren die Organe der Ländlichen Entwicklung, die über die Parzellierung der Flur und über das Wegenetz bestimmen. Im Folgenden sind verschiedene Maßnahmen aus unterschiedlichen Abschnitten des Fließweges beschrieben.

\subsection{Flächige, schlaginterne Maßnahmen zur Erhöhung der Oberflächenrauheit}

Zentraler Ansatzpunkt schlaginterner Maßnahmen ist die Erhöhung und Stabilisierung der Oberflächenrauheit. Die Rauheit wird von der Bedeckung bestimmt, die der Bodenoberfläche aufliegt, d.h. (niedriger) Bewuchs und Mulch, und von der Mikrotopographie des Bodens, die von der Bodenbearbeitung abhängt und im Laufe der Zeit durch die Witterung eingeebnet wird. Wie die Rauheit der Bodenoberfläche durch Bearbeitung verändert, durch Bodenbiomasse stabilisiert und durch nachfolgende Regen eingeebnet wird, kann mit den in der Revised Universal Soil Loss Equation 2 [3] angegebenen Gleichungen bei Bedarf taggenau modelliert werden.

Die Rauheit stellt für den Schichtabfluss das wesentliche Strömungshindernis dar. Sie 
erhöht auch die Infiltration, weil die Wasserspeicherung hinter einzelnen Rauheitselementen relativ hoch sein kann, der Abfluss lange unterwegs ist und damit auch nach Regenende infiltrieren kann. Vor allem aber schützen hohe Bodenbedeckungsgrade die Bodenoberfläche vor Verschlämmung, und sie schaffen eine stabile, heterogene Oberflächenstruktur, bei der sich das Wasser weniger leicht eigene Bahnen schaffen kann. Dadurch fließt der Abfluss über eine längere Strecke breitflächig und damit langsam, bevor sich der Abfluss einschneidet und der schnellere Rillen- und Rinnenabfluss beginnt. Durch eine Erhöhung der Bodenbedeckung kann daher eine überproportionale Abflussverzögerung in der Fläche erzielt werden. Weitere positive Nebeneffekte sind die Reduktion des Bodenabtrags und die Reduktion der Verdunstung. Hohe Bodenbedeckungsgrade wirken daher ausgleichend auf den Wasserhaushalt und mindern Hochwasser wie Trockenheit gleichermaßen. Aufgrund der zahlreichen und positiven Eigenschaften gelten durchgehend hohe Bedeckungsgrade als beste Maßnahme des Bodenschutzes [4]. Etablierte Möglichkeiten, eine hohe Bedeckung zu erreichen, sind:

- Mulch- oder Direktsaatverfahren (mit $\geq 30 \%$ Mulchbedeckung)

- Konsequenter Anbau von Zwischenfrüchten oder Untersaaten

- Verzicht auf eine wendende Bodenbearbeitung

- Mehrjährige Kulturen (Kleegras).

Wirkung von Zwischenfrüchten und Untersaaten

Zwischenfrüchte werden meist im Herbst umgebrochen, was ihre Wirkung auf einen kurzen Zeitraum beschränkt (• Abb. 6.2, obere Tafel). Ihre Wirksamkeit steigt stark, wenn auf den Umbruch verzichtet wird, da dadurch die meiste Zeit des Jahres Bedeckungsgrade $>50 \%$ erreicht werden können (• Abb. 6.2, untere Tafel). Auch Untersaaten ermöglich, dass die Bodenoberfläche auch nach der Ernte der
Hauptfrucht noch effektiv durch eine hohe Bedeckung geschützt ist (• Abb. 6.3). Sie vermeiden die Lücke in der Bedeckung zwischen der Ernte der Hauptfrucht und der Bestandsbildung der Zwischenfrucht.

Eine hohe Rauheit der Bodenoberfläche kann auch durch ackerbauliche Maßnahmen gefördert werden. Dazu zählen:

- Höhenlinienparallele Bewirtschaftung

- Streifenbearbeitung (englisch „Strip Till“ oder „Strip Tillage“; im Gegensatz zum Streifenanbau, dem „Strip Cropping“)

- Anbau von Kulturen wie Mais in höhenlinienparalleler Dammbauweise (engl. „Ridge Tillage“).

Aufgrund ihrer Verbreitung wird auf die höhenlinienparallele Bewirtschaftung detaillierter eingegangen, obwohl sie im Hinblick auf den Abfluss (deutlich) weniger effektiv ist als z. B. die Streifenbearbeitung, die jedoch in Deutschland bisher noch kaum Verbreitung gefunden hat. Bei der Konturbearbeitung bzw. hang- oder höhenlinienparallelen Bewirtschaftung entstehen aus kleinen, quer zur Gefällerichtung angeordneten Mulden- und Rillenstrukturen Widerstände für den Oberflächenabfluss. Dies erhöht die Infiltration und verlängert die Strecke flächenhaften Fließens. Damit dies der Fall ist, müssen aber mehrere Bedingungen gegeben sein [8-10]: Erstens darf der Niederschlag nicht zu extrem sein (Wiederkehrintervalle <15 Jahre). Zweitens muss die Oberfläche auch wirklich rau sein, also Höhenunterschiede von mindestens mehreren Zentimetern über die gesamte Vegetationsperiode aufweisen. Damit Letzteres erreicht wird, muss der Bedeckungsgrad zwangsläufig hoch sein, weil nur dann die (natürliche) Einebnung der Bodenoberfläche durch die Witterung gering ist [Gleichungen siehe 35]. Drittens sollte die Neigung unter $9 \%$ (besser unter $5 \%$ ) sein, weil dann die Wasserspeicherung hinter einzelnen Rauheitselementen noch relativ groß und der Infiltrationszuwachs relevant wird. Viertens 


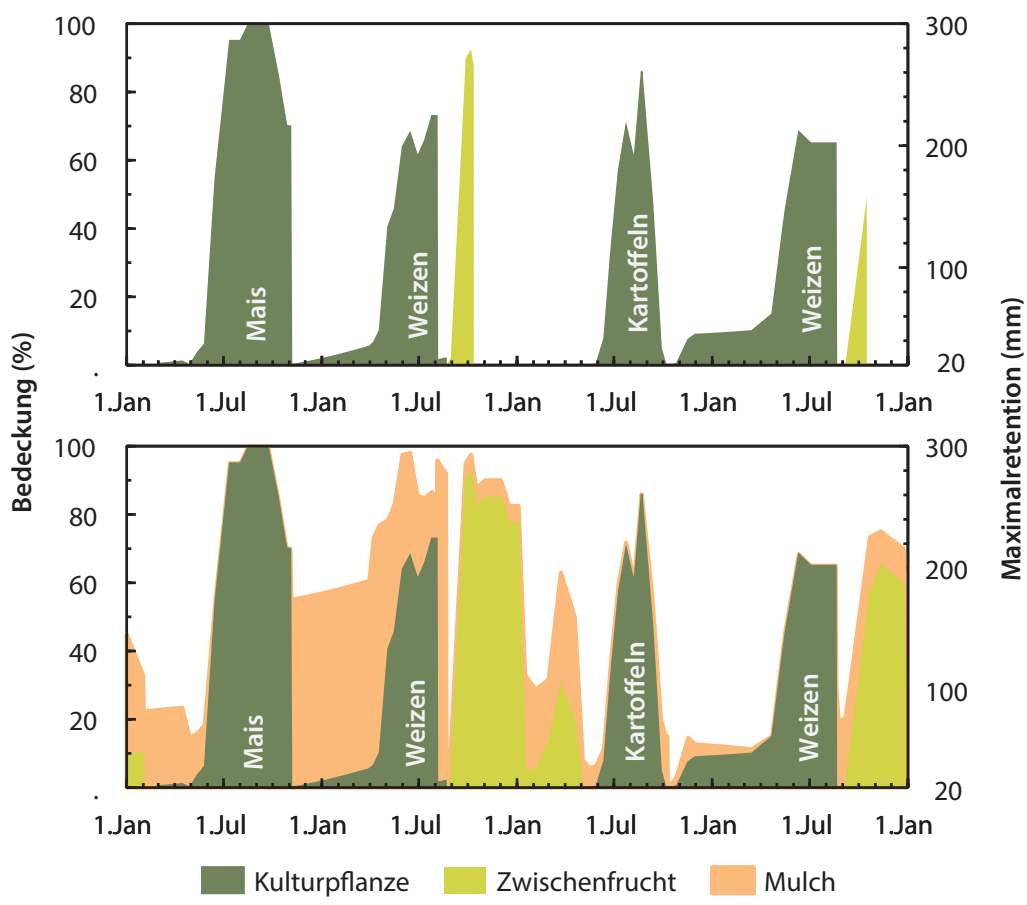

- Abb. 6.2 Veränderung von Bodenbedeckung (linke Achse) und maximaler Retention (rechte Achse) bei einem unendlichen langen Regen auf Ackerschlägen im Verlauf mehrerer Jahre, wobei oben die Zwischenfrüchte im Herbst eingearbeitet wurden, während sie unten über den Winter standen, abfroren und eine dichte Mulchschicht für die folgenden Reihenkulturen (Mais bzw. Kartoffeln) lieferten [5]. Die Maximalretention wurde über das CN-Verfahren [6] und den Zusammenhang zwischen Bedeckung und CN-Wert geschätzt

darf die Fließlänge bzw. das oberirdische Einzugsgebiet nicht groß sein, weil sonst der Oberflächenabfluss die Querstrukturen durchbricht. Damit ist zu rechnen, wenn die Hanglänge in Richtung des Hauptgefälles länger als die kritische Hanglänge ist. Die kritische Hanglänge sinkt mit zunehmender Neigung, da das Wasserspeicherungspotenzial der Mikrotopographie und kleiner Rauheitselemente dann abnimmt. Die kritische Hanglänge kann nach > Gl. 6.1 ermittelt [11] oder aus den Werten in $\bullet$ Tab. 6.1 abgeschätzt werden:

$$
H L_{k r i t}=170 \cdot e^{-0,13 \cdot H N}
$$

mit

$\mathrm{HL}_{\text {krit }}$ - Kritische Hanglänge (m)

$\mathrm{HN}$ - Hangneigung (\%)

\section{- Beispiel}

Um den Effekt der verschiedenen schlaginternen Maßnahmen auf die Abflussverzögerung im Feldmaßstab quantitativ abzuschätzen, können über die Rauheit, die Ausbildung des Entwässerungsnetzes und über die GMS-Gleichung Fließgeschwindigkeit und Fließzeit bestimmt werden. Das Vorgehen wird exemplarisch anhand eines $170 \mathrm{~m}$ langen und $135 \mathrm{~m}$ breiten Feldes (2,3 ha) mit einer einheitlichen Neigung von $4 \%$ für verschiedene Bedeckungsgrade (0, 10, $30 \%)$ und getrennt für eine Bearbeitung in Gefällerichtung bzw. höhenlinienparallelen Anbau illustriert. Dabei wird von einer abflusswirksamen Niederschlagshöhe von $15 \mathrm{~mm}$ in $30 \mathrm{~min}$ 


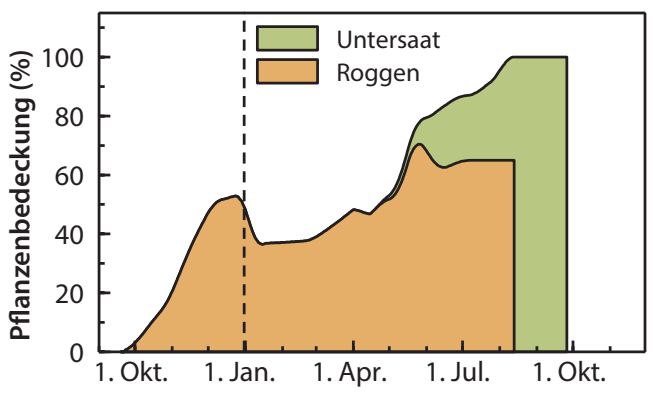

- Abb. 6.3 Untersaaten liefern nach der Ernte der Hauptfrucht durchgehend Rauheit durch Pflanzenbedeckung, ohne dass ein Saatbett notwendig ist und damit eine Lücke entsteht (Daten aus [7])

ausgegangen. Da die GMS-Gleichung lediglich die Fließwiderstände berücksichtigt und den Einfluss auf die Infiltration und den Abflussrückhalt hinter den Rauheitselementen nicht abbildet, ist davon auszugehen, dass die reale Abflussverzögerung bei den Varianten mit hohem Bedeckungsgrad noch deutlich größer sein dürfte.

Die Streckenlänge des Schichtabflusses kann anhand der Rauheit und über $>\mathrm{Gl}$. 8.1 abgeschätzt werden. Zur Bestimmung der Fließstrecke des Rillen- und Rinnenabflusses wird nach $>$ Gl. 8.2 vereinfachend angenommen, dass sie der doppelten Länge des Schichtabflusses entspricht (insofern der Abfluss nicht schon vorher den Feldrand erreicht). Weiter wird davon ausgegangen, dass sich Rillen und Rinnen bündeln und die verbleibende Strecke bis zum Erreichen des Feldrands auf den Hangmuldenabfluss entfällt (vgl. das Beispiel in - Abb. 3.6). Rauheitsbeiwerte des Schichtabflusses wurden für die unterschiedlichen Bedeckungsgrade bzw. zur Berücksichtigung der Querbearbeitung aus - Tab.8.2 entnommen. Die Schichtdicke des Abflusses und damit der hydraulische Radius wurden iterativ so bestimmt, dass die Abflussraten in den einzelnen Abflusspfaden für die verschiedenen Varianten einheitlich waren. Die Zusammenfassung und
Gegenüberstellung der Berechnungsergebnisse in - Tab. 6.2 zeigt, dass die Fließzeit gegenüber einer unbedeckten Oberfläche mit Bewirtschaftung in Hauptgefällerichtung (19 min) durch eine hangparallele Bewirtschaftung und eine Bedeckung von $30 \%$ fast vervierfacht werden kann (73 min). Bleibt die Bedeckung unter $30 \%$, ist die Wirkung deutlich geringer. Bei den Berechnungen wurden, um nur dem Effekt der Rauheit auf die Fließgeschwindigkeit zu quantifizieren, von gleichen Abflussraten bei allen sechs Varianten ausgegangen. Da • Abb. 6.1 aber zeigt, dass mit $30 \%$ Bedeckung der Abfluss bei Starkregen nur halb so groß ist wie bei $0 \%$ Bedeckung, werden die Unterschiede noch wesentlich größer. Unterschiede um den Faktor 10 zwischen 0 und $30 \%$ Bedeckung sind realistisch. Zusammengenommen ergibt sich auf der Feldskala ein enormes Potenzial zur Abflussverzögerung, das jedoch nur bei konsequenter Umsetzung der Maßnahmen genutzt werden kann. Zentraler Mechanismus ist die Förderung einer größtmöglichen Rauheit und ihres Schutzes durch hohe Bedeckungsgrade. Eine Rauheit stellt nicht nur das wesentliche Strömungshindernis dar, sie beeinflusst auch die Ausbildung der Entwässerungswege.

Wird davon ausgegangen, dass eine Veränderung der Bewirtschaftungsrichtung im Mittel die Fließzeit um $30 \%$ verlängert, alle oben genannten Bedingungen für Querbearbeitung zutreffen (dies ist in dem Beispiel nicht der Fall, da die Hanglänge größer als die kritische Hanglänge und da die Niederschlagsrate hoch ist) und dass der Scheitel einer Abflusswelle näherungsweise proportional zu Fließzeit und Abflussvolumen ist, würde sich durch Querbearbeitung analog am unteren Feldrand eine Scheitelminderung von etwa $30 \%$ einstellen (die zusätzlich erhöhte Infiltration ist dabei noch nicht berücksichtigt). Das Potenzial von Direktsaat, Oberflächenabfluss langsam und weitgehend ohne Erosion aus 
- Tab. 6.1 Kritische Hanglängen für unterschiedliche Hangneigungen; die Werte wurden nach $>$ Gl. 6.1 ermittelt

\begin{tabular}{|l|l|l|l|l|l|l|l|l|l|l|}
\hline Hangneigung $(\%)$ & 2 & 4 & 6 & 8 & 10 & 12 & 14 & 16 & 18 & 20 \\
\hline Kritische Hanglänge $(\mathrm{m})$ & 131 & 101 & 78 & 60 & 46 & 36 & 28 & 21 & 16 & 13 \\
\hline
\end{tabular}

- Tab. 6.2 Abschätzung der mittleren Fließzeit von Oberflächenabfluss auf einem $170 \mathrm{~m}$ langen, $135 \mathrm{~m}$ breiten (2,3 ha) und $4 \%$ geneigten Feldes bei unterschiedlichen Bedeckungsgraden und Bewirtschaftungsrichtungen für eine abflusswirksame Niederschlagshöhe von $15 \mathrm{~mm}$. Die Rauheitswerte für Schichtabfluss wurden entsprechend der Bedeckung aus - Tab. 8.2 entnommen. Für den Abfluss in Rinnen und Rillen wurde einheitlich ein Rauheitswert von $k=20$, für den Abfluss in der Hangmulde in Anlehnung an - Tab. 5.1 ein Rauheitswert von $\mathrm{k}=30\left(\mathrm{~m}^{1 / 3} \mathrm{~s}^{-1}\right)$ angenommen. Die Fließtiefe und damit der hydraulische Radius wurden optimiert, sodass in allen Fällen die Abflussrate identisch war

\begin{tabular}{|c|c|c|c|c|c|c|}
\hline \multirow{2}{*}{$\begin{array}{l}\text { Bewirtschaftungsrichtung } \\
\text { Bedeckung (\%) }\end{array}$} & \multicolumn{3}{|c|}{ In Hauptgefällerichtung } & \multicolumn{3}{|c|}{ Höhenlinienparallel } \\
\hline & 0 & 10 & 30 & 0 & 10 & 30 \\
\hline \multicolumn{7}{|l|}{ Schichtabfluss } \\
\hline Rauheit $\left(\mathrm{m}^{1 / 3} \mathrm{~s}^{-1}\right)$ & 17 & 12 & 5 & 12 & 8 & 5 \\
\hline Hydraulischer Radius (cm) & 0,23 & 0,30 & 0,48 & 0,30 & 0,38 & 0,52 \\
\hline Fließpfadlänge (m) & 49 & 58 & 89 & 58 & 71 & 100 \\
\hline Fließgeschwindigkeit $\left(\mathrm{cm} \mathrm{s}^{-1}\right)$ & 6,0 & 4,9 & 2,8 & 4,9 & 3,9 & 2,4 \\
\hline Fließzeit (min) & 13,5 & 19,5 & 52,6 & 19,5 & 30,4 & 69,1 \\
\hline \multicolumn{7}{|l|}{ Rinnen- und Rillenabfluss } \\
\hline Anzahl (-) & 30 & 20 & 10 & 15 & 10 & 5 \\
\hline Rauheit $\left(\mathrm{m}^{1 / 3} \mathrm{~s}^{-1}\right)$ & 20 & 20 & 20 & 20 & 20 & 20 \\
\hline Hydraulischer Radius (cm) & 2,1 & 2,2 & 1,7 & 3,1 & 2,8 & 2,3 \\
\hline Fließpfadlänge (m) & 97 & 112 & 81 & 112 & 99 & 70 \\
\hline Fließgeschwindigkeit $\left(\mathrm{cm} \mathrm{s}^{-1}\right)$ & 31 & 31 & 27 & 39 & 37 & 32 \\
\hline Fließzeit (min) & 5,2 & 6,0 & 5,1 & 4,7 & 4,4 & 3,7 \\
\hline \multicolumn{7}{|l|}{ Hangmuldenabfluss } \\
\hline Anzahl (-) & 1 & 0 & 0 & 0 & 0 & 0 \\
\hline Rauheit $\left(\mathrm{m}^{1 / 3} \mathrm{~s}^{-1}\right)$ & 30 & 0 & 0 & 0 & 0 & 0 \\
\hline Hydraulischer Radius (cm) & 6,9 & 0 & 0 & 0 & 0 & 0 \\
\hline Fließpfadlänge (m) & 24 & 0 & 0 & 0 & 0 & 0 \\
\hline Fließgeschwindigkeit $\left(\mathrm{cm} \mathrm{s}^{-1}\right)$ & 101 & 0 & 0 & 0 & 0 & 0 \\
\hline Fließzeit (min) & 0,4 & 0 & 0 & 0 & 0 & 0 \\
\hline Gesamtfließzeit (min) & 19 & 26 & 58 & 24 & 35 & 73 \\
\hline Gesamtfließzeit (\%) & 100 & 133 & 301 & 126 & 182 & 380 \\
\hline
\end{tabular}




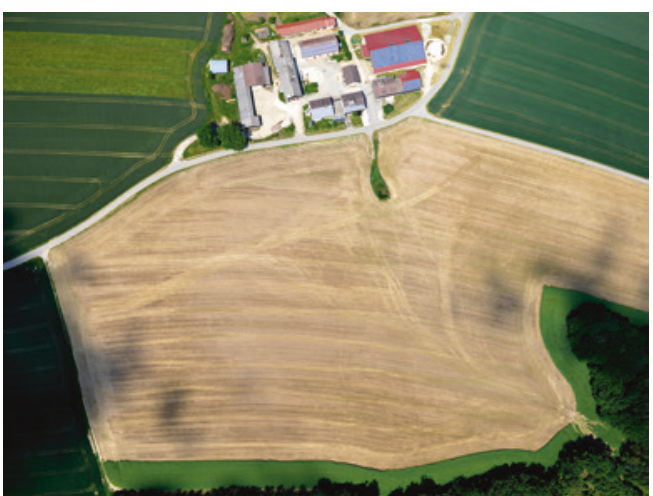

- Abb. 6.4 Luftbildaufnahme eines mit MaisDirektsaat bestellten Feldes vom 06.06.2016, das nur geringere Spuren von Wasserabfluss und Bodenaustrag in den Schutzstreifen unten rechts zeigt, obwohl es einem Starkregen von ca. $50 \mathrm{~mm}$ in einer Stunde ausgesetzt war. (Quelle: W. Bauer, Agroluftbild in 3)

der Fläche abzuleiten, ist auch durch Luftbildaufnahmen nach Starkregenereignissen dokumentiert (• Abb. 6.4).

Die Bewirtschaftungsrichtung wird indirekt durch den Flächenzuschnitt und die Erschließung der Fläche durch das Wegenetz vorgeben, da die Bearbeitung in Richtung der längeren Seite arbeitswirtschaftlich vorteilhaft ist. Um hangparallele Bewirtschaftung zu fördern, sollte im Rahmen von Boden- und Flurneuordnungsverfahren die Längsseite der Flurparzellen parallel zu den Höhenlinien verlaufen und die Erschließung über die Breitseite, idealerweise durch Wege auf dem Hangrücken erfolgen. Hinweise zur Flächenparzellierung und dem Wegebau sind in Abschn. 6.5, 6.7 und $>$ Anhang 8.7 beschrieben.

\section{Wirkung von Streifenbearbeitung \\ Die streifenförmige Bearbeitung einzelner Schläge (• Abb. 6.5) (,Strip Till“) ist eine Alternative zur Direktsaat als bodenschonendes, erosionsminderndes, wasser- und energiesparendes Bestellverfahren für Reihenfrüchte. Streifenbearbeitung ist in Deutschland noch kaum verbreitet, obwohl sie die}

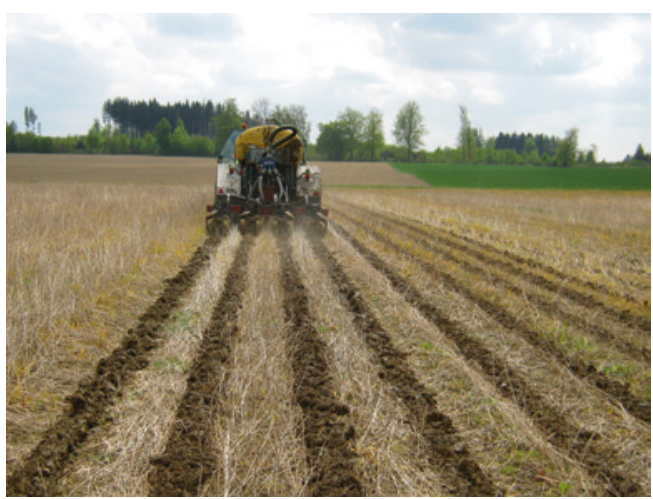

- Abb. 6.5 Bodenbearbeitung in Streifen (Strip-Till) kann die Vorteile von intensiver Bodenbearbeitung und von Direktsaat verbinden. 50-70\% der Oberfläche werden nicht bearbeitet und verfügen über eine hohe Rauheit und hohe Infiltrationsfähigkeit, wodurch der Abfluss stark gebremst wird. (Quelle: H. Kirchmeier)

Vorteile von Bodenbearbeitung und Direktsaat verbindet. Dadurch, dass bei diesem Verfahren 50-70 \% der Fläche unbearbeitet bleiben, ergeben sich ein deutlich geringeres Erosionsrisiko, eine gute Entwicklung der Bodenstruktur und ein 10-20\% höheres Infiltrationsvermögen für Niederschläge als auf konventionell bestellten Schlägen. Nach Studien der Bayerischen Landesanstalt für Landwirtschaft werden zumeist gleichwertige oder sogar höhere Erträge als bei Direktsaat erzielt [12]. Die Ergebnisse werden auch durch Versuche aus Sachsen bestätigt. Zusätzliche Infiltrationsversuche im Feld zeigen dort außerdem, dass die Infiltration bei Streifenbearbeitung und Direktsaat nahezu identisch und fast 5-mal so hoch wie bei konventioneller Bodenbearbeitung war [13].

\section{Wirkung des Dammanbaus}

Der (nahezu) höhenlinienparallele Anbau von Kulturen auf Dämmen (engl. „Ridge 
Tillage") ist eine weitere ackerbauliche Alternative. Mais kann beispielsweise auch auf dauerhaften und damit besonders stabilen Dämmen entweder in Monokultur oder im Wechsel mit einer anderen Reihenkultur wie Soja angebaut werden. Erfahrungen aus den USA zeigen, dass damit die Rauheit in Gefällerichtung erhöht und der Oberflächenabfluss um 30 bis $40 \%$ reduziert werden kann, wobei die Wirkung bei kleinen Ereignissen größer, bei großen Ereignissen geringer ist [14, 15]. Die Anlage dauerhafter Dämme setzt voraus, dass die Dämme eine geringe, einheitliche Neigung gegenüber den Höhenlinien haben, sodass der Oberflächenabfluss langsam zur Seite geleitet wird und sich nicht hinter dem Damm sammeln kann und dass geeignete wasserableitende Strukturen dort vorhanden sind, wo die Dämme das Wasser hinleiten. Das kann der Feldrand oder eine Hangmulde sein. Dort sind begrünte Abflussmulden allerdings fast zwingend notwendig, da durch die dort auftretende Bündelung des Abflusses ansonsten ein sehr hohes Risiko für das Entstehen von Gullys besteht.

Für alle Maßnahmen, die den Wasserfluss leiten oder verändern, wozu auch die Querbearbeitung oder der Dammanbau zählen, müssen die Übergangsbereiche von einem Fließabschnitt zum nächsten so gestaltet und gesichert werden, dass sie den Oberflächenabfluss schadlos aufnehmen und abführen können. Innerhalb landwirtschaftlicher Schläge kann dies vor allem durch Grünstreifen oder dauerhaft begrünte (erosionssichere) Abflussmulden am Feldrand oder in Hangmulden, ggf. auch begrünte Vorgewende geschehen. Fehlen sie, wird der Abfluss durch die Querstrukturen zwar schadlos aus der Fläche abgeleitet, im daran anschließenden Abschnitt des Entwässerungsweges sind Erosionsprobleme allerdings oft vorprogrammiert. Ein Beispiel dafür zeigt der Kartoffelacker in - Abb.6.6. Die Kartoffeldämme sorgten bei einem Starkregen dafür, dass in der Fläche kein Wasser in Hauptgefällerichtung abfloss. Im vegetationsfreien Vorgewende am linken Feldrand, das den Oberflächenabfluss aufnahm und ableitete, kam es dagegen zu starker Erosion.

\subsection{Grünstreifen}

Dauerhaft begrünte Flächen können Bereiche hoher Infiltrationskapazität schaffen, Sediment aus dem Wasser auskämmen oder als lineare Strukturen helfen, Oberflächenabfluss schadlos aus der Fläche ab- und entlang angelegter Fließwege in ein Gewässer zu leiten. Je nach Konzeption werden sie über eine relativ kurze Strecke durchflossen und sind dann Grünstreifen, die in diesem Kapitel behandelt werden, oder sie werden der Länge nach durchflossen, wie im Fall der begrünten Abflussmulden, die im folgenden Kapitel behandelt werden. Grünstreifen können zum einen die Abflusshöhe reduzieren - unter welchen Bedingungen welcher Effekt zu erwarten ist, wird im ersten Teil dieses Kapitels behandelt. Zum anderen können sie die Abflussgeschwindigkeit bremsen - dies wird am Ende des Kapitels quantifiziert. Für beide Effekte ist wichtig, dass der Abfluss möglichst langsam und breitflächig fließt. Das gilt grundsätzlich für alle Formen von Grün-, Filter- oder Pufferstreifen, die rasch an Wirkung verlieren, wenn sie schnell oder konzentriert durchströmt werden [16].

Abflussminderung: Grundsätzlich haben dauerhaft begrünte Flächen niedrigere CN-Werte als Ackerflächen. Damit können Grünstreifen, wie auch begrünte Abflussmulden, von den Ackerflächen kommenden Abfluss durch Infiltration vermindern. Der Unterschied ist besonders groß in Zeiten, in denen auf den Ackerflächen wenig Bedeckung vorhanden ist. Und der Unterschied ist besonders groß bei den hydrologischen Bodengruppen $\mathrm{A}$ und $\mathrm{B}$, bei denen 


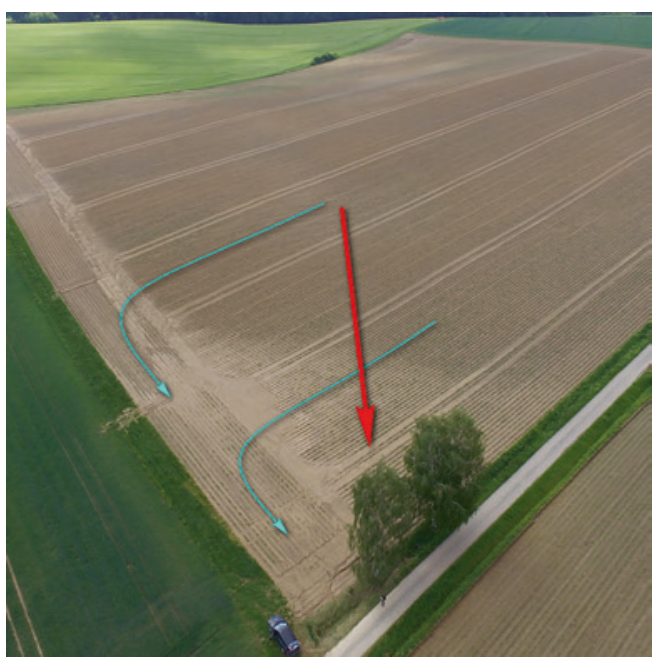

- Abb.6.6 Kartoffelacker mit quer zum Gefälle (roter Pfeil) orientierter Bewirtschaftung. Bei einem Regen mit $18 \mathrm{~mm}$ konnten die Kartoffeldämme Erosion und Oberflächenabfluss innerhalb des Feldes in Hauptgefällerichtung verhindern. Durch die Querstrukturen wurde der Abfluss entlang der Dämme in das Vorgewende am linken Feldrand und dort hangabwärts geleitet (hellblaue Pfeile). Aufgrund mangelnder Sicherung und fehlender Bedeckung wurde das Vorgewende durch starke Erosion weitgehend zerstört. Um dem vorzubeugen, hätte das Vorgewende schmaler ausfallen können und durch einen grassed waterway gesichert werden müssen. (Bildquelle: H\&S Ingenieure)

die CN-Werte von Grünland sich stärker von denen bei Ackernutzung unterscheiden als bei Bodengruppe C oder D (vgl. • Tab. 4.1).

Die Minderung wird vor allem bei kleinen Abflussereignissen auftreten. Sobald die begrünte Fläche selbst Abfluss liefert, wenn also der Regen größer ist als der Anfangsverlust, kann die begrünte Fläche auch kein zufließendes Wasser mehr versickern. Geht man von einem CN-Wert von 72 bei Grünland und hydrologischer Bodengruppe $\mathrm{C}$ aus (-Tab.4.1), ergeben sich eine Maximalretention von etwa $100 \mathrm{~mm}$ und damit ein Anfangsverlust von $20 \mathrm{~mm}$. Für Regen, die mehr als $20 \mathrm{~mm}$ erbringen, wird die Wirkung eines Grünstreifens klein. Bei den hydrologischen Bodengruppen $\mathrm{A}$ beträgt der
CN-Wert einer Wiese nur 30. Die Anfangsretention beträgt dann $120 \mathrm{~mm}$. Unter diesen Bodenverhältnissen wird die Infiltrationskapazität von Grünstreifen bis zu Regen von $120 \mathrm{~mm}$ noch nicht durch den Regen selbst ausgeschöpft. Wenn dann auch noch die darüberliegende Ackerfläche zur Bodengruppe A gehört und daher nur wenig Abfluss liefert, wird die Versickerungsleistung eines Grünsteifens in vielen Fällen ausreichen. Umgekehrt gilt natürlich, dass bei Vorliegen der hydrologischen Bodengruppe D eine noch geringere Wirkung auf die Abflussreduktion zu erwarten ist als bei Bodengruppe C.

Weiterhin gilt, dass die Wirkung bei kurzer Fließstrecke nicht groß sein kann, weil die Zeit, die der Oberflächenabfluss für das Durchfließen des Grünstreifens braucht, kurz ist und weil die Menge an Wasser, die angeliefert wird, hoch ist. Dennoch zeigen Versuche, dass die Wirkung von Grünstreifen auf die Abflussminderung in der Summe aller kleinen und großen Ereignisse nicht unerheblich ist. In den USA konnten Grünstreifen, die $10 \%$ der gesamten Hanglänge einnahmen (bei Hanglängen von $300 \mathrm{~m}$ also $30 \mathrm{~m}$ breite Streifen), die Abflussmenge etwa um $40 \%$ vermindern (•Abb. 6.7). Wurde die Gesamtbreite auf zwei (bis drei) Streifen aufgeteilt und an mehrere Stellen des Hanges platziert, wobei aber mindestens ein Streifen am Hangfuß lag, war die Wirkung etwas geringer. Eine Minderung von $40 \%$ gilt im Mittel mehrerer Jahre, während der es auch viele kleine Ereignisse gibt, bei denen die Wirkung groß ist, auch wenn sie bei großen Ereignissen schwindet. Die Belastung von Gewässern mit gelösten Stoffen und noch mehr durch partikuläre Stoffe, wird dadurch wesentlich vermindert. Für einen Schutz vor Sturzfluten oder Hochwasser, die durch ganz große Regen ausgelöst werden, haben die Streifen dagegen eine geringere Bedeutung.

Geschwindigkeitsminderung: Um die Bremswirkung von Grünstreifen auf den Abfluss in Abhängigkeit von der Durchströmung (konzentriert vs. flächig) zu ver- 


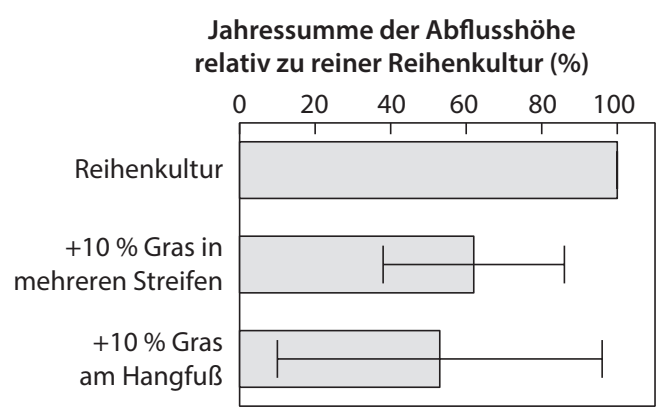

- Abb. 6.7 Wirkung von Grünstreifen kombiniert mit einer Reihenkultur relativ zur Abflussmenge einer reinen Reihenkultur. Der Grünstreifen nahm mindestens $10 \%$ der gesamten Hanglänge ein und war am Hangfuß angeordnet. Eine Teilung der Grasfläche in mehrere Streifen, wobei immer noch einer am Hangfuß lag, vermindert die Wirkung etwas. Die Fehlerbalken zeigen den $95 \%$-Vertrauensbereich. Die Wirkung ist also gerade noch signifikant. Datengrundlage: 12 Parzellen, 4 Jahre, 70 Abflussereignisse, Hanglängen 110 bis $290 \mathrm{~m}$ [17]

anschaulichen, werden zwei Fallbeispiele verglichen. Dabei wird analog zum Beispiel in - Tab. 6.2 von einem $170 \mathrm{~m}$ langen, $135 \mathrm{~m}$ breiten (entspricht 2,3 ha) und $4 \%$ geneigten Acker mit geradem Fließen (ohne konvergentem oder divergentem Fließen) ausgegangen. Der Grünstreifen ist jeweils auf den untersten $12 \mathrm{~m}$ des Feldes angelegt. Seine Größe ist mit $7 \%$ der Feldfläche geringer als die oben geforderte Fläche von $10 \%$, dafür entspricht die Breite eher einem typischen Gewässerrandstreifen.

Im Fall 1 wird die Ackerfläche in Gefällerichtung konventionell bewirtschaftet (d.h. wendende Bodenbearbeitung, geringe Bedeckung des Saatbetts). Für den Fall wurde in - Abschn. 6.1 geschätzt, dass sich Schicht- und Rinnenabfluss nach knapp $150 \mathrm{~m}$ gebündelt haben (vgl. - Tab.6.2) und der Abfluss folglich in konzentrierter Form als Hangmuldenabfluss am unteren Feldrand auf den Grünstreifen trifft. Durch die erhöhte Rauheit des Streifens (Annahme $\mathrm{k}=15 \mathrm{~m}^{1 / 3} \mathrm{~s}^{-1}$ ) ist $\mathrm{zu}$ erwarten, dass sich der Fließquerschnitt des
Abflusses beim Eintritt in den Streifen gegenüber der Breite auf der Ackerfläche ausdehnt, der Abfluss den Streifen aber trotzdem noch in konzentrierter Form durchquert. Dadurch ist bereits intuitiv eine geringe Bremswirkung des Grünstreifens zu erwarten. Für eine quantitative Abschätzung des Effektes mit der GMS-Gleichung wird angenommen, dass sich die Fließbreite des Hangmuldenabflusses durch die erhöhte Rauheit im Grünstreifen gegenüber der Situation in der Ackerfläche verdoppelt. Dadurch reduziert sich zwar die Fließgeschwindigkeit im Streifen um $40 \%$, durch seine geringe Breite von $12 \mathrm{~m}$ wird er aber trotzdem in weniger als einer halben Minute durchflossen. Der relative Anteil der Fließzeit von der oberen bis zur unteren Feldgrenze, die auf den Streifen entfällt, beträgt dabei gerade einmal $2 \%$ (• Tab.6.3). Ein $5 \mathrm{~m}$ breiter Gewässerrandstreifen würde unter diesen Bedingungen den Abfluss sogar nur um 10 bis $20 \mathrm{~s}$ verzögern. Dies ist vernachlässigbar.

Im Fall 2 wird ebenfalls analog zu dem Beispiel in - Tab. 6.2 von einem höhenlinienparallelen Anbau und $10 \%$ Bodenbedeckung ausgegangen. Durch die erhöhte Rauheit der Ackerfläche verläuft die Bündelung des Wassers langsamer und der Großteil des Oberflächenabflusses trifft in kleinen Rinnen und Rillen auf den Grünstreifen. Wie beim Fall 1 wird angenommen, dass durch die erhöhte Rauheit des Puffers die Fließbreite im Grünstreifens gegenüber der Breite der Rinnen und Rillen zunimmt (Annahme: um den Faktor 4, da die Konzentration in den Rinnen und Rillen geringer ist als in der Hangmulde wie bei Fall 1). Entsprechend nimmt die Fließzeit stärker zu. Allerdings wird der Filterstreifen trotzdem in weniger als einer Minute durchflossen. Der Streifen trägt wieder nur $2 \%$ zur Gesamtfließzeit bei (• Tab. 6.3). Selbst bei vergleichsweise günstigen Bedingungen bleibt daher die Wirkung schmaler Grünstreifen auf Abflussmenge und Abflussgeschwindigkeit vernachlässigbar. 
- Tab. 6.3 Abschätzung der Verzögerung des Oberflächenabflusses durch Grünstreifen am unteren Feldrand bei unterschiedlichen Bewirtschaftungsbedingungen oberhalb. Es wurde von einem $170 \mathrm{~m}$ langen, 135 m breiten und einheitlich $4 \%$ geneigten Acker (2,3 ha) ausgegangen, bei dem sich am unteren Feldrand ein $12 \mathrm{~m}$ breiter Grünstreifen befindet. Die verwendeten Daten und Annahmen entsprechen denen in - Tab. 6.2. Die Berechnung mit der GMS-Gleichung geht von stationären Bedingungen aus und berücksichtigt ausschließlich die Abflussverzögerung, nimmt also eine vernachlässigbare Infiltration im Grünstreifen an

\begin{tabular}{|c|c|c|}
\hline Fließabschnitt & $\begin{array}{l}\text { Blankes Saatbett, Bewirtschaftung } \\
\text { in Gefällerichtung, Grünstreifen am } \\
\text { unteren Feldrand }\end{array}$ & $\begin{array}{l}10 \% \text { Bedeckung, } \\
\text { höhenlinienparalleler Anbau, } \\
\text { Grünstreifen am unteren Feldrand }\end{array}$ \\
\hline Schichtabfluss & $14,5 \min (70 \%)$ & $30,4 \min (88 \%)$ \\
\hline Rinnen und Rillen & $5,2 \min (27 \%)$ & $3,9 \min (11 \%)$ \\
\hline Hangmulde & $0,4 \min (1 \%)$ & - \\
\hline Grünstreifen & $0,4 \min (2 \%)$ & $0,6 \min (2 \%)$ \\
\hline Gesamtfließzeit & $19,6 \min (100 \%)$ & $35 \min (100 \%)$ \\
\hline
\end{tabular}

\subsection{Begrünte Abflussmulden (Grassed Waterways)}

Begrünte Abflussmulden (GWW in diesem Kapitel, von engl. "grassed waterway") sind natürliche oder konstruierte, dauerhaft begrünte Fließwege, um Oberflächenabfluss schadlos, d.h. mit nicht-erosiver Geschwindigkeit entlang der natürlichen (topographischen) Entwässerungswege aus der Fläche abzuleiten. GWWs gelten vor allem in Regionen mit großflächiger landwirtschaftlicher Nutzung, darunter den USA, seit den 1970er- und 1980er-Jahren als bewährter und wirksamer Standard zur Förderung des Wasser- und Stoffrückhalt in der Fläche [18, 19]. Ihre wesentlichen Potenziale sind:

- Sie verhindern Erosionsrinnen bei Starkregen, da die Bodenoberfläche durch die Bedeckung und das Wurzelwerk der Grasnarbe gesichert wird [20].

- Sie reduzieren den Stoffaustrag durch Sedimentation, Adhäsion und Sorption partikulärer Stoffe innerhalb der begrünten Mulde.
- Sie dämpfen Hochwasserscheitel durch Bremsen des Abflusses und (je nach Ausführung) Reduktion des Abflussvolumens durch erhöhte Infiltration [21].

Hinzu kommen zahlreiche weitere, vor allem ökologische aber auch landschaftsästhetische Effekte, wodurch GWWs eine sehr hohe, multifunktionale Wirkung haben (einen Überblick und eine Quantifizierung dieser Wirkungen geben [22, 23]). Trotz dieser Potenziale und obwohl die Grundzüge des Konzeptes auch in Deutschland bereits in den 1980er-Jahren beschrieben wurden [24], sind GWWs bis heute in weiten Teilen Mitteleuropas nur selten anzutreffen. Dabei ist auch in Mitteleuropa inzwischen die Größe der Ackerflächen stark angewachsen, und GWWs könnten zur kontrollierten Entwässerung einer Vielzahl von Flächen genutzt werden. Im Gegensatz zu Filter- und Gewässerrandstreifen werden GWWs kaum thematisiert, obwohl sie eine viel größere Wirkung auf den Wasserund Stoffhaushalt haben, da sie bei Starkregen über eine lange Strecke durchströmt werden. 
Lediglich im Freistaat Sachsen werden gegenwärtig Bemühungen unternommen, GWWs wieder verstärkt in der Fläche zu etablieren $[25,26]$.

GWWs sollten prinzipiell entlang aller topographisch bedingten, erosionsanfälligen Entwässerungswege in der Landschaft installiert werden. Form und Beschaffenheit können dabei entlang des Fließweges variieren (- Abb.6.8 a). Wesentlich für ihre Funktion ist, dass die Übergänge von den angrenzenden Flächen so beschaffen sind, dass Oberflächenabfluss dem GWW ungehindert zufließen kann (- Abb.6.8 b). Anderenfalls fließt der Abfluss entlang der Ackerrandfurche und der Erosionsschaden wird nicht verhindert. Die Positionen, an denen GWWs in der Landschaft installiert werden sollten, lassen sich leicht mit digitalen Geländemodellen identifizieren (• Abb. 6.8 c). Fehlen sie, kann das Ausmaß möglicher Erosionsrinnen enorm sein (• Abb. 6.8 d). Gegebenenfalls ist auch der Auslass der begrünten Mulde gegen Erosion zu sichern, z. B. durch eine Steinschüttung. Je nach Zielsetzung sind schmale, unterhalb der Geländeoberkante gelegene Abflussmulden zum schnellen, aber schadlosen Ableiten von Wasser, sehr breite und flache Mulden zum Ableiten und Bremsen hoher Abflussraten oder als multifunktionale Fließwege mit hohem ökologischen Wert möglich [23].

\section{Wirkung von begrünten \\ Abflussmulden}

Die Wirksamkeit von GWW ergibt sich einerseits aus Rückhalt und Versickerung des Abflusses und andererseits aus dem Bremsen des Abflusses. Die Wirksamkeit ist umso besser,

- je breiter und flacher die begrünte Mulde angelegt ist,

- je länger die begrünte Mulde ist,
- je hydraulisch rauer die bodennahe Vegetation ist (Hochstauden mit dichter Streuauflage),

- je geringer die Hangneigung ist und

- je kürzer und je kleiner die Zuflussspitze ist, die abzupuffern ist.

Nicht alle diese Parameter lassen sich verändern (z. B. Zuflussspitze oder Hangneigung). In günstigen Fällen (hohe Rauheit, trockene Bedingungen, kurze schauerartige Niederschläge) kann eine Verzögerung von vielen Stunden erreicht werden, in ungünstigen Fällen (Extremereignisse, geringe Bedeckung, wassergesättigtes Porenvolumen im Boden, Hangneigung $>9 \%$ ) ist im Mittel immer noch eine Verzögerung in der Größenordnung von 10 min möglich. Dies haben Feldmessungen eines $650 \mathrm{~m}$ langen und $10 \mathrm{~m}$ (oben) bis 50 m (unten) breiten GWWs ergeben, bei dem sich der Spitzenabfluss am Auslass der begrünten Mulde im Mittel um $40 \%$, bei häufigen Ereignissen sogar um deutlich mehr vermindern ließ [21, 22]. Modellierungsstudien legen darüber hinaus nahe, dass GWWs auch den Abfluss großer Gebiete (>1000 ha) mindern können. Selbst unter ungünstigen Bedingungen (kleine, schmale GWWs, seltene Winterereignisse) konnten Scheitelreduktionsraten von $15 \%$ erreicht werden, wobei GWWs am Ende des Winters immer die geringste Effektivität aufwiesen [29, 30]. Auch eine umfangreiche Studie zum vorbeugenden Hochwasserschutz im Einzugsgebiet der Mulde in Sachsen [31] stuft GWWs als besonders effektive, fluruntergliedernde Maßnahme zum Wasser- und Stoffrückhalt in der Fläche ein. 

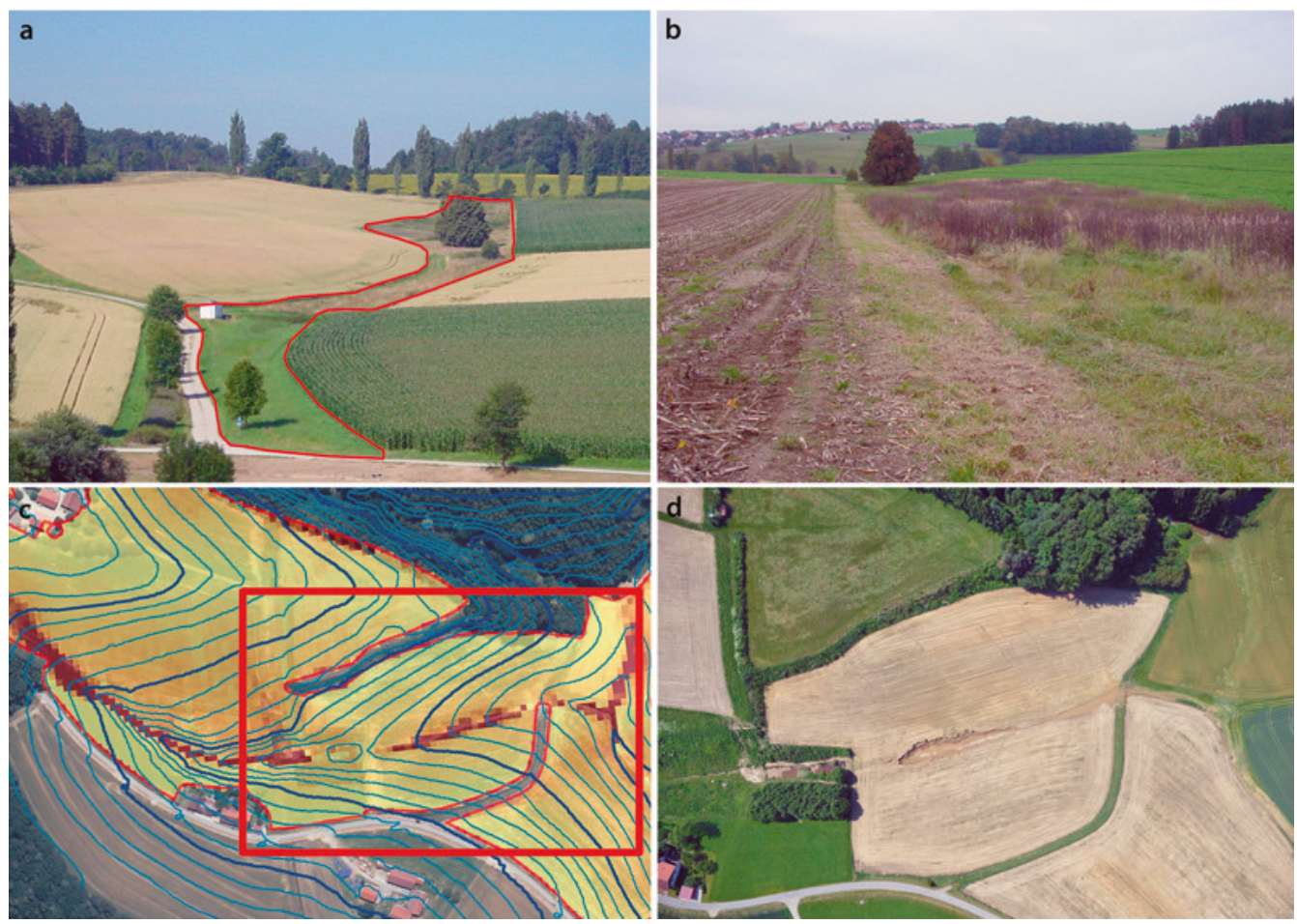

- Abb. 6.8 (a) Eine begrünte Abflussmulde (GWW) kann entlang des Fließweges sowohl in der Breite wechseln, um den Flächenzuschnitt der angrenzenden Felder zu optimieren, als auch in der Vegetationsbeschaffenheit, um z. B. durch Mulchen die Vegetationsrauhigkeit nicht im gleichen Jahr entlang der gesamten Fließstrecke zu beseitigen (unterer Teil des GWW im Aufnahmejahr gemulcht, um verholzende Pflanzen zu unterdrücken, oberer Teil mehrjährig nicht gemulcht). (b) Der Übergang vom Feld zum GWW muss ohne Randfurche erfolgen, damit der Oberflächenabfluss nicht am ungeschützten Feldrand kanalisiert wird. Abgestorbene Stängel von Hochstauden erzeugen auch im Winter eine stabile hydraulische Rauheit. (c) Die Gefahr von Grabenerosion und die optimale Lage von GWWs lassen sich gut aus der Topographie vorhersagen (Modellierung der Bayerischen Landesanstalt für Landwirtschaft mithilfe der differenzierenden Allgemeinen Bodenabtragsgleichung dABAG [27, 28]; der Bildausschnitt von (D) ist durch einen roten Rahmen markiert; dunkelbraune Farben indizieren ein hohes Risiko für Grabenerosion; Abstand der Höhenlinien 2 m). (d) Die massive Auskolkung einer Erosionsrinne in der Tiefenlinie des kleinen Einzugsgebietes durch das Fehlen eines GWW bei einem einzelnen Starkregenereignis im Juni 2016 passt gut mit der Prognose links (c) zusammen. Breite der Auskolkung mehr als $8 \mathrm{~m}$ (vgl. Straßenbreite), Tiefe ca. 4 m. (Foto: R. Brandhuber)

GWWs sind inzwischen relativ gut untersucht. Informationen über Bauausführung, Anlageund Unterhaltskosten, aber auch ausführliche Erläuterungen der Vor- und Nachteile von GWWs aus verschiedenen Perspektiven sind in der wissenschaftlichen Literatur [20, 23, 32] und in Praxisleitfäden [25, 26, 33, 34] dokumentiert. Für die praktische Umsetzung sind im Wesentlichen die Dimensionierung und die Festlegung des Verlaufs in der Fläche wichtig. Letzterer ergibt sich aus dem natürlichen Verlauf des Oberflächenabflusses bei Starkregen, dem Talweg. Das Querprofil einer natürlichen Abflussbahn sollte eine flache Parabel sein. Meist genügt es, die vom Relief vorgegebene Abflussbahn dauerhaft zu begrünen. Die Breite der zu begrünenden Fläche hängt von der Größe der zu entwässernden Fläche, der Geometrie und dem Sohlgefälle der Abflussbahn ab. Je größer das Einzugsgebiet und je steiler das Sohlgefälle, desto breiter und flacher muss die 
begrünte Mulde angelegt werden. Längere Abflussbahnen können auch in Abschnitte unterschiedlicher Begrünungsbreite eingeteilt werden, sodass die Breite zum Unterlauf hin, entsprechend der zunehmenden Einzugsgebietsgröße und dem dort oftmals geringeren Gefälle, steigt. Auf eine Begrünung mit speziellen Arten, sofern diese nicht als Untersaat etabliert werden können, sollte verzichtet werden, selbst wenn dies aus biotischen Gründen wünschenswert wäre. Der Grund liegt darin, dass GWWs immer in dem am stärksten durch Erosion gefährdeten Bereich angelegt werden. Arten mit langsamer Keimung, schwacher Jugendentwicklung und dem Bedarf für ein feines Saatbett lassen sich dort nicht durch Aussaat etablieren. Zum Standort und der Nutzung passende Arten werden sich mittelfristig auch ohne Ansaat einfinden.

Faustzahlen für die Dimensionierung von GWWs können abhängig von der Einzugsgebietsgröße und dem Gefälle mithilfe der GMS-Gleichung abgeschätzt werden (- Tab.6.4). Die Breite der Parabel sollte mit zunehmendem Gefälle zunehmen, um geringe Fließgeschwindigkeiten $\mathrm{zu}$ erreichen. Der Flächenbedarf von GWWs beträgt erfahrungsgemäß etwa $2 \%$ der Einzugsgebietsgröße. Neben den hydrologischen Parametern sollte die Planung auch die durch die Landtechnik bedingten Bearbeitungsbreiten in den angrenzenden Ackerflächen berücksichtigen. Dies erleichtert nicht nur die Bearbeitung der angrenzenden Ackerflächen, sondern auch die Pflege der begrünten Abflussmulde. Da ein GWW den Abfluss aus den angrenzenden Ackerflächen aufnehmen soll, dürfen die Ackerflächen keinesfalls hydraulisch vom GWW abgetrennt werden, z. B. durch eine Ackerrandfurche oder ein Vorgewende. Die Erfahrung zeigt, dass diese Bedingung Landwirten besonders schwer zu vermitteln ist, obwohl es eigentlich die Arbeit erleichtert, wenn auf das arbeitsaufwendige Vorgewende verzichtet werden kann.

Ein schematisches Arbeitsbeispiel zur Platzierung von GWWs in der Flur ist in - Abb.6.9 dargestellt. Die Ausgangslage (linkes Bild) zeigt, dass sich die Flurstücke viel-

- Tab. 6.4 Faustzahlen zur Festlegung der Breite B in $\mathrm{m}$ von begrünten Abflussmulden in Abhängigkeit von der zu entwässernden Fläche in ha, dem Sohlgefälle in \% und der Fließtiefe t in m bei Spitzenabfluss. Die Werte wurden anhand der GMS-Gleichung für etwa 50-jährliche Niederschläge ermittelt, bei denen Ackerflächen Scheitelabflussspenden in Höhe von rund $50 \mathrm{I} \mathrm{s}^{-1}$ ha $\mathrm{a}^{-1}$ liefern können. Dabei wurde einheitlich von einem Rauheitswert von $20 \mathrm{~m}^{1 / 3} \mathrm{~s}^{-1}$ ausgegangen. Die Breite der begrünten Mulde wurde so festgelegt, dass der ermittelte Scheitelabfluss abgeführt werden kann, ohne Fließgeschwindigkeiten $>1 \mathrm{~m} \mathrm{~s}^{-1}$ zu erreichen. Um ein möglichst breitflächiges Fließen zu erreichen, wurde die mittlere Seitenneigung des Muldenquerschnitts zusätzlich auf $2 \%$ beschränkt

\begin{tabular}{|c|c|c|c|c|c|c|c|c|c|c|c|c|c|c|}
\hline \multirow{2}{*}{$\begin{array}{l}\text { Gefälle } \\
(\%)\end{array}$} & \multicolumn{2}{|c|}{2,5 ha } & \multicolumn{2}{|c|}{5 ha } & \multicolumn{2}{|c|}{10 ha } & \multicolumn{2}{|c|}{15 ha } & \multicolumn{2}{|c|}{20 ha } & \multicolumn{2}{|c|}{30 ha } & \multicolumn{2}{|c|}{50 ha } \\
\hline & B & $t$ & B & $\mathbf{t}$ & B & $t$ & B & $t$ & B & $t$ & B & $t$ & B & $t$ \\
\hline 1 & 4 & 0,13 & 6 & 0,20 & 8 & 0,22 & 8 & 0,25 & 10 & 0,31 & 10 & 0,36 & 12 & 0,45 \\
\hline 2 & 4 & 0,11 & 6 & 0,16 & 8 & 0,18 & 8 & 0,18 & 10 & 0,25 & 10 & 0,29 & 16 & 0,31 \\
\hline 3 & 4 & 0,09 & 6 & 0,14 & 10 & 0,14 & 10 & 0,14 & 12 & 0,20 & 14 & 0,21 & 20 & 0,24 \\
\hline 4 & 4 & 0,09 & 6 & 0,13 & 10 & 0,13 & 10 & 0,13 & 14 & 0,17 & 18 & 0,17 & 24 & 0,19 \\
\hline 5 & 4 & 0,08 & 6 & 0,12 & 10 & 0,12 & 10 & 0,12 & 16 & 0,14 & 20 & 0,15 & 28 & 0,17 \\
\hline 6 & 4 & 0,08 & 8 & 0,10 & 10 & 0,11 & 12 & 0,10 & 18 & 0,13 & 24 & 0,12 & 32 & 0,14 \\
\hline 7 & 4 & 0,07 & 8 & 0,09 & 10 & 0,11 & 12 & 0,10 & 18 & 0,12 & 26 & 0,11 & 36 & 0,13 \\
\hline 8 & 4 & 0,07 & 8 & 0,09 & 10 & 0,10 & 12 & 0,09 & 20 & 0,11 & 28 & 0,10 & 38 & 0,12 \\
\hline
\end{tabular}



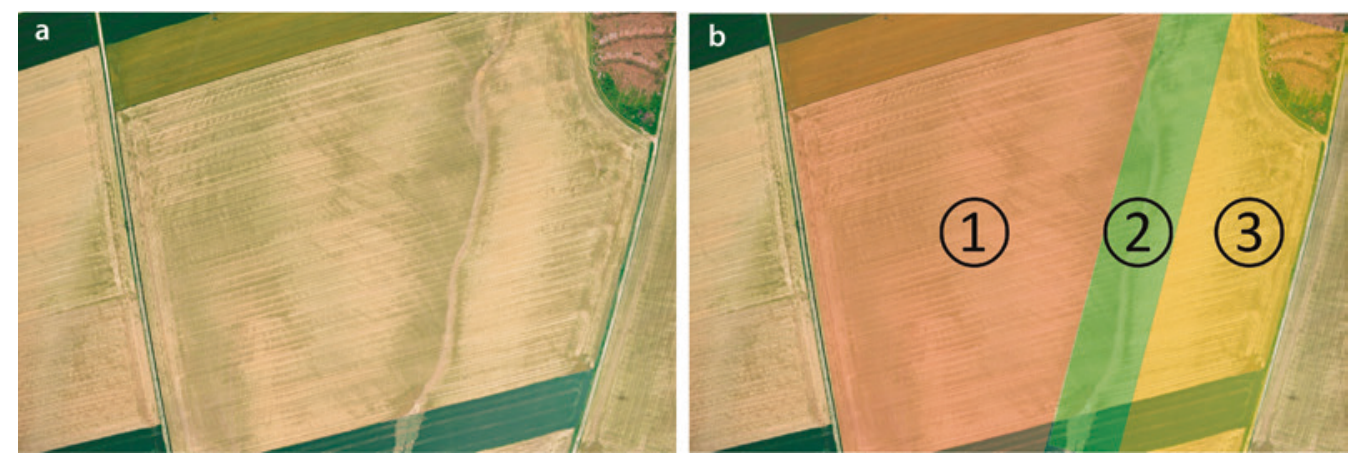

- Abb. 6.9 Schematisches Planungsbeispiel, wie durch die Veränderung der Flächenparzellierung starke Rinnenerosion (a) verhindert werden kann, indem eine begrünte Mulde in der Tiefenlinie eines Maisfeldes angelegt wird, die daran angrenzenden Felder an der Topographie der Landschaft ausgerichtet und dadurch der ländliche Hochwasserschutz und die Flächenbewirtschaftung gleichermaßen verbessert werden (b). Nummer 1 und 3 in (b) kennzeichnen die beiden Felder; Nummer 2 ist die begrünten Abflussmulde. (Quelle: W. Bauer, Agroluftbild)

fach nicht an den Fließwegen der Landschaft orientieren, obwohl dies für den ländlichen Hochwasserschutz und für die Bewirtschaftung gleichermaßen günstig wäre. Eine Erosionsrinne läuft quer durch das Maisfeld mit wenig Bedeckung, und das dunkelgrüne Winterweizenfeld am unteren Bildrand konnte dem konzentrierten Zufluss nicht standhalten. In dem Beispiel wurde durch die Veränderung der Flächenparzellierung (rechtes Bild) Feld 1 nicht kleiner als das bisherige Maisfeld. Die Bearbeitung liegt aber nun parallel zur Straße. Ein Vorgewende entlang der begrünten Mulde ist nicht notwendig und darf nicht gemacht werden, sondern man wendet in der begrünten Mulde. Die Bewirtschaftung (gedacht in Richtung der längeren Seite) wird dadurch einfacher und Verdichtungsschäden werden durch den Wegfall des Vorgewendes vermieden. Zusätzlich liegt die Bearbeitung nun fast quer zum Hang mit einem leichten Gefälle zur begrünten Mulde. So ist die Erosionsschutzwirkung am größten. Das Feld 3 ist deutlich größer als das bisherige Winterweizenfeld und hat nun perfekt parallele Seiten, was die Bewirtschaftung erleichtert. Zusätzlich liegt auch hier die Bearbeitung jetzt quer zum Hang und nicht mehr in Gefällerichtung und schützt zusätzlich. Das ist immer so, wenn die Felder nach der Tiefenlinie ausgerichtet werden. Zwischen Feld 1 und Feld 3 wird eine begrünte Mulde angelegt. Dass sich die Abflusslinie schlängelt, bedeutet nicht, dass sich die begrünte Mulde auch schlängeln muss. Im Gegenteil, sie sollte breit ausgeführt werden, schon um dort Wendemanöver bei der Flächenbewirtschaftung praktizieren $\mathrm{zu}$ können.

Erwähnenswert ist, dass es sich bei GWWs eigentlich um sehr altes, sehr lange praktiziertes Wissen handelt. Erst im Zuge der Anpassung der Landschaft an die Technik ging es verloren (dabei hätte man von einer fortschrittlichen Technik eigentlich erwarten können, dass sich die Technik an die Landschaft anpasst). Dieses alte Wissen ist durch historische Karten, z. B. durch die Reichsbodenschätzung, anschaulich dokumentiert. Ausschnitte aus dem Tertiärhügelland in Bayern von 1958 belegen, dass damals noch nahezu alle Tiefenlinien als Dauergrünland genutzt wurden. $\mathrm{Zu}$ dieser Zeit verliefen zahlreiche, Ost-/West-orientierte, grüne Bänder entlang der Niederungen und Tiefenlinien der Landschaft (•Abb. 6.10). Durch Meliorationsmaßnahmen sind heute die meisten dieser Grünlandstandorte verschwunden, die früher den Wasser- und Stoffrückhalt in der Landschaft gefördert hatten 


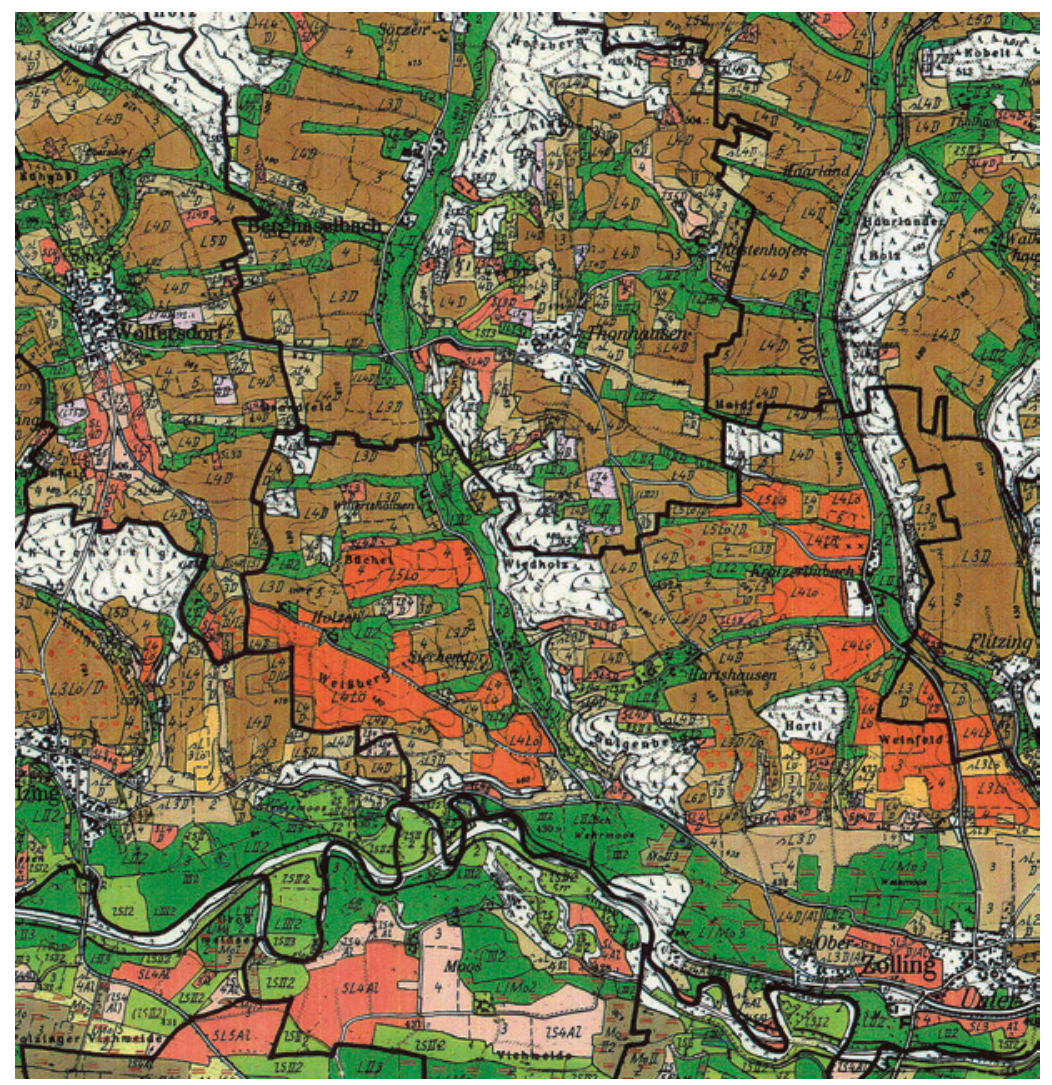

- Abb. 6.10 Ausschnitt der Bodenschätzungsübersichtskarte nördlich von Zolling im Tertiärhügelland von 1958 (Blatt 7536, Freising Nord) mit Darstellung von Grünland (Grüntöne), Acker (Braun-, Rot- und Orangetöne) und Wald (weiße Flächen). Historische Bodenschätzungsübersichtskarten können vielfach kostenfrei bezogen werden

und gleichzeitig wichtige Korridore für Tierund Pflanzenarten und damit für die biotische Diversität bedeutsam waren [35]. Diese Veränderung der Landschaftsstruktur und ihr Einfluss auf das Abflussgeschehen wird anhand eines Beispiels aus dem Tertiärhügelland in - Abschn. 6.5.2 anschaulich illustriert. Ähnliches ist auch aus Sachsen beschrieben [25] und kann vielerorts leicht aus dem Vergleich historischer und aktueller Luftbilder, topographischer Karten und insbesondere aus der Gegenüberstellung historischer Bodenschätzungskarten mit der aktuellen Nutzung nachvollzogen werden. Diese Entwicklung ist auch insofern bemerkenswert, da die Bodenschätzungskarten aus einer Bewertung der Ertragsfähigkeit der landwirtschaftlichen Grundstücke hervorgehen.
Das bedeutet, dass eine ackerbauliche Nutzung feuchter Niederungen und Tiefenlinien als ökonomisch nicht sinnvoll erachtet wurde. Erst durch die Melioration dieser Standorte hat sich daran etwas geändert, ohne dass aber dadurch die Wertzahlen, die die Wirtschaftlichkeit quantifizieren, angestiegen wären.

\subsection{Kleinstrückhaltebecken in der landwirtschaftlichen Flur}

Da Hochwasserschäden vor allem durch den Hochwasserscheitel entstehen, die meiste Zeit die Abflussrate aber niedriger ist, liegt es nahe, den Scheitelabfluss zwischenzuspeichern und 


\begin{tabular}{|c|c|c|c|c|c|c|c|}
\hline \multicolumn{4}{|c|}{ Einzugsgebietseigenschaften } & \multicolumn{4}{|c|}{ Eigenschaften der Rückhaltebecken } \\
\hline \multirow[t]{2}{*}{$\begin{array}{l}\text { Becken- } \\
\text { bezeichnung }\end{array}$} & Größe & $\begin{array}{l}\text { Mittlerer } \\
\text { Jahres- } \\
\text { abfluss }\end{array}$ & $\begin{array}{l}\text { Mittlere } \\
\text { Hang- } \\
\text { neigung }\end{array}$ & $\begin{array}{l}\text { Max. } \\
\text { Wasser- } \\
\text { höhe }\end{array}$ & $\begin{array}{l}\text { Max. } \\
\text { Volumen }\end{array}$ & $\begin{array}{l}\text { Volumen pro } \\
\text { Einzugs- } \\
\text { gebietsfläche }\end{array}$ & $\begin{array}{l}\text { Durchmesser } \\
\text { der } \\
\text { Lochblende }\end{array}$ \\
\hline & ha & $\mathrm{mm} \mathrm{a}^{-1}$ & $\%$ & $\mathrm{~m}$ & $\mathrm{~m}^{3}$ & $\mathrm{~mm}$ & $\mathrm{~m}$ \\
\hline A & 1,6 & 43 & 7 & 1,2 & 423 & 26 & 0,025 \\
\hline B & 3,6 & 62 & 7 & 1,2 & 486 & 14 & 0,040 \\
\hline C & 4,0 & 25 & 9 & 1,4 & 335 & 8 & 0,040 \\
\hline D & 7,8 & 6 & 9 & 1,1 & 221 & 3 & 0,040 \\
\hline
\end{tabular}

erst im abklingenden Ast der Welle wieder abzugeben. Dies ist mit Retentions- oder Rückhaltebecken möglich. Kleine Retentionsbecken (Volumina von einigen hundert bis tausend Kubikmetern) lassen sich oft mit einfachen Mitteln und geringen Kosten in die landwirtschaftlich genutzte Flur integrieren. Für größere Rückhaltebecken ist dagegen ein vergleichsweise hoher planerischer und konstruktiver Aufwand erforderlich [36]. Werden hinreichend viele dieser kleinen Becken installiert und über das Einzugsgebiet verteilt, können sie einen deutlichen Beitrag zum Wasser- und Stoffrückhalt leisten und Hochwasserschäden mindern - entlang der Entwässerungswege, aber auch im kompletten Einzugsgebiet.

Für die Funktion ist wichtig, dass sich Becken nicht schon im ansteigenden Ast der Hochwasserwelle vollständig füllen, weil sonst der Scheitelabfluss ungehindert durchfließen würde. Ungesteuerte Becken werden daher meist mit einem gedrosselten Auslauf versehen, sodass kleinere Abflüsse einfach durchlaufen und das Speicherbecken frei und funktionsfähig bleibt. Bei größeren Regen wird dagegen ein Teil zurückgehalten und verzögert durch die Drossel wieder abgegeben. Solche gedrosselten Ausläufe wurden bereits in den frühen Jahren des 20. Jahrhunderts in den USA eingesetzt [37]. Ist die Zwischenspeicherung kurz (wenige Tage) und das Ein- zugsgebiet klein (einige Hektar), sodass nur kleine Volumina erforderlich sind, können Rückhaltebecken auch innerhalb von Ackerund Grünlandflächen angelegt werden, da landwirtschaftliche Kulturen, bei richtiger Dimensionierung der Drossel, einen kurzzeitigen Überstau tolerieren (einzig bei Kartoffeln ist nach mehr als zwei bis drei Tagen Überstau mit Schäden zu rechnen). Solche kleinen, in der landwirtschaftlichen Flur angelegten Becken bieten dadurch die Vorteile, dass sie kaum zusätzliche Fläche benötigen und meist mit einfachen Mitteln angelegt und unterhalten werden können. Für die in - Tab. 6.5 zusammengestellten Becken trat ein Einstau im Mittel fünfmal pro Jahr auf und dauerte im Schnitt 1,5 Tage. Der längste Überstau dauerte 5 Tage und trat im Mittel nur einmal in 12 Jahren auf. Am längsten dauert der Überstau auch nur im tiefsten Teil und betrifft daher immer nur eine kleine Fläche des Beckens, deren Gesamtfläche bei den in - Tab.6.5 zusammengestellten Fällen nur $100 \mathrm{~m}^{2}$ oder weniger betragen hatte.

Im Folgenden wird ein Überblick gegeben, wie solche Becken angelegt werden können, wie die Dimensionierung der Drossel sein sollte und welche Effekte zu erwarten sind. Hinsichtlich der Details der Ausgestaltung sei auf eine Vielzahl von technischen Anleitungen [38-40] und die hydraulische wie wasserbau- 
liche Grundlagenliteratur verwiesen [z. B. 42, 43, 44]. Die DIN 19700 [41], die für Planung, Bau, Betrieb und Überwachung von Stauanlagen gilt, betrachtet Retentionsräume, die infolge von Verkehrsdämmen oder ähnlichen Aufschüttungen oder Abgrabungen entstanden sind, ebenso wie Regenrückhaltebecken nicht als Hochwasserrückhaltebecken im engeren Sinne. Um solche kleinen Becken geht es aber hier. In der englischsprachigen Literatur werden diese nur kurzzeitig gefüllten Becken „detention ponds“ oder „dry ponds“ genannt, während „retention ponds“ oder „wet ponds“ dauerhaft Wasser enthalten und meist so konzipiert sind, dass sie auch dem Stoffrückhalt und -abbau dienen.

\section{- Anlage}

Kleine Retentionsbecken bieten sich überall dort an, wo lineare Strukturen quer durch Hangmulden geführt werden. Im Folgenden wird von Feldwegen ausgegangen, aber es könnten genauso gut Feldraine oder Hecken sein. Durch Erhöhung des Weges an der tiefsten Stelle - dazu genügen oft schon die in der Landwirtschaft vorhandenen Geräte wird oberhalb des Weges ein Becken geschaffen. Die Böschung sollte nicht steiler als 1:3 (vertikal:horizontal) sein, aber im unteren Teil auch nicht wesentlich flacher, damit der Teil, der regelmäßig überstaut wird, keine zu große Fläche und kein zu großes Volumen einnimmt. Die Erhöhung des Weges hat für dessen Benutzung gleichzeitig den Vorteil, dass der Weg über den feuchtesten Teil der Mulde hinausragt, trocken bleibt und dass die Steigungen des Weges geringer werden. Den schematischen Aufbau zeigt - Abb. 6.11, ein reales Becken ist in Abb. 6.12(c) dargestellt. Wie groß das Becken wird, richtet sich nach den lokalen Gegebenheiten. Billiger, besser beherrschbar und effizienter ist es meist, kleine, aber viele statt wenige große Becken zu schaffen. Insbesondere kaskadenförmig hintereinander geschaltete kleine Becken können vorteilhaft sein, weil dann der Abfluss mehrfach gedämpft wird. Auch werden dann die unteren Becken besser genutzt, da selten alle Flächen gleichzeitig liefern, aber bei mehreren Lieferflächen die Wahrscheinlichkeit steigt, dass eine liefert. Die oberhalb liegenden Becken stellen sicher, dass das unterste Becken nicht überlastet wird. Dadurch kann bei allen Becken die gleiche preisgünstige Bauweise verwendet werden.

Durch den Damm muss ein Ableitungsrohr geführt werden. Am Einlauf in dieses Rohr wird eine Drossel in Form

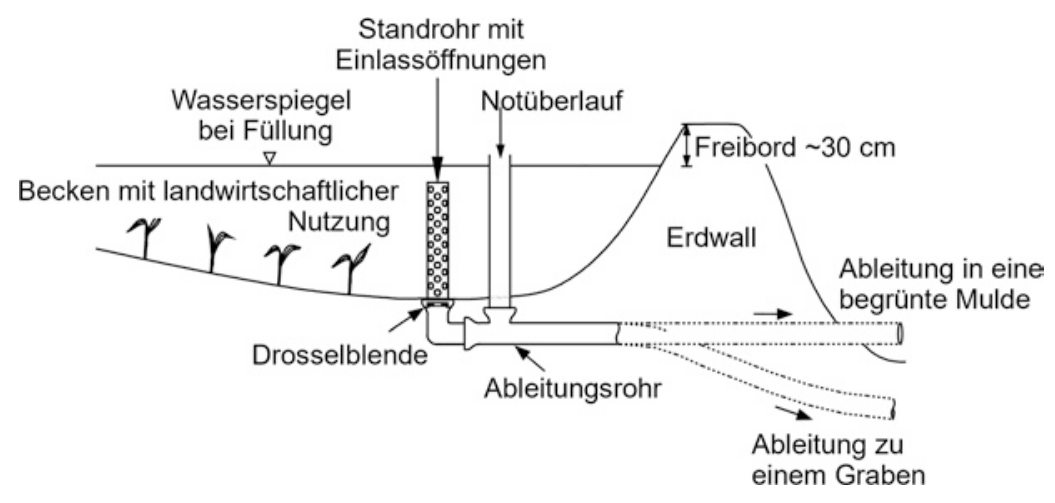

- Abb. 6.11 Schematischer Querschnitt (ca. 3-fach überhöht) durch ein Kleinstrückhaltebecken. Ein perforiertes Standrohr stellt sicher, dass der Zufluss zum Ableitungsrohr nicht verstopfen kann. Eine tauschbare Drosselblende am Übergang vom Standrohr zum Ableitungsrohr erlaubt eine vollständige Entleerung des Beckens, führt aber bei hohen Zuflussraten zu einem Anstau im Becken; ein zweites, nicht gedrosseltes, nur oben offenes Überlaufrohr stellt sicher, dass der Damm nicht überflossen wird und ein ausreichender Freibord erhalten bleibt 

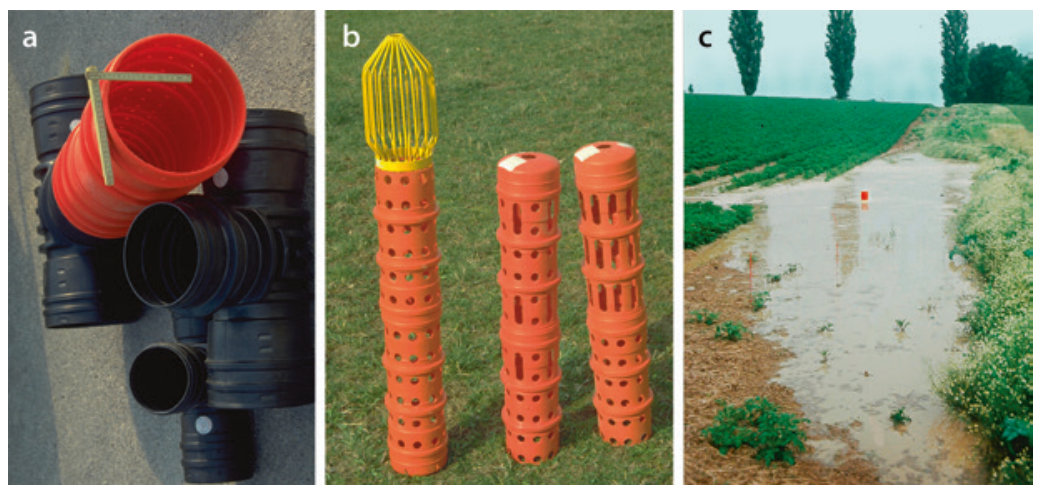

- Abb. 6.12 (a) Ableitungsrohr (schwarz) und abnehmbares Einlassrohr (orange); am Übergang von Einlass- zum Ableitungsrohr sitzt die wechselbare Drossel. (b) Verschiedene Konfigurationen von verlängerbaren Einlassrohren. (c) Gefülltes Becken (Becken B in - Tab. 6.5), bei dem in der Mitte das obere Ende des Einlassrohres gerade noch aus dem Wasser ragt. Das Becken wurde durch Erhöhung eines Feldrains geschaffen. Dieses spezielle Becken war bereits wenige Jahre nach Anlage stark verlandet. Das ursprüngliche Beckenvolumen musste im Herbst des Aufnahmejahrs durch Ausbaggern wiederhergestellt werden. (Fotos: Stephan Weigand)

einer Verengung eingebaut (im Normalfall eine Lochblende). Es ist zu verhindern, dass diese Drossel z. B. durch Stroh verstopft. Deshalb muss der Einlass Stroh zurückhalten, darf aber selbst nicht verstopfen. In den USA sind seit vielen Jahrzehnten entsprechende, senkrecht stehende, bei Bewirtschaftungsmaßnahmen (z. B. Pflanzenschutzmittelausbringung) einfach entfernbare Einlassrohre mit runden oder schlitzförmigen Öffnungen kommerziell verfügbar (•Abb.6.12) (z. B. hickenbottominc.com, $>$ www.agridrain.com).

Auch wenn Einlassrohr und Drossel nicht verstopfen, kann bei besonders großen Ereignissen der Fall eintreten, dass das Becken überzulaufen droht. Dies ist unbedingt zu verhindern, da es dann zu einer rückschreitenden Erosion des Dammes käme, der brechen und den gespeicherten Abfluss in einem Schwall entlassen könnte. Damit dies nicht geschieht, sollte ein Notüberlauf installiert werden und selbiger, ebenso wie das Rohr, das durch den Damm führt, so dimensioniert werden, dass darüber ein seltener Abfluss in jedem Fall abgeleitet werden kann. Der zu erwartende Scheitelabfluss einer Zuflusswelle kann mit den
Methoden in Kap. 3 ermittelt werden. Dann kann mit der GMS-Gleichung $(\triangleright$ Gl. 5.5) der Rohrquerschnitt ermittelt werden, bei dem das Rohr nicht vollständig gefüllt wird. Eine technisch einfache Lösung zur Konstruktion des Notüberlaufs ist die Installation eines zweiten, nicht gedrosselten Einlaufrohrs, dessen Einlauf ausreichend weit unter der Dammkrone liegt (ca. $30 \mathrm{~cm}$; „Freibord“) (vgl. - Abb.6.11). Da das Auslassrohr viel mehr Wasser ableiten kann, als die Drossel durchlässt, wird in dem Fall der Abfluss ungebremst weitergeleitet. Sobald der Zufluss soweit zurückgegangen ist, dass der Wasserspiegel unter dem Noteinlass liegt, ist die normale Funktion des Beckens wiederhergestellt. Alternativ kann auch ein befestigter Überlauf über die Dammkrone konstruiert werden.

Der kritische Punkt solcher Retentionsbecken kommt nach dem Auslassrohr, da durch dieses der Abfluss konzentriert wird. In Folge kommt es leicht $\mathrm{zu}$ einem Einschneiden des Abflusses auf unterhalb gelegenen Ackerflächen. Um dies zu verhindern, bieten sich zwei Lösungen an:

1. Ideal ist, den Abfluss in einer begrünten Abflussmulde weiterzuführen, die in 
einer Hangmulde sowieso vorhanden sein sollte (vgl. $>$ Abschn. 6.3). Durch die permanente Begrünung reicht normalerweise der Schutz aus, um den Abfluss gefahrlos abzuleiten (ggf. ist der Bereich am Auslaufrohr zusätzlich zu sichern, z. B. mit Gabionen). Innerhalb der begrünten Mulde können meist noch an mehreren weiteren Stellen Dämme geschaffen und so eine Speicherkaskade angelegt werden. Diese Dämme verhindern dann auch, dass die begrünte Abflussmulde zu einem in Gefällerichtung befahrenen Weg umfunktioniert wird und ihre eigentliche Funktion einbüßte.

2. Der Abfluss könnte auch durch ein unterhalb des Bearbeitungshorizontes verlegtes Rohr bis zum Vorfluter oder besser in eine große Sickerfläche geführt werden. Am gleichen Rohr können mehrere in der gleichen Hangmulde untereinander angeordnete Becken angeschlossen werden, um es effizient $\mathrm{zu}$ nutzen. Diese Lösung ist aber eindeutig nur zweite Wahl, da der Abfluss im Rohr sehr schnell erfolgt und dadurch der Abflussscheitel steigt. Der Abfluss erfolgt schnell, weil das Rohr ein großes Gefälle aufweist, da es parallel zur Bodenoberfläche mit derselben Neigung wie die unterhalb folgenden Felder verlegt wird, weil das Wasser darin in großer Schichtdicke fließt und weil der Rauheitsbeiwert konventioneller Rohre sehr hoch ist. Der Rauheitsbeiwert von Plastikrohren kann Werte von $90 \mathrm{~m}^{1 / 3} \mathrm{~s}^{-1}$ und mehr erreichen und liegt damit weit über den Werten natürlicher Oberflächen (vgl. - Abschn. 6.6). Innen geriffelte Rohre sind daher empfehlenswert. Sie senken den Rauheitsbeiwert aber auch nur auf ca. die Hälfte und beseitigen nicht das Problem der großen Schichtdicke. Die scheitelmindernde Wirkung des Beckens muss daher wesentlich größer sein als die beschleunigende Wirkung des Rohres. Dies ist eigentlich nur dann erreichbar, wenn das Speichervolumen im Vergleich zur Lieferfläche groß ist. Wird der Abfluss in eine Sickerfläche geleitet, ist davon auszugehen, dass diese aufgrund der im Abfluss transportierten Feststoffe regelmäßig geräumt werden muss.

\section{- Dimensionierung}

Die Dimensionierung kann sich prinzipiell nach der Befüllung oder nach der Entleerung des Speichers richten. Wenn die Befüllung maßgebend ist, wird das Beckenvolumen mithilfe von Modellregen so ermittelt, dass ein bestimmter Spitzenabfluss gerade noch gedämpft wird, ohne dass das Becken überläuft. Dies ist das übliche im technischen Hochwasserschutz bei größeren Becken praktizierte Vorgehen. Es soll sicherzustellen, dass ein festgelegter (Regel-)Abfluss unterhalb eines Rückhaltebeckens nicht überschritten wird. Für die Berechnung muss der Abflussgang des Modellregens erzeugt und dann der Verlauf der Speicherfüllung bei gleichzeitigem Ausfluss, meist für verschiedene Drosselöffnungen, ermittelt werden. Schon die genaue Wahl des Modellregens ist relativ problematisch und oft müssen viele verschiedene Varianten verglichen werden [46]. Einfacher und für kleine Becken im ländlichen Raum in der Regel hinreichend ist es, die Entleerung des Speichers am verfügbaren Beckenvolumen auszurichten. Ist ein potenzieller Beckenstandort identifiziert, kann das Volumen eines Speicherbeckens durch Computerprogramme heutzutage leicht und hinreichend genau aus einem (hochauflösenden) digitalen Geländemodell und der geplanten Höhe der Dammkrone (abzüglich des Freibords) abgeleitet werden. Je flacher das Gelände oberhalb des Damms ist, umso mehr Wasser lässt sich mit moderaten Dammhöhen zwischen 1 und 1,5 $\mathrm{m}$ stauen. Geht man davon aus, dass die landwirtschaftliche Kultur im Bereich des Speicherbeckens nur zwei Tage überstaut werden soll, muss sich das volle Becken innerhalb von 
zwei Tagen vollständig entleeren, sofern kein Zufluss mehr erfolgt. Um die Drosselöffnung entsprechend zu dimensionieren, genügt eine einfache Gleichung [47, 48], da der Abfluss im Ableitungsrohr frei abfließen kann und nicht zurückstaut. Der Index „o“ steht dabei für „orifice“ (Blende):

$$
q_{o}=C_{o} \cdot A_{o} \cdot \sqrt{2 g h_{0}}
$$

wobei

$q_{o}$ - Durchfluss durch eine Lochblende $\left(\mathrm{m}^{3} \mathrm{~s}^{-1}\right)$

$\mathrm{C}_{\mathrm{o}}$ - Durchflusskoeffizient; bei kreisförmigen Blenden mit einem Lochdurchmesser $<5 \mathrm{~mm}$ ist $C_{0} 0,60$, bei größerem Durchmesser 0,62

$A_{o}$ - Fläche der Blendenöffnung $\left(\mathrm{m}^{2}\right)$

$\mathrm{g}$ - Erdbeschleunigung $\left(9,81 \mathrm{~m} \mathrm{~s}^{-2}\right)$

$h_{\circ}$ - Höhe der Wassersäule über der Blendenöffnung (m); um eine mittlere Durchflussrate zu schätzen, kann als Höhe der Wassersäule ein Drittel der maximalen Stauhöhe angenommen werden

Wird eine kurze Entleerungszeit (z. B. ein Tag) angenommen, sinkt die Pufferwirkung des Beckens. Das Becken wird bei vielen (kleinen) Abflüssen nahezu funktionslos, weil die Blendenöffnung reicht, um den Zufluss durchzulassen. Allerdings werden von so einem Becken sehr hohe, selten auftretende Abflussspitzen noch abgemildert, weil es selten ganz gefüllt ist. Wird eine wesentlich längere Entleerungszeit angestrebt (z. B. vier Tage), puffert das Becken auch kleinere Abflüsse und wird daher sehr viel häufiger wirksam sein. Allerdings wird es bei seltenen, großen Abflussraten bereits weitgehend gefüllt sein, sodass gerade diese Raten ungepuffert über den Notüberlauf weitergeleitet werden. Wenn der Fokus mehr auf der Verbesserung der Gewässerqualität liegt, ist es meist besser, viele kleine Ereignisse zu puffern und wenige große über den Notüberlauf abzuleiten. Oft werden dann die Becken sogar so konzipiert, dass Sedimentation partikulärer Stoffe unterstützt wird und dass möglichst ganzjährig Wasser im Becken ist, weil dann der Rückhalt von Nährstoffen und der Abbau von
Pflanzenschutzmitteln besser wird [50]. Für die Hochwasserminderung steht dagegen das Beherrschen der großen Ereignisse im Vordergrund [51]. Welcher dieser Varianten der Vorzug zu geben ist, kann daher nur im Einzelfall unter Berücksichtigung der Gesamtsituation entschieden werden. Kommerziell verfügbare Systeme verfügen normalerweise über wechselbare Drosselblenden. Dadurch kann, wenn Erfahrung mit einem Becken gesammelt worden ist, einfach nachjustiert und die Drosselung verstärkt oder gemindert werden.

In der landwirtschaftlich genutzten Flur lässt sich oft ein Verhältnis von Beckenvolumen zu Einzugsgebietsfläche (spezifisches Rückhaltevolumen) von über $10 \mathrm{~mm}$ erzielen (Becken A und B in - Tab.6.5), womit auch bei Flächen, die aufgrund der Bodenverhältnisse und der Nutzung stark zu Oberflächenabfluss neigen (Einzugsgebiete $A$ und B), bereits eine deutliche Hochwasserminderung erreicht werden kann. Bei geringerer Neigung zu Oberflächenabfluss (Becken D in - Tab.6.5) reicht auch ein geringeres spezifisches Rückhaltevolumen.

\section{- Wirkungen}

Die Fläche eines Beckens ist normalerweise winzig im Vergleich zur Lieferfläche. Eine Verminderung des Abflussvolumens durch Versickerung kann man daher vernachlässigen. Auch die Verdunstung innerhalb der kurzen Einstauphase ist meist vernachlässigbar. Die hochwassermindernde Wirkung ergibt sich daher praktisch ausschließlich aus der Pufferung zwischen Zufluss und Abfluss. Ein Beispiel von Becken B in - Tab.6.5 zeigt - Abb. 6.13 oben. Der Spitzenabfluss wurde durch das Becken um $70 \%$ reduziert. Außerdem wurde der Spitzenabfluss um ca. sechs Stunden nach hinten verschoben. Die Verzögerung des Ausflussscheitels gegenüber dem Scheitel des Zuflusses wird dabei umso größer, je stärker die Dämpfung ist und je länger der Regen andauert [52]. Der Scheitel des Ausflusses tritt daher erst auf, 
wenn auf anderen Flächen in ähnlicher Position, die nicht durch ein Becken gepuffert sind, längst kein Oberflächenabfluss mehr auftritt, was die Gebietsentwässerung entzerrt. Das weitere Entwässerungssystem unterhalb eines Beckens wird daher in zweifacher Weise entlastet. Da dort die Abflussrate geringer wird, verringert sich auch entlang der gesamten weiteren Fließstrecke des Wassers die Fließgeschwindigkeit, sodass die Beckenwirkung noch weiter verstärkt wird. Allerdings erfasst das in - Abb.6.14 dargestellte Becken nur knapp 4 ha. Trotz seiner großen Wirkung am Beckenauslass ist der Effekt im nächsten Fließgewässer vermutlich kaum mehr nachweisbar. Modellierungen zeigen, dass die Gesamtwirkung in etwa linear mit dem Flächenanteil der geschützten Fläche

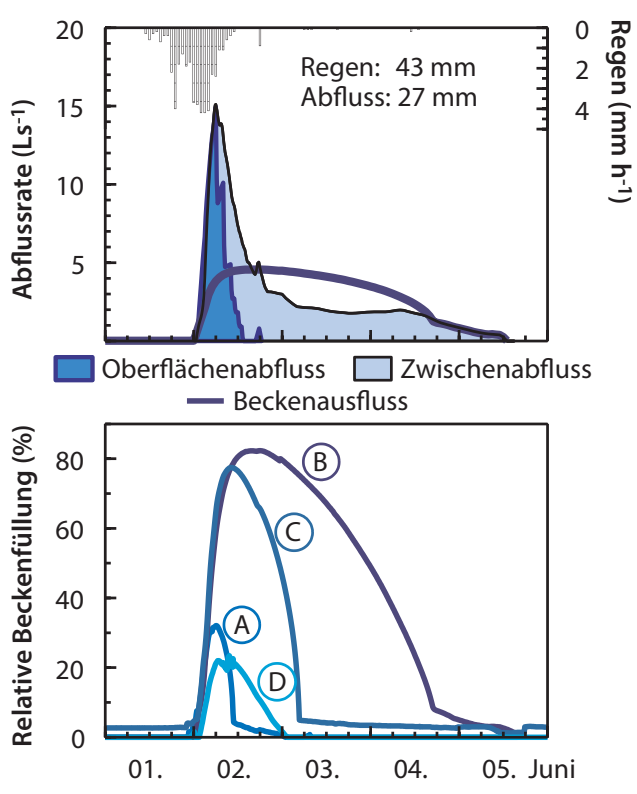

- Abb. 6.13 Oben: Gemessene Zuflussraten in ein kleines Speicherbecken (Becken B in - Tab. 6.5) und gemessene Ausflussraten aus dem Speicherbecken. In diesem Fall lieferte das Einzugsgebiet zusätzlich zum Oberflächenabfluss noch über mehrere Tage Zwischenabfluss. Dadurch dauerte es vier Tage, bis das Becken wieder vollständig entleert war. Unten: Relativer Füllungsgrad der vier in - Tab. 6.5 charakterisierten Becken beim gleichen Regen zurückgeht. Für den in • Abb. 6.13 dargestellten Fall wäre also zu erwarten, dass der Scheitel statt um 70 nur um $7 \%$ reduziert würde, wenn nur die 4 ha in einem insgesamt 40 ha großen gleichzeitig abflussliefernden Gesamtgebiet durch das Becken erfasst würden. Das spezifische Rückhaltevolumen für das Gesamtgebiet wären dann auch nur $1,4 \mathrm{~mm}$, während das spezifische Rückhaltevolumen der geschützten 4-ha-Fläche $14 \mathrm{~mm}$ beträgt. Es benötigt daher viele solcher Becken, umso mehr, je größer das betrachtete Fließgewässer ist, um einen deutlichen Effekt zu erzeugen. Dadurch wird dann allerdings, im Gegensatz zu einzelnen großen Rückhaltebecken, nicht nur ein Ort am Fließgewässer, sondern das gesamte Einzugsgebiet geschützt. Dies bestätigen auch Untersuchungen aus 8 und $17 \mathrm{~km}^{2}$ großen Einzugsgebieten, wo Rückhaltebecken eine erkennbare Wirkung auf große Hochwasserabflüsse hatten, sobald ihr spezifisches Rückhaltevolumen $3 \mathrm{~mm}$ überstieg [36].

Der Vergleich verschiedener Becken beim gleichen Regen (• Abb. 6.13 unten) zeigt, wie unterschiedlich die Reaktion der Einzugsgebiete ist, je nach Bedeckung der Flächen. Becken A und D wurden kaum gefüllt, weil deren Lieferflächen zum Zeitpunkt des Regens durch einen voll entwickelten Weizenbestand gut bedeckt waren. Becken B und $\mathrm{C}$ wurden dagegen wesentlich stärker in Anspruch genommen, weil der Mais in ihren Liefergebieten noch wenig entwickelt war. In allen Fällen stieg die Beckenfüllung aber nie über $80 \%$ des Beckenvolumens. Auch deutlich größere Abflussspitzen hätten also noch beherrscht werden können, ohne dass der Notüberlauf angesprungen wäre.

Die praktische Umsetzung solcher Konzepte sind für Deutschlands nur sehr spärlich in der Literatur dokumentiert. Ein Fall ist aus der im Landkreis Pfaffenhofen a. d. Ilm durch eine Diplomarbeit bekannt [53]: Auf einer knapp $17 \mathrm{~km}^{2}$ großen Fläche in der Hallertau, dem größten Hopfenanbaugebiet Deutschlands (Nutzflächenneigungen zwischen 7 und $14 \%$ ), wurden zum Rückhalt 


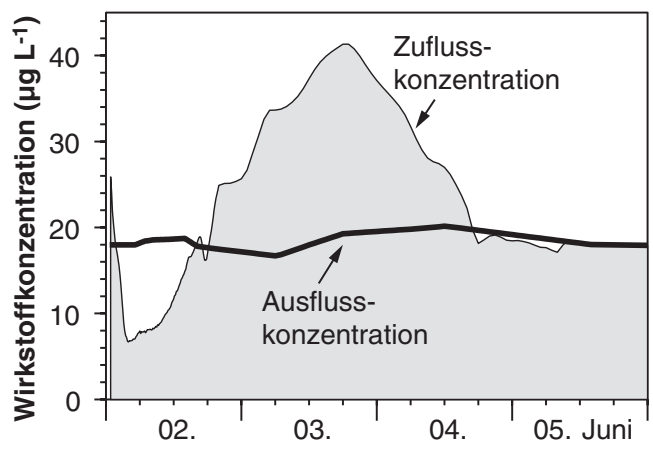

- Abb. 6.14 Das leicht lösliche Herbizid Terbutyalzin wurde durch den infiltrierenden Regen bereits am Anfang des Regenereignisses in den Boden eingewaschen. Daher wurde die Spitzenkonzentration im zufließenden Abfluss erst am zweiten Tag erreicht, als kein Oberflächenabfluss mehr den exfiltrierenden Zwischenabfluss verdünnte. Im Ausfluss aus dem Retentionsbecken war durch die Durchmischung die Konzentration immer im mittleren Bereich und die doppelt so hohen Spitzenkonzentrationen wurden vermieden. Die Daten und Ergebnisse stammen von dem gleichen Ereignis, das schon in • Abb. 6.13 dargestellt wurde

von Oberflächenabfluss aus einer Vielzahl von Geländemulden, Senken, Tallinien, aber auch durch Wege und Straßen insgesamt etwa 130 kleine Erdbecken mit einem mittleren Volumen von $250 \mathrm{~m}^{3}$ angelegt (Gesamtvolumen $\approx 30.000 \mathrm{~m}^{3}$ ). Dies entspricht einem Becken je 13 ha und zeigt das große Potenzial für die Anlage solcher Becken. Berechnungen ergaben, dass durch die Summe der Rückhaltebecken ein Schutz vor etwa 20-jährlichen Sommerhochwasserereignissen in den Unterliegergemeinden geschaffen werden konnte. Ein ähnlicher Fall ist bereits aus den 1980er-Jahren für das Flurbereinigungsgebiet Freinhausen dokumentiert, allerdings ohne die Wirkung durch Modellierung abzuschätzen [54].

Neben der Dämpfung des Abflussscheitels wird auch die Konzentration von Nährstoffen und Agrochemikalien, insbesondere von Pflanzenschutzmitteln, gedämpft. Deren Konzentration ist meist am Anfang des Abflussereignisses groß, lässt dann aber im
Laufe des Ereignisses rasch nach. Da im Becken früher Abfluss mit hoher Konzentration zurückgehalten und mit späterem Zufluss mit geringerer Konzentration vermischt wird, werden die Spitzenkonzentrationen vermieden, auch wenn sich die Gesamtmenge des Wirkstoffabtrags dadurch nicht ändert (• Abb. 6.14).

Die Fließgeschwindigkeit des Oberflächenabflusses wird innerhalb des Beckens wegen der großen Einstauhöhe praktisch null. Dadurch sinkt die Transportkapazität und ein Großteil des Erosionsmaterials wird im Becken abgelagert [37, 49]. In der Gesamtwirkung beträgt der Sedimentrückhalt etwa $70 \%$ (mit weiter Spanne), da nur bei Beckenfüllung ein Rückhalt zu erwarten ist. Bei kleinen Ereignissen und am Anfang großer Ereignisse ist dagegen der Rückhalt gering, weil in beiden Fällen kaum Einstau auftritt.

Durch den Sedimentrückhalt verringern sich das Speichervolumen und die Pufferwirkung. Die Pufferwirkung geht dabei noch wesentlich schneller zurück als das Speichervolumen, weil die Drossel an der ursprünglichen Stelle bleibt und damit unterhalb des durch Sedimentschichten angehobenen Beckenbodens liegt. Selbst wenn das Becken noch gar nicht gefüllt ist, entspricht die Höhe der Wassersäule über der Blendenöffnung bereits beim ersten Zulauf schon der Sedimenthöhe. Entsprechend $>$ Gl. 6.2 ist damit der Wasserdurchfluss durch die Drossel von Anfang an hoch. Bei einem Bodenabtrag von $10 \mathrm{tha}^{-1} \mathrm{a}^{-1}$, was als typischer Wert bei konventionellem Anbau angesehen werden kann, würden bei einem Einzugsgebiet von 2 ha und einem Rückhalt von $50 \%$ ca. $10 \mathrm{~m}^{3}$ Speichervolumen pro Jahr verloren gehen. Bei den in - Tab.6.5 dargestellten Becken wäre also nach 10 Jahren ein Viertel bis die Hälfte des Speichervolumens mit Sediment belegt. Als Alternative zu einem flächigen Erosionsschutz kommen Retentionsbecken daher im Normalfall nicht in Frage. Der Bau von Retentionsbecken macht dagegen vor allem dann Sinn, wenn auf der Fläche 
ein sehr guter Erosionsschutz praktiziert wird oder man Unterhaltskosten für das regelmäßige Ausbaggern des Sediments in Kauf nimmt. Auch mit gutem Erosionsschutz ist damit zu rechnen, dass Sediment von Zeit zu Zeit entfernt werden muss, um das volle Speichervolumen und die volle Pufferwirkung wiederherzustellen. Besonders vorteilhaft sind Retentionsbecken daher in Grünlandgebieten, in denen das Problem der Sedimentation kaum auftritt. Gerade in Grünlandgebieten können solche Becken wertvoll sein, da dort weniger Möglichkeiten als im Ackerbau bestehen, Infiltration und Gebietsrückhalt $\mathrm{zu}$ fördern und die Fließgeschwindigkeit zu senken.

\subsection{Flurgliederung und Flächenarrangement}

Strukturen und Hindernisse verlängern Fließpfade in der Fläche, vermindern ihr Gefälle und verzögern die Bündelung des Abflusses. Dies reduziert die Geschwindigkeit des Oberflächenabflusses. Gleichzeitig entscheidet die Flächenparzellierung oftmals über die Bewirtschaftungsrichtung und damit über den Verlauf und die hydraulischen Eigenschaften der Fließpfade zwischen Wasserscheide und Gewässer. Um den Einfluss der Flurgliederung auf die Abflusskonzentration zu quantifizieren, werden im Folgenden mehrere Beispiele betrachtet. Zunächst erfolgt eine theoretische Analyse, bei der die Fließzeiten unterschiedlicher Flächenparzellierungen, der erforderliche Bedarf für wasserableitende Strukturen und der resultierende Retentionsspeicher der einzelnen Varianten verglichen werden. Im Anschluss folgen zwei Praxisbeispiele. Zunächst wird das aktuelle, in einem Untersuchungsgebiet vorhandene Netz aus Fließpfaden zwischen Wasserscheide und Gewässernetz mit einer historischen, deutlich feingliedrigeren Flächenparzellierung des Gebietes vor der Flurbereinigung verglichen.
Im zweiten Fall wird durch den Vergleich unterschiedlicher Flurneuordnungsvarianten gezeigt, dass auch bei einer zeitgemäßen Optimierung der Flächenparzellierung, die für den Wasser- und Stoffrückhalt wesentlichen Strukturen ohne Nachteile für die Bewirtschaftung berücksichtigt werden können.

\subsubsection{Konzentrationszeit und Flächenbedarf abflussmindernder Fließpfade}

Um den Effekt des Arrangements von Flurstücken auf den Wasser- und Stoffrückhalt bei Starkregen zu illustrieren, wurden schematisch für eine 15 ha große, landwirtschaftliche Fläche (einheitliche Längsneigung $10 \%$ bzw. Querneigung 2\%) unterschiedliche Feldzuschnitte entworfen. Sie unterscheiden sich im Wesentlichen in der Bewirtschaftungsrichtung, in der Art und Weise, wie die Schläge voneinander abgetrennt sind, sowie in den konstruierten und den sich bei Regen natürlicherweise ausbildenden Fließpfaden (• Abb. 6.15). Das dargestellte Beispiel und seine Modifikationen sind sehr schematisch. Dies soll den Rechenweg nachvollziehbar machen, den Einfluss der verschiedenen Gestaltungsmöglichkeiten quantifizieren und das Potenzial einer möglichen Abflussverzögerung aufzeigen. Die nachfolgend dargestellten Prinzipien und Möglichkeiten sollen helfen, an die reale Landschaft angepasste Lösungen zu finden.

Die Fließzeiten entlang des längsten, hinsichtlich der Nutzung typischen Fließweges von der Wasserscheide (Punkt X oben links) bis zum Gebietsauslass (unten rechts) wurden mithilfe der GMS-Gleichung (s. - Abschn. 5.3.4) für einen starken Niederschlag, bei dem $30 \mathrm{~mm}$ in $30 \mathrm{~min}$ abfließen, abgeschätzt und verglichen. Zur zusätzlichen Bewertung der verschiedenen Arrangements werden der Bodenabtrag durch 

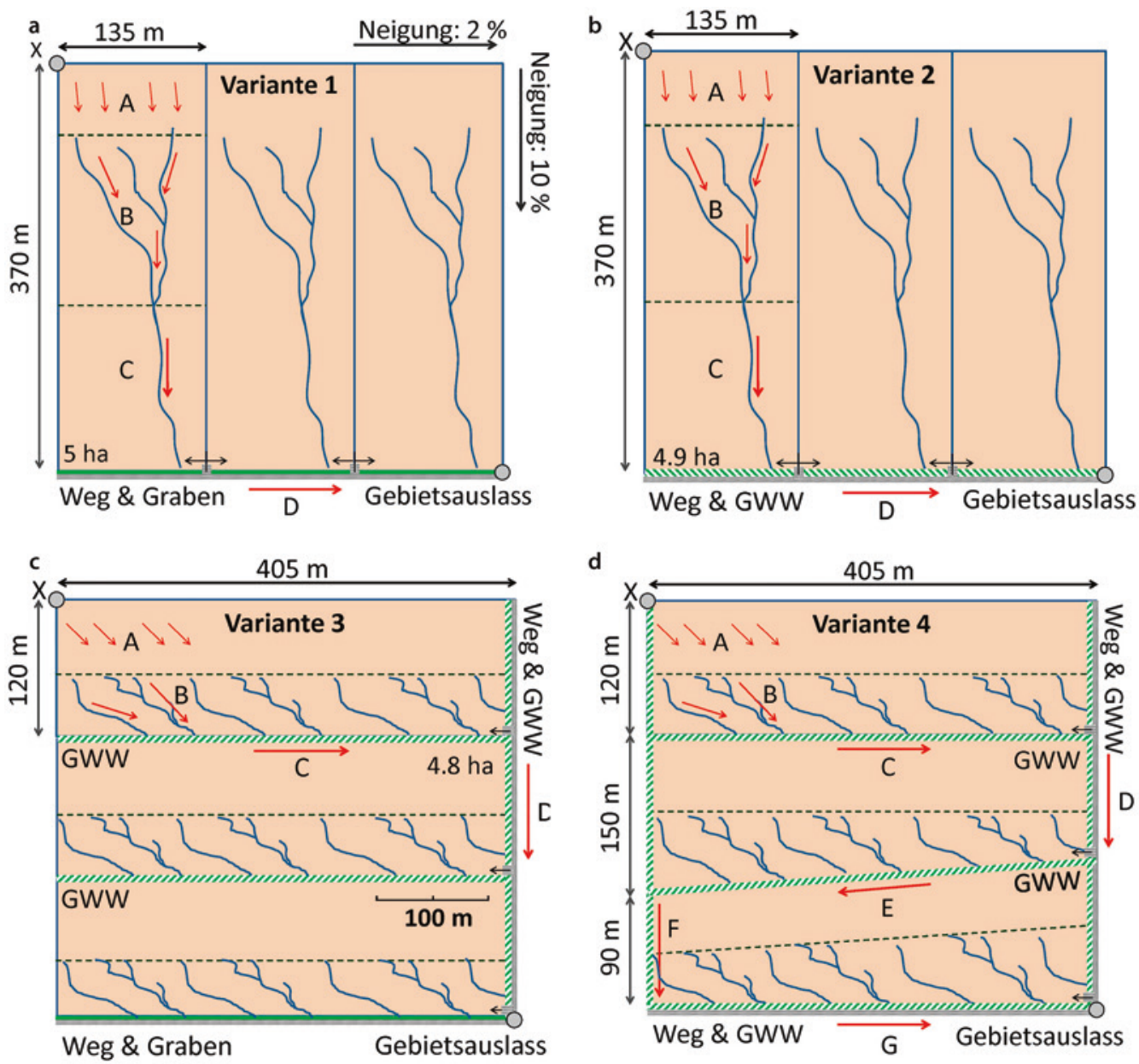

- Abb. 6.15 Vier Varianten der Gliederung einer 15 ha großen Fläche in drei Schläge. Die Breite der Felder wurde auf das Mehrfache einer typischen Maschinenarbeitsbreite von $15 \mathrm{~m}$ festgelegt (Ausnahme d). Die obere Flächengrenze entspricht der Wasserscheide. Die Bewirtschaftungsrichtung erfolgt entlang der längeren Seite. Das zu erwartende Fließpfadmuster ist durch blaue Linien schematisch dargestellt, der längste Fließweg vom Punkt X an der Wasserscheide bis zum Gebietsauslass ist mit roten Pfeilen markiert, wobei die einzelnen Abschnitte durch die Großbuchstaben A bis $G$ bezeichnet wurden. Gräben, begrünte Abflussmulden und Wege sind als grüne, grün-schraffierte bzw. graue Linien dargestellt. Die Zufahrten in die Felder sind durch Pfeile gekennzeichnet. Schwarz gestrichelte Linien markieren den Bereich, wo sich der Abflusstyp ändert, also z. B. der Schichtabfluss sich in Rillen und Rinnen bündelt

Erosion nach der Allgemeinen Bodenabtragsgleichung [55], sowie der mit der Strukturanreicherung einhergehende Flächenverlust bestimmt. Darüber hinaus wird das Volumen des Wassers ermittelt, dass auf der Fläche, in den Rillen, Rinnen und den Gräben fließt. Dies ist näherungsweise der oberflächliche Retentionsspeicher und hängt ebenfalls vom
Feldlayout ab. Dieser Retentionsspeicher versickert zum Teil nach dem Regen („Nachregen-Infiltration“) und erhöht so die Infiltration; zum größeren Teil fließt dieser Retentionsspeicher nach Regenende langsam ab. Er verursacht den typischen und unproblematischen, lang abfallenden Ast einer Abflusswelle. Je größer die Retention, 
umso langsamer fließt das Wasser, umso mehr infiltriert noch nach dem Regen und umso größer und länger ist auch der abfallende Ast der Abflusswelle, was bedeutet, dass dieses Wasser nicht zum Abflussscheitel beiträgt.

Es wird angenommen, dass die konstruierten Fließwege an beliebiger Stelle und in beliebiger Form angelegt werden können (also unabhängig von Eigentumsverhältnissen oder anderen Einflüssen sind) und nur physikalische Gesetzmäßigkeiten berücksichtigt werden müssen. Darüber hinaus wird davon ausgegangen, dass die entstehenden Fließpfade des Oberflächenabflusses von der Flurgliederung abhängen. Bei langen, in Hauptgefälle ausgerichteten Schlägen (Variante 1 (a) und 2 (b) in $\bullet$ Abb. 6.15) ist zu erwarten, dass sich der Schichtabfluss (Fließabschnitt A) zunächst in Rinnen und Rillen (Fließabschnitt B) und dann in der Hangmulde (Fließabschnitt C) bündelt. Die beiden Feldlayouts unterschieden sich nur darin, dass bei Variante 1 der Hangfuß in einen typischen Wegseitengraben (trapezförmig, geräumt) entwässert (Fließabschnitt D), wohingegen dieser bei Variante 2 durch eine breite und hydraulisch raue begrünte Abflussmulde ersetzt wurde. So lässt sich der Einfluss dieses Entwässerungsabschnittes unabhängig vom restlichen Fließpfad beurteilen.

Bei quer zum Gefälle ausgerichteten und bewirtschafteten Schlägen (Variante 3 (c) und 4 (d) in - Abb. 6.15) ist zu erwarten, dass sich die Fließstrecke des Schichtabflusses wegen der quer zum Hauptgefälle liegenden Bearbeitungsrauheit etwas verlängert und das (verhältnismäßig schnelle) Fließen in der Hangmulde bei dieser Feldaufteilung entfällt, weil der Abfluss die Schlaggrenze erreicht, bevor er sich bündeln kann. Daraus erwächst ein großes Potenzial zum Bremsen des Abflusses. Ob dieser Effekt in der Praxis genutzt werden kann, hängt im Wesentlichen von der Feldbreite ab bzw. von den Distanzen, nach denen sich Schichtabfluss (Fließabschnitt A) in Rinnen und Rillen bzw. Letztere in Hangmulden bündeln, welche stark von der Rauheit der Oberfläche bestimmt werden (s. - Anhang 8.2). Zudem ist die konstruktive Gestaltung der Fließwege wichtig. Strukturen wie Ranken, Mulden, flache Wälle oder auch Hecken können als abflussableitende Strukturen gestaltet werden. Erfolgt dies nicht, werden sie bei Starkregen meist schnell überspült und haben keinen Effekt.

Die vier Arrangements unterscheiden sich in ihrem Verhalten erheblich (- Tab. 6.6). Variante 1 verursacht den höchsten Bodenabtrag und die kürzeste Fließzeit (16,5 min). Durch die Anlage einer begrünten Abflussmulden (Variante 2) kann die Fließzeit bis zum Auslass gegenüber Variante 1 um 19\% erhöht werden. Allerdings wird diese begrünte Abflussmulde wegen des hohen Abtrags in der Fläche und der Verringerung der Fließgeschwindigkeit schnell durch Sediment verfüllt werden.

Bei horizontaler Ausrichtung der Schläge und der Anlage einer konstruierten Wasser-

- Tab. 6.6 Veränderungen von (mittlerer) Schlaggröße, Fließzeit, zwischengespeichertem Abflussvolumen und Bodenabtrag für Feldgliederungsvarianten, bei denen unterschiedliche Flächenanteile zur Lenkung des Abflusses vorgesehen und aus der Nutzung genommen wurden

\begin{tabular}{|c|l|l|l|l|l|l|}
\hline Variante & $\begin{array}{l}\text { Schlag- } \\
\text { größe }\end{array}$ & Fließzeit & $\begin{array}{l}\text { Fließzeit- } \\
\text { verlängerung }\end{array}$ & $\begin{array}{l}\text { Speicher- } \\
\text { volumen }\end{array}$ & $\begin{array}{l}\text { Abtrags- } \\
\text { reduktion }\end{array}$ & $\begin{array}{l}\text { Flächen- } \\
\text { bedarf }\end{array}$ \\
\hline- & ha & min & $\%$ & mm & $\%$ & $\%$ \\
\hline 1 & 5,0 & 16,5 & 0 & 3,4 & 0 & 0 \\
\hline 2 & 4,9 & 19,6 & 19 & 5,2 & 0 & 0,8 \\
\hline 3 & 4,8 & 23,7 & 43 & 7,7 & 51 & 3,1 \\
\hline 4 & 4,7 & 39,5 & 139 & 11,4 & 51 & 4,6 \\
\hline
\end{tabular}


führung erhöht sich die Fließzeit gegenüber Variante 1 in Variante 3 und 4 um $43 \%$ bzw. $139 \%$ auf $24 \mathrm{~min}$ bzw. $40 \mathrm{~min}$. Eine Verlängerung der Fließzeit um $100 \%$ führt am Gebietsauslass zu einer Halbierung des Scheitels der Abflusswelle von kurzzeitigen Intensitätsspitzen. „Kurzzeitige Abflussspitzen“ bedeutet, dass sie kürzer sind als die Fließzeit von $40 \mathrm{~min}$. Nur wenige Gewitterregen haben Intensitätsspitzen, die länger andauern. Zusätzlich wird in Variante 3 und 4 der Bodenabtrag gegenüber Variante 1 bzw. 2 um $50 \%$ reduziert und die Menge an zwischengespeichertem Wasser erhöht sich um das Drei- bis Vierfache. Die Verminderung des Bodenabtrags ist nicht nur aus Gründen des Bodenschutzes wichtig, sondern auch, weil sie die Unterhaltskosten für die Gräben und begrünten Abflussmulden senkt. Durch Streifenanbau ( Abschn. 4.5.2) ließe sich der Bodenabtrag sogar noch mal halbieren und damit auf $25 \%$ senken.

Durch eine Optimierung der Flurgliederung ergeben sich also sowohl für den Wasser- als auch für den Stoffrückhalt enorme Potenziale. Der „Preis“ dieser Maßnahmen ist der Flächenbedarf für die Erschließung und das Anlegen der GWWs, der gegenüber der ersten Variante um ein bis fünf Prozent steigt. Bei Variante 4 wird die Bewirtschaftung durch schiefe Stöße in zwei der drei Schläge zusätzlich erschwert. Allerdings wird die Bewirtschaftung auch erleichtert, weil die Rinnen als Hindernisse wegfallen. Es ist zu erwarten, dass die Erträge um mindestens so viel steigen, dass sie den Flächenverlust ausgleichen. Das hat zwei Gründe: 1) Den Pflanzen steht durch die Nachregen-Infiltration mehr Wasser zur Verfügung. 2) Die Feldbewirtschaftung kann viel präziser auf die Kulturpflanzenentwicklung abgestimmt werden, weil die größten Bodenunterschiede entlang des Gefälles auftreten und nun nicht mehr in einem einzigen Feld anzutreffen sind.

Die Verlängerung der Fließzeit und die Reduktion des Bodenabtrags resultieren bei horizontaler Ausrichtung (Variante 3 (c) in - Abb.6.15) im Wesentlichen daraus, dass der Fließweg des Schichtabflusses länger wird, weil die Bearbeitungsspuren ein Bündeln verzögern, und weil der schnelle Hangmuldenabfluss durch die in Gefällerichtung schmalen Felder weitgehend verhindert wird. Damit das Potenzial zur Abflussverzögerung voll genutzt werden kann, ist es erforderlich, dass der Oberflächenabfluss an den unteren Feldrändern gesammelt und über „bremsend“ gestaltete Fließpfade an den Feldrand und von dort weiter zum Gebietsauslass gelenkt wird. Dazu müssen die horizontalen Fließpfade an den unteren Feldrändern als begrünte, hydraulisch raue Mulde, idealerweise mit einem kleinen, talseitigen Wall angelegt werden. Dies stellt sicher, dass der Abfluss nicht unkontrolliert in das unterhalb liegende Feld gelangt. Der Fließweg sollte darüber hinaus durch eine in Bodennähe dichte Bepflanzung gesichert werden, um die Gefahr eines Durchbrechens zu minimieren. Ähnliches gilt für den Fließabschnitt D von Variante 3 am rechten Feldrand. Er verläuft in Gefällerichtung und entwässert das komplette Einzugsgebiet. Bei Starkregen werden dort große Abflussmengen mit hoher Geschwindigkeit abgeführt, sodass ein flacher, breiter und hydraulisch rauer Grassed-Waterway zwingend erforderlich wird. Andernfalls kommt es hier zu Erosion. Das Potenzial zum Wasserrückhalt in Variante 4 (- Abb. 6.15 (d)) wird gegenüber der vorherigen noch deutlich weiter erhöht, da das Wasser über "Umwege“ zum Auslass geleitet wird. Die Fließstrecke ist hier mehr als doppelt so lang wie bei den vorher skizzierten Varianten. Die Planung eines solchen Layouts wird aber durch die gegebenen Randbedingungen (Maschinenarbeitsbreite, Gefällesituation) schnell anspruchsvoll.

Die dargestellten Gliederungsvarianten illustrieren nur einen kleinen Teil der denkbaren Möglichkeiten. Eine weitere Option zur zusätzlichen Förderung des Wasserrückhalts in der Fläche besteht besonders bei Variante 3 und 4 darin, kleine Rückhaltebecken entlang der Fließwege zu platzieren (Skizze in - Abb. 6.16). Insbesondere wenn mehrere, in Reihe geschaltete Becken zum Einsatz kommen, ist neben der zeitlichen Verzögerung auch ein Stoff- und Volumenrück- 


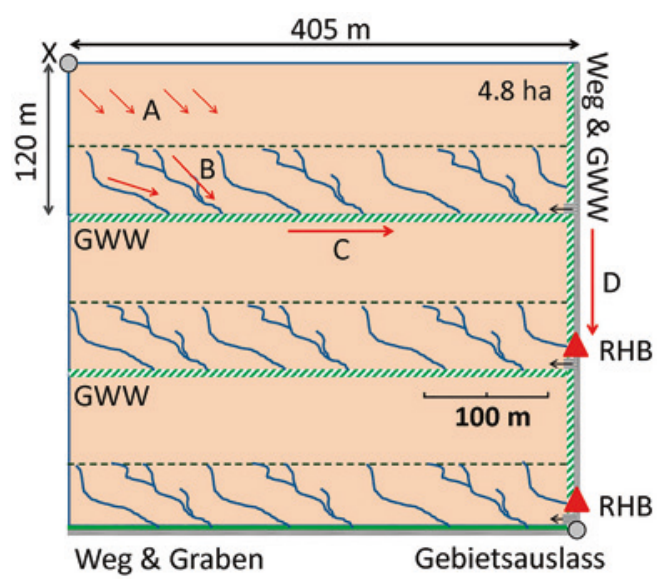

- Abb. 6.16 Schematische Darstellung zur Platzierung kleiner Rückhaltebecken (rote Dreiecke, RHB) oberhalb von Zufahrten (kleine, schwarze Pfeile). Wie in $\bullet$ Abb. 6.15 ist das Fließpfadmuster durch blaue Linien und der längste Fließweg vom Punkt $X$ an der Wasserscheide (oben links) bis zum Gebietsauslass (unten rechts) mit roten Pfeilen markiert. Gräben, begrünte Abflussmulden und Wege sind als grüne, grün-schraffierte und graue Linien dargestellt

halt möglich. Dazu muss an den Zufahrten, die vom Weg in die Felder führen, ein Damm mit Durchlass aufgeschüttet und der darüber entstehende Raum vertieft werden. Das Potenzial von Rückhaltebecken wird in - Abschn. 6.4 ausführlicher und quantitativ beschrieben.

\subsubsection{Vergleich aktueller und historischer Flurgliederungen}

Um den Effekt unterschiedlicher Flurgliederungen auf die Abflusskonzentration in einem realen Landschaftsausschnitt $\mathrm{zu}$ quantifizieren, wurde die aktuelle Flächenparzellierung eines kleinen Untersuchungsgebietes einem historischen Zustand vor der Flurbereinigung gegenübergestellt (etwa um 1960). Dort erfolgte in den 1960er- und 1970er-Jahren eine Flurneuordnung. Heute beträgt die Zahl der Ackerflächen im dargestellten Ausschnitt nur noch 61 statt ursprünglich 237, und die durchschnittliche Ackerschlaggröße hat von 0,6 auf 2,4 ha zugenommen (• Abb. 6.17).

Für ein Teileinzugsgebiet (rote Linie in - Abb.6.17) wurden die oberflächlichen Fließwege für beide Zeitpunkte bestimmt. Dazu wurden entlang der Wasserscheide 16 Punkte im Abstand von etwa $100 \mathrm{~m}$ definiert, von denen ausgehend die Fließpfade bis zum Gebietsauslass ermittelt wurden. Für die aktuelle Situation wurden die Fließpfade innerhalb der ackerbaulichen Nutzfläche durch Auswertung eines digitalen Geländemodells (Rasterweite $5 \mathrm{~m}$ ) mithilfe eines Fließpfadalgorithmus bestimmt. Der Verlauf der Fließpfade von der Schlaggrenze zum Gebietsauslass wurde im Gelände validiert und teilweise angepasst, da wesentliche, den Abfluss lenkende Strukturen wie Wegseitengräben bei dieser Auflösung nicht automatisch erkannt wurden. Für jeden Fließpfad wurden Länge und Gefälle bestimmt. Zusätzlich wurde der Streckenanteil jedes Fließweges auf Ackerflächen, im Grünland bzw. in Gräben und Rohren ermittelt. Außerdem wurden die Ranken gezählt, die jeder Fließpfad zwischen Wasserscheide und Tiefenlinie kreuzt. Für den historischen Zustand wurden der gleiche Gebietsauslass und die gleichen Punkte an der Wasserscheide wie für den aktuellen Zustand verwendet. Bei der Bestimmung des Fließpfadverlaufes wurden jedoch zusätzlich zur Topographie die damals vorhandenen Feldgrenzen berücksichtigt, die aus historischen Flurkarten rekonstruiert wurden. Es wurde davon ausgegangen, dass eine Feldgrenze damals als wasserableitende Barriere fungierte. Für den aktuellen Zustand wurde von dieser Annahme abgewichen, da Ranken heute aufgrund der größeren Schläge, der damit verbunden höheren Bündelungswirkung des Abflusses und in Folge durch den höheren Zustrom bei Starkregen meist überströmt werden. Dies ist auch durch Luftbildaufnahmen von Starkregenereignissen bekannt [56]. 

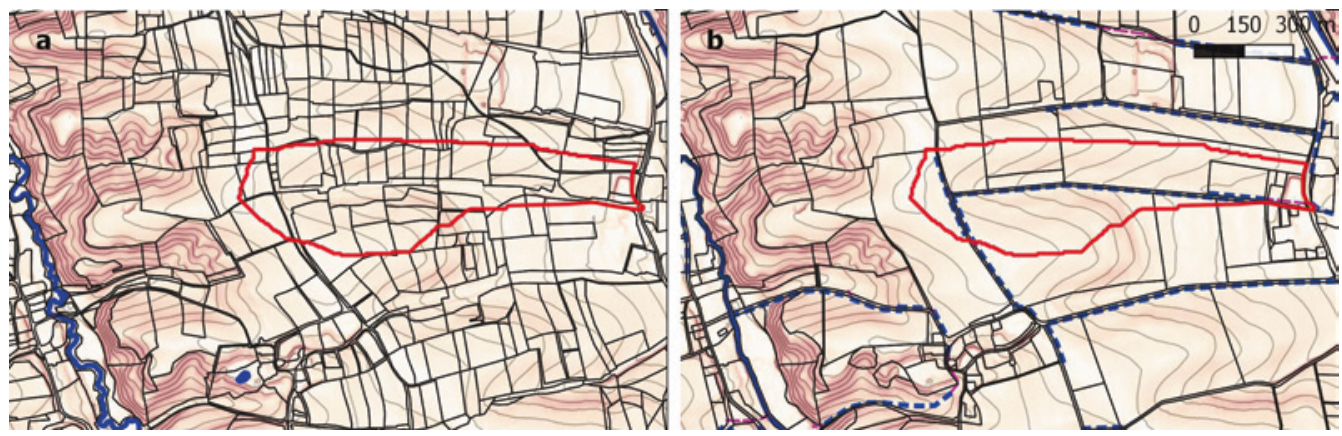

- Abb. 6.17 Flächenparzellierung um 1960 vor der Flurbereinigung (a) und heute (b) in einem 258 ha großen Landschaftsausschnitt nördlich von Freising bei Zolling. Die Linien kennzeichnen Flurstücksgrenzen (schwarz), Höhenlinien (grau), Wegseitengräben (blau gestrichelt), Rohre (magenta gestrichelt), Gewässer (blau) sowie die Wasserscheide (rot) eines 28 ha großen Teileinzugsgebietes. (Geobasisdaten: Bayerische Vermessungsverwaltung)

Um 1960 entwässerte das komplette Gebiet über Grünland entlang der Tiefenlinie, mit Ausnahme einer kleinen Teilfläche auf der Hangkuppe nahe der Wasserscheide im Westen des Gebietes (• Abb. 6.18, links). Die Erschließung der Flur erfolgte damals über Wege auf der Hangkuppe. Durch die Ranken änderten viele Fließpfade stufenartig ihre Richtung. Im Zuge der Flurbereinigung (• Abb.6.18, rechts) wurden die Schläge vergrößert und Straßen und Gräben in die Tiefenlinie verlegt, wodurch die topographisch bedingten Fließpfade vielfach unterbrochen und verändert wurden. Oberflächenabfluss aus dem Teil südlich der mittig in Ost-West Richtung verlaufenden Straße erreicht die Tiefenlinie heute beispielsweise nicht mehr; er wird über einen Wegseitengraben südlich der Straße zum Gebietsauslass hin abgeleitet. Gleiches gilt für den Bereich ganz im Westen, der durch die Straße abgeschnitten ist. Dieser Teil wurde über einen Graben und eine Rohrleitung an den zuvor erwähnten Wegseitengraben angeschlossen. Durch diese Maßnahmen veränderten sich die Entwässerungswege von knapp 2/3 der Einzugsgebietsfläche. Nur Oberflächenabfluss aus dem nördlichen Teil entwässert auch heute noch über die Tiefenlinie bis zum Beginn der Ortschaft.
Im Gegensatz $\mathrm{zu}$ früher wird dort heute allerdings der komplette Abfluss über zwei Rohre (DN 600) gefasst und unter der neu entstandenen Siedlungsfläche hindurch auf die andere Seite der Straße geleitet, wo sich der Gebietsauslass befindet.

Der quantitative Vergleich der beiden Zustände zeigt folgende Entwicklungen: Die Fließpfade in den Ackerflächen verlaufen heute direkter als beim historischen Zustand, aber im Grunde nicht wesentlich anders als früher. Mittlere Länge und mittleres Gefälle blieben quasi unverändert. Dagegen nahm der im Grünland verlaufende Fließpfadanteil um rund $70 \%$ ab (84 vs. $15 \%)$. Gleichzeitig verlaufen heute $58 \%$ der betrachteten Fließpfadstrecke in Wegseitengräben oder Rohren. Auf dem Verlauf zwischen Wasserscheide und Tiefenlinie kreuzte jeder Fließpfad früher im Mittel einen Ranken. Heute sind derartige Hindernisse seltene Ausnahmen (•Tab.6.7). Eine Auswertung der Fließzeit von der Wasserscheide ganz im Westen bis zum Gebietsauslass im Osten (längster Fließpfad) mithilfe der Geschwindigkeitsmethode ergab eine mittlere Verkürzung der Fließzeit von 50 auf $35 \mathrm{~min}$ (Reduktion um $30 \%$ ).

Die Entwicklung hin zu größeren und einheitlicher gestalteten Nutzflächen fand und findet in zahlreichen Naturräumen, 

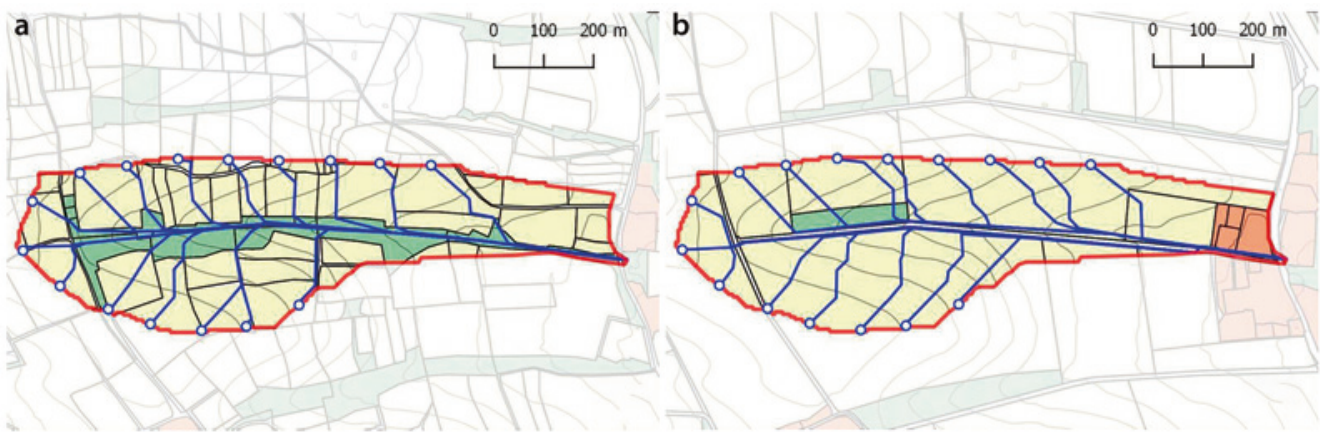

- Abb. 6.18 Fließpfade (blaue Linien) zwischen Wasserscheide (rote Linie) und Gebietsauslass um 1960 (a) und heute (b). Die Landnutzung wurde entsprechend der aktuellen bzw. der in der historischen Karte ausgewiesen Nutzung in Acker (gelb), Grünland (grün) und Siedlungsfläche (orange) unterschieden. Der Verlauf der Fließpfade in den Acker- und Grünlandflächen wurde mit einem Fließpfadalgorithmus aus einem Geländemodell (Rasterweite $5 \mathrm{~m}$ ) extrahiert und durch Kartierungen im Feld angepasst bzw. validiert. Beim historischen Zustand wurden Feldgrenzen innerhalb der Ackerflächen als Abflussbarriere interpretiert. (Geobasisdaten: Bayerische Vermessungsverwaltung)

\begin{tabular}{|c|c|c|c|c|c|}
\hline Zeitraum & $\begin{array}{l}\text { Mittlere } \\
\text { Fließpfadlänge } \\
\text { (m) }\end{array}$ & $\begin{array}{l}\text { Mittlere } \\
\text { Fließpfad- } \\
\text { neigung (\%) }\end{array}$ & $\begin{array}{l}\text { Im Grünland } \\
\text { verlaufender } \\
\text { Anteil (\%) }\end{array}$ & $\begin{array}{l}\text { Fließstrecke } \\
\text { in Gräben und } \\
\text { Rohren (\%) }\end{array}$ & $\begin{array}{l}\text { Kreuzende } \\
\text { Ranken und } \\
\text { Raine }\end{array}$ \\
\hline Um 1960 & 960 & 3,8 & 84 & 0 & 1,1 \\
\hline Heute & 945 & 3,9 & 15 & 58 & 0,3 \\
\hline
\end{tabular}

national wie international statt $[57,58]$. Die Konsequenzen werden bisher vornehmlich unter ökologischen, kulturellen und ästhetischen Gesichtspunkten diskutiert. Wie stark der Einfluss des Strukturverlustes der folgenden Nutzungsänderung und der Anlage künstlicher Entwässerungswege auf Abflussbeschleunigung und Veränderung des Landschaftswasserhaushaltes ist, wurde nur sehr selten quantifiziert. Eine Ausnahme ist aus Nordfrankreich bekannt: Für die dort typischen Wallheckenlandschaften wurde ermittelt, dass in strukturverarmten und vereinheitlichten Landschaften 1,5 bis 2-fach höhere Scheitelabflussraten auftreten als an Standorten mit hoher Dichte linearer und gliedernder Landschaftselemente [59].

\subsubsection{Flurneuordnung unter Berücksichtigung abflussverzögernder Strukturen und Maßnahmen}

Um zu untersuchen, wie abflussverzögernde Strukturen bei Flurneuordnungsverfahren berücksichtigt werden können, wurde in einem knapp 50 ha großen Gebiet im Tertiärhügelland bei Manholding (- Abb. 6.19) eine virtuelle Flurneuordnung durchgeführt und mit einem bestehenden Neuordnungsentwurf ohne explizite Berücksichtigung entsprechender Strukturen und Maßnahmen verglichen [60]. Letztere wird im Folgenden als „konventionelle Planung" bezeichnet. 


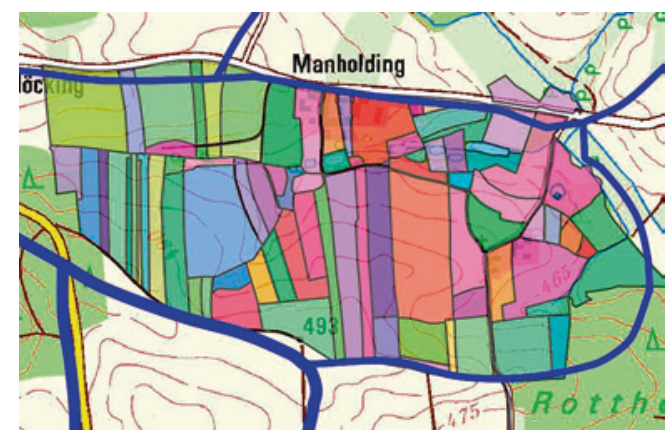

- Abb. 6.19 Flurstücke im Beispielgebiet Manholding vor Durchführung der Flurneuordnung.

(Quelle: BBV-LS in [60])

Die virtuelle Flurneuordnung berücksichtigte dabei etablierte und standardisierte Verfahrensweisen [61]: Die Einlagefläche wurde analysiert und durch Überlagerung mit den Bodenwertzahlen wurden die Wertverhältnissummen aller Eigentümer ermittelt. Zusätzlich zum üblichen Vorgehen wurden im Vorfeld wichtige hydrologische Prozesse und Fließwege im Gelände erfasst (vgl. Abschn. 5.3 und Anhang 8.8). Darauf aufbauend wurden Maßnahmen zum Wasser- und Stoffrückhalt abgeleitet. Bei der Neuverteilung wurden zunächst die Flächen für die gemeinschaftlichen und öffentlichen Anlagen festgelegt. Dies berücksichtigte Wege und alle Flächen für abflussverzögernde Maßnahmen. In den verbleibenden Gewannen wurden dann die Flurstücke der Einlieger platziert, indem die aus den Wertverhältnissummen resultierenden Ansprüche mit möglichst wenig Flurstücken abgegolten wurden (der Gebietsabzug wurde prozentual zur Einlagewertverhältniszahl berücksichtigt). Alle üblichen Aspekte wie bestehende Flurzwänge, die Entfernung der Flächen von der Hofstelle oder dass Eigentümer mit wenig Fläche (nur ein Abfindungsflurstück) gut zugeschnittene Flächen erhalten, gingen in die Neuverteilung ein. Für den neuen, virtuellen Planungsentwurf und die konzeptionelle Planung wurden die Fließzeiten von der

Wasserscheide bis zum Gebietsauslass nach der Geschwindigkeitsmethode abgeschätzt und übliche Kenngrößen wie Flurstücksgröße und Zusammenlegungsverhältnis erhoben und gegenübergestellt.

Im Detail wurden im virtuellen Planungsentwurf unterschiedliche Maßnahmen zur Förderung des Wasser- und Stoffrückhalts berücksichtigt (• Abb.6.20 links): Beispielsweise wurde der von Manholding nach Süden führende Erschließungsweg von der Senke (konventionelle Planung) auf einen Höhenrücken gelegt. Dies sollte den Einfluss der Verkehrsfläche auf die Gebietsentwässerung minimieren. Weitere strukturelle Maßnahmen umfassten die Anlage einer begrünten Abflussmulde unmittelbar westlich der Straße in der südlichen Tiefenlinie des Gebietes, die Umwandlung von drei Fischweihern in kleine Rückhaltebecken sowie die Anlage von zwei Terrassenstufen. Zur Förderung der hangparallelen Bewirtschaftung wurden auf den südlichen Teilflächen ausschließlich längliche Flurstücksformen ausgewiesen. Lediglich im Bereich der begrünten Abflussmulde resultierten einige wenige, geometrisch ungünstig geformte Flurstücke. Auch die Entstehung von Ackerrandfurchen in Gefällerichtung ließ sich bei diesem Planungsentwurf nicht vollständig verhindern. Im Wesentlichen sind die Flächen des resultierenden Entwurfes jedoch nicht ungünstiger geschnitten oder verortet als die der konventionellen Entwurfsplanung (- Abb.6.20, rechts). Die mittlere Flurstückfläche ist in der abflussverzögernden Variante sogar größer und die Zahl der Flurstücke geringer als bei der konventionellen Planung. Da die resultierenden Schlaglängen zwischen 400 und $550 \mathrm{~m}$ liegen, ist davon auszugehen, dass die Flächenzuschnitte der abflussverzögernden Planung auch unter arbeits- und betriebswirtschaftlichen Gesichtspunkten mit der konventionellen Planung konkurrieren können (betriebswirtschaftlich werden die größten Einsparungspotenziale bei Schlaglängen bis $\mathrm{zu}$ von $400 \mathrm{~m}$ und Schlaggrößen von 5 ha erreicht [62]). 

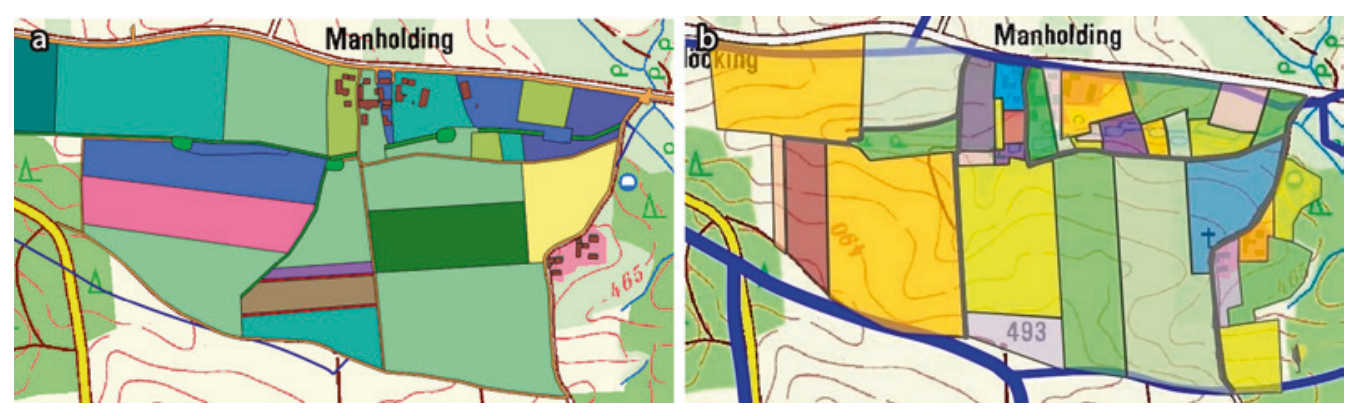

- Abb. 6.20 Entwurfsplanungen zur Flächenparzellierungen eines Landschaftsausschnitts im Tertiärhügelland. Die Farben markieren die verschiedenen Besitzverhältnisse. Die linke Variante (a) berücksichtigt Aspekte und Maßnahmen zum Wasser- und Stoffrückhalt. Die rechte (b) zeigt die konventionelle Planung, ohne explizite Berücksichtigung dieser Aspekte. Im virtuellen Entwurf berücksichtigte Maßnahmen zum Wasserrückhalt sind die hangparallele Ausrichtung der Felder, drei Rückhaltebecken (grüne Ovale), eine begrünte Abflussmulde (dunkelgrüner, mittig von unten zum mittleren Rückhaltebecken verlaufender Linienzug), aufgeweitete Entwässerungsgräben (kurze, dunkelgrüne Linienzüge im Talweg) sowie zwei Terrassenstufen im Süden des Gebietes (dunkelrote Linien). Die blauen Linien in der rechten Tafel zeigen den Verlauf der Wasserscheide. (Verändert nach [60])

\begin{tabular}{|c|c|c|c|c|c|c|}
\hline \multicolumn{7}{|l|}{ - Tab. 6.8} \\
\hline & Flurstücke & $\begin{array}{l}\text { Mittlere } \\
\text { Größe }\end{array}$ & $\begin{array}{l}\text { Verkehrs- } \\
\text { fläche }\end{array}$ & $\begin{array}{l}\text { Fläche für } \\
\text { abfluss- } \\
\text { verzögernde } \\
\text { Maßnahmen }\end{array}$ & $\begin{array}{l}\text { Gebiets- } \\
\text { abzug }\end{array}$ & $\begin{array}{l}\text { Flächen- } \\
\text { zuschnitt }\end{array}$ \\
\hline & - & ha & $\mathrm{m}^{2}$ & ha & $\%$ & - \\
\hline Ausgangszustand & 65 & 0,7 & 1918 & 0 & - & - \\
\hline $\begin{array}{l}\text { Konventionelle } \\
\text { Planung }\end{array}$ & 25 & 1,8 & 8634 & 0 & 1,5 & + \\
\hline $\begin{array}{l}\text { Abflussverzögernde } \\
\text { Planung }\end{array}$ & 22 & 2,0 & 5640 & 1,5 & 4,0 & 0 \\
\hline
\end{tabular}

Die mittlere Fließzeit nahm dagegen gegenüber der konventionellen Planung bei etwa 10-jährlichen Starkregenereignissen um rund $80 \% \mathrm{zu}$. Bei extremen, >100-jährlichen Ereignissen betrug die Zunahme immer noch etwa $66 \%$ (•Tab. 6.8). Der „Preis“ der Maßnahmen zum Wasser- und Stoffrückhalt ist ein gegenüber der konventionellen Planung um 2,5\% erhöhter Flächenbedarf, der sich im Gebietsabzug entsprechend widerspiegelt.

Die Fallstudie zeigt, dass durch wenige zusätzliche Flurelemente ein erheblicher Beitrag zum Wasser- und Stoffrückhalt geleistet werden kann. Trotz zusätzlicher Randbedingungen konnten identische Flurstückzahlen, -größen und Zusammenlegungsverhältnisse erzielt werden wie bei einer konventionellen Planung. Davon ausgenommen war lediglich ein einziges, an die begrünte Mulde grenzendes Flurstück. Der Flurneuordnung kommt daher eine fundamentale Bedeutung im Hinblick auf die langfristige Etablierung hochwassermindernder Abflussnetze in der Landschaft zu. Ähnliche Fallstudien [z. B. 63, 64] sind jedoch rar und oft nur spärlich in der grauen Literatur dokumentiert und somit kaum auffindbar. 


\subsection{Abflussgeschwindigkeit in Gräben und Rohren}

Gräben zur Wasserführung, Wegeentwässerung oder Drainage beschleunigen normalerweise den Abfluss und verschärfen damit die Gebietsentwässerung. Fallbeispiele dazu sind unter anderem aus einem 900 ha großen Einzugsgebiet in Frankreich bekannt, wo der Scheitelabfluss durch ein Grabensystem um bis $\mathrm{zu} 40 \%$ zugenommen hat [65]. Noch stärker beschleunigend wirken hydraulisch glatte Rohre. Prinzipiell haben Gräben jedoch auch das Potenzial zum Bremsen, vor allem, wenn dadurch der Fließweg länger und die Sohlneigung geringer wird, wie zum Beispiel bei einer Terrassierung des Geländes. Gräben sind daher, trotz ihres geringen Flächenanteils, oft von hoher Bedeutung für den Wasserhaushalt und die Entwässerung einer Landschaft [66].

Wirkung verschiedener Gerinnetypen Die Abflussgeschwindigkeit verschiedener Gerinnetypen für typische, in Einzugsgebieten $<100$ ha auftretende Bedingungen illustrieren Vergleichsrechnungen mit der GMS-Gleichung ( $\triangleright$ GI. 5.5). In allen Fällen wurden einheitliche Bedingungen (Fließweglänge $=2000 \mathrm{~m}$, Gefälle $=1,5 \%$, Abflussrate $=1 \mathrm{~m}^{3} \mathrm{~s}^{-1}$ ) angenommen. Nur Gerinneform, -querschnitt und -rauheit wurden verändert (• Tab. 6.9). Die Auswertung zeigt, dass eine moderate Grabenaufweitung in Kombination mit einer Verkrautung den Abfluss gegenüber einem geräumten Graben um $30 \%$ verzögert. Eine flache, verkrautete Mulde verzögert um $62 \%$, während eine Verrohrung den Abfluss um 40 \% beschleunigt. Diese Ergebnisse gelten nur für den stationären Fall (d. h. der Abfluss fließt lange Zeit mir gleicher Rate), da Benetzungs- und Retentionseffekte nicht berücksichtigt wurden. Die tatsächliche Wirkung von Aufweitung und dem Tolerieren von Bewuchs auf die Abflussverzögerung ist sogar noch größer, da raue und breite Gräben mehr Wasser zurückhalten können. Dieser Effekt gilt insbesondere für kurze, schauerartige Starkregen, deren Dauer unter $1 \mathrm{~h}$ und damit in der Größenordnung der typischen Konzentrationszeit kleiner Einzugsgebiete liegt. Der Effekt wird durch trockene Vorbedingungen noch verstärkt. Dadurch lassen eine Grabenaufweitung und das Tolerieren von Bewuchs einen besonders hohen Effekt auf die Abflussminderung bei kurzen, schauerartigen Starkregen in kleinen Einzugsgebieten erwarten.

Der Vergleich verschiedener Gerinnetypen legt nahe, dass sich die Fließgeschwindigkeiten auf etwa der Hälfte aller Fließpfade in der landwirtschaftlichen Flur um rund $60 \%$ beschleunigt haben, weil die Entwässerung, die früher weitgehend über Grünlandzüge in Hangmulden (breite, begrünte Mulde) erfolgte, heute durch geräumte und dadurch effektive Wegseitengräben mit Regelprofil ersetzt wurde (vgl. auch Abschn.6.5.2 und - Kap. 7). Bei Wegseitengräben in steilem Gelände, insbesondere für hangseitige Gräben bei Forststraßen kommt noch ein weiterer Effekt hinzu: Dadurch, dass sich Gräben hier tief ins Bodenprofil einschneiden, erschließen sie auch den Bereich, in dem Zwischenabfluss fließt, und machen aus ihm Oberflächenabfluss [67]. Der Effekt ist in - Abb. 8.17 illustriert und vor allem für Wälder auf steilen Standorten relevant. Die abflussdämpfende Wirkung beruht dort weniger auf hohen Versickerungsraten, sondern darauf, dass ein Großteil des nicht tief versickernden Wassers als Zwischenabfluss auf einem der im Wald zahlreichen Bodenhorizonte abgeleitet wird. Dieser Zwischenabfluss fließt immer langsamer als Oberflächenabfluss und führt zu der bekannten langen Verzögerung des Abflusses 


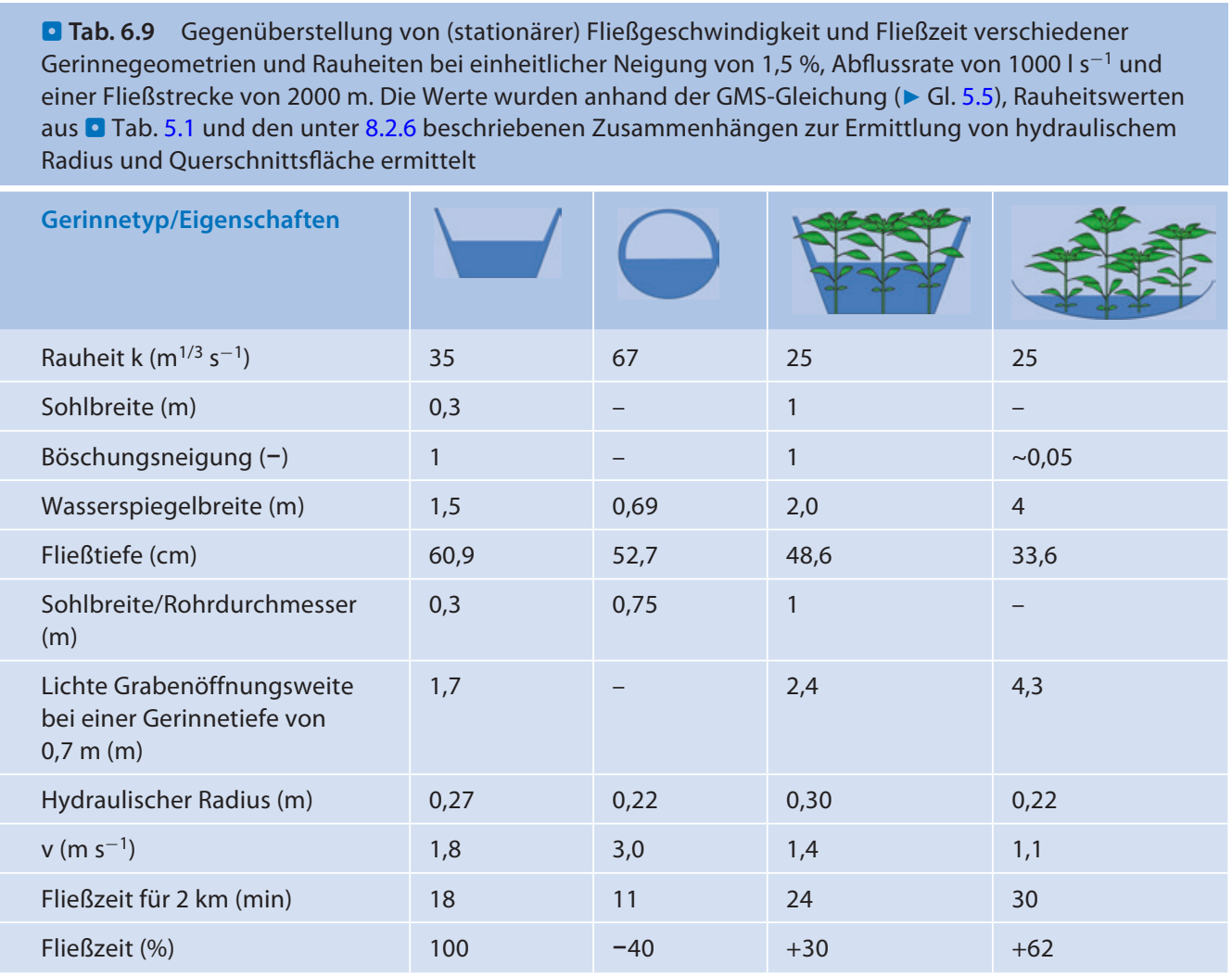

im Wald. Durch Wegseitengräben im steilen Gelände besteht das Risiko, diesen Zwischenabfluss aufzufangen und rasch abzuleiten. (Steile) Wälder können dann ähnlich schnell liefern wie landwirtschaftliche Flächen.

Ist ein Graben erforderlich, sollte dieser aus hydrologischer Perspektive grundsätzlich breit und flach sowie hydraulisch rau angelegt werden. Konkret wird eine Sohlbreite von wenigstens $1 \mathrm{~m}$ und eine Böschungsneigung von 1:1,5 empfohlen (• Abb. 6.21). (Zum Vergleich: In der Richtlinie für die Anlage und Dimensionierung Ländlicher Wege [62] wird eine Sohlbreite von 0,3 m empfohlen.) Wenn Gräben größere Einzugsgebiete entwässern (>20 ha), sollte die Sohle bis auf 1,5 m verbreitert werden, da andernfalls bei Starkregen ein Überlaufen zu erwarten ist. Rauheit ist am einfachsten durch das Tolerieren von Bewuchs erreichbar. Entsprechend sollte ein Unterhalt von Wegseitengräben ausschließlich bei
Bedarf, z. B. bei größerem Gehölzaufwuchs oder der Gefahr von Verklausungen und keinesfalls vorsorglich erfolgen. Ist im Rahmen des Unterhalts, zum Beispiel zum Erreichen der erforderlichen Grabentiefe, ein schälendes Werkzeug wie eine Humusschaufel erforderlich, sollten zu Beginn der Arbeiten Grassoden abgetragen und nach der Räumung, zumindest abschnittsweise, wieder auf die glatte Oberfläche aufgebracht werden. Dies fördert einen schnelleren Aufwuchs und reduziert das Erosionsrisiko. Eine entsprechende Verbreiterung der Sohle mindert darüber hinaus nicht nur die Abflussgeschwindigkeit bei Starkregen, sondern fördert auch den Wasserrückhalt bei kleinen und mittleren Niederschlägen.

Diese Empfehlungen beruhen auf hydraulischen Vergleichsrechnungen, bei denen der Effekt von Aufweitung und Bewuchs auf die Fließgeschwindigkeit in einem Wegseitengraben für verschiedene Grabenquer- 


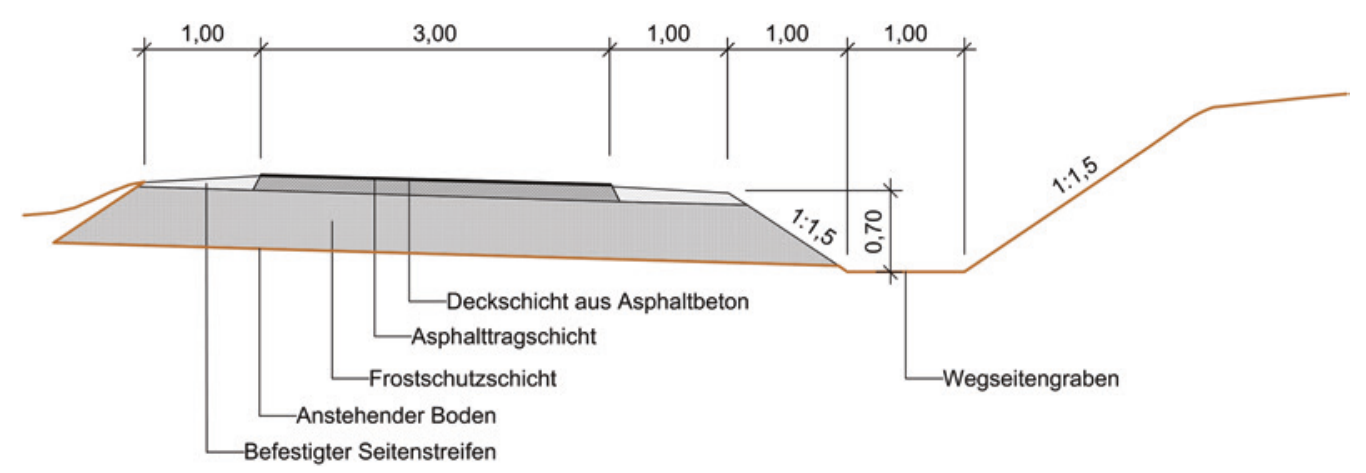

- Abb. 6.21 Regelquerschnitt eines Wegs mit Wegseitengraben mit einer auf $1 \mathrm{~m}$ verbreiterten Sohle. (Quelle: Ingenieurbüro Lenz)

schnitte und Rauheiten bei identischen Abflüssen verglichen wurde. Als Referenz dient ein typischer geräumter Graben mit einer Sohlbreite von $0,3 \mathrm{~m}$, einer Böschungsneigung von 1:1,5 (Höhe:Breite) und einer Tiefe von $0,7 \mathrm{~m}$, wie er von der Richtlinie für die Anlage und Dimensionierung Ländlicher Wege (RLW) empfohlen wird [69]. Ausgehend davon reduziert sich bei einer Verdoppelung der Öffnungsweite von 2,4 auf 4,8 m (z. B. durch eine Sohlbreite von $2,8 \mathrm{~m}$ und gleicher Böschungsneigung) die Fließgeschwindigkeit (und damit der Scheitelabfluss) um knapp $20 \%$. Ob die Öffnungsweite durch eine flachere Böschung oder durch eine breitere Sohle verbreitert wird, ist weitgehend irrelevant. Der hydraulische Radius reduziert sich in beiden Fällen von etwa 0,26 (typische Verhältnisse) auf $0,19 \mathrm{~m}$ (sehr breiter Graben). Wird die Grabensohle von $0,3 \mathrm{~m}$ auf $1 \mathrm{~m}$ verbreitert, ergibt sich bei gleicher Tiefe und Böschungsneigung eine Öffnungsweite von 3,1 m. Dadurch steigt der Platzbedarf des Grabens um knapp $20 \%$, die Fließgeschwindigkeit vermindert sich allerdings nur geringfügig im niedrigen einstelligen Prozentbereich (• Abb.6.22, "geräumter Graben"). Dennoch kann mit einer solchen Verbreiterung der Abfluss gebremst werden, wenn parallel dazu die Rauheit (stark) erhöht wird, wozu bei einer $1 \mathrm{~m}$ breiten Sohle bereits genug Platz vorhanden wäre. Werden typische Rauheitsbeiwerte für stark verkrautete
Bäche und Fließgewässer angesetzt, ist eine Verzögerung des Abflusses von etwa 20\% $\mathrm{zu}$ erwarten. Werden Rauheitsbeiwerte sehr rauer Standorte (z. B. Sukzessionsflächen oder Hochstaudenfluren) angesetzt, sind sogar Verzögerungen von 35-40 \% möglich (• Abb. 6.22, „bewachsen“ und „dicht bewachsen“). Die zusätzliche Verstärkung des Effekts durch eine Zunahme der Retention ist dabei noch nicht

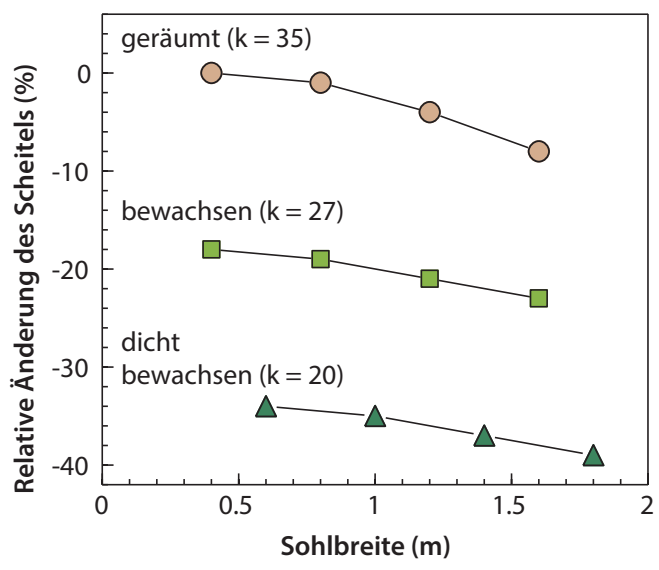

- Abb. 6.22 Relative Reduktion des Abflussscheitels durch einen Graben bei unterschiedlicher Sohlbreite und Rauheit für eine einheitliche Abflussrate von $800 \mathrm{I} \mathrm{s}^{-1}$. In allen Fällen wurden trapezförmige Abflussquerschnitte (Böschungsneigung 1:1,5) und eine Grabentiefe von 0,7 $\mathrm{m}$ angenommen. Die Grabengesamtbreite nimmt von links nach rechts von etwa 2,5 auf $4 \mathrm{~m}$ zu 
berücksichtigt. Ein dichter Bewuchs ist daher essenziell, da für eine (deutliche) Aufweitung von Gräben nur in den seltensten Fällen Flächen verfügbar sind. Gleichzeitig lässt sich ein dichter Bewuchs bei breiten Gräben leichter etablieren und managen, sodass beide Einflüsse Hand in Hand gehen. Bei ausreichender Flächenverfügbarkeit sollte eine Aufweitung des Grabens $>5$ m, ggf. auch in Kombination mit unterschiedlichen Böschungsneigungen erwogen werden.

Um die Bedeutung von Wegseitengräben für die Entwässerung eines Gebietes zu beurteilen, werden Verlauf und Eigenschaften des Grabennetzwerks und die Einzugsgebiete der Gräben benötigt. Für hydraulische Berechnungen sind zusätzlich Querschnittsgeometrie, Gefälle und Rauheit wichtig. Gräben können teilweise auch digital aus dem Verlauf ländlicher Wege und hochauflösender Geländemodelle abgeleitet werden [70]. Es ist zusätzlich jedoch fast immer eine Geländebegehung notwendig, da hochaufgelöste Daten meist durch Artefakte behaftet sind, z. B. durch Abschattungen oder Verrohrungen, und da Informationen über Querprofile gegenwärtig grundsätzlich nur im Gelände ermittelt werden können.

Fehlen Querschnitts- und Profildaten, gibt die Richtlinie zur Anlage und Dimensionierung ländlicher Wege (RLW) [62] Hinweise auf typische Größen. Die Gestalt von Gräben weicht in der Praxis allerdings häufig stark von den Empfehlungen der Richtlinie ab. Letztere gibt vor, dass zur Entwässerung ländlicher Verbindungs- und Hauptwirtschaftswege, unabhängig vom Einzugsgebiet, ein Wegseitengraben anzulegen ist. Übliche Dimensionierungsvorgaben der trapezförmigen Regelprofile sind: Sohlbreite $30 \mathrm{~cm}$, Böschungsneigung Höhe:Breite $\leq 1: 1,5$, Tiefe $60-70 \mathrm{~cm}$ je nach Hangneigung und Stärke von Planum und Wegekörper. Zusätzlich gibt die RLW vor, dass Wegseitengräben zu begrünen sind, um sie vor Erosion zu schützen. Mulden werden nur in Ausnahmefällen konstruiert. Typische Abflussraten trapezförmiger Gräben mit Regelprofil betragen bei flachem Terrain
(Gefälle $1 \%$ ) etwa $0.8 \mathrm{~m}^{3} \mathrm{~s}^{-1}$. Bei steilem (Gefälle $5 \%$ ) erhöht sich die maximale Abflussrate auf etwa $1,6 \mathrm{~m}^{3} \mathrm{~s}^{-1}$, bevor es $\mathrm{zu}$ einem Überlaufen kommt.

\section{- Praxisbeispiel}

Abflussverzögernde Maßnahmen an Gräben können sehr vielfältig umgesetzt werden, wobei die angrenzende Topographie und Flächenverfügbarkeit meist die wesentlichen Randbedingungen vorgeben. Die Wirkung von Gräben auf die Abflussgeschwindigkeit wird hier an einem Praxisbeispiel illustriert. Ein weiteres, ausführliches Rechenbeispiel zum Einfluss von Gräben auf die Gebietsentwässerung in der Gemeinde Birnbach gibt - Kap. 7.

Hier wird eine kleine, bereits umgesetzte Maßnahme aus einem boden:ständig-Projekt in der Gemeinde Teugn im Landkreis Kehlheim in Bayern skizziert. Anlass waren wiederkehrende Abfluss- und Erosionsprobleme, da Siedlungsflächen in wassersensible Bereiche wie Unterhänge und Talauen expandiert hatten, das oberhalb liegende Einzugsgebiet (Hangneigungen 5-15\%) zu ca. $70 \%$ ackerbaulich genutzt wird (Maisanteil ca. $30 \%$ ) und ein zentraler Entwässerungsweg der Fläche durch die südöstlichen Ortsrandlagen führte. Die im Folgenden dargestellte Grabenaufweitung ist nur eine von mehreren Maßnahmen zur Abflussminderung im Gebiet.

Der bestehende Graben hatte eine durchschnittliche Breite $4 \mathrm{~m}$, ein Gefälle von $5 \%$ und eine Länge von rund $500 \mathrm{~m}$. Er lag unmittelbar oberhalb der Ortschaft und war Bestandteil des Fließpfades, über den die Fläche entwässerte (•Abb.6.23, links). Eine Berechnung mit der GMS-Gleichung (Rauheitsbeiwert $=30 \mathrm{~m}^{1 / 3} \mathrm{~s}^{-1}$ ) ergab, dass bei einem Gebietsniederschlag von $75 \mathrm{~mm}$ im bestehenden Graben mit einer (enormen) Fließgeschwindigkeit von $3,3 \mathrm{~m} \mathrm{~s}^{-1}$ zu rechnen ist. Dividiert man die $500 \mathrm{~m}$ Grabenstrecke durch die Fließgeschwindigkeit, ergibt sich eine Fließzeit von nur 2,5 min. 

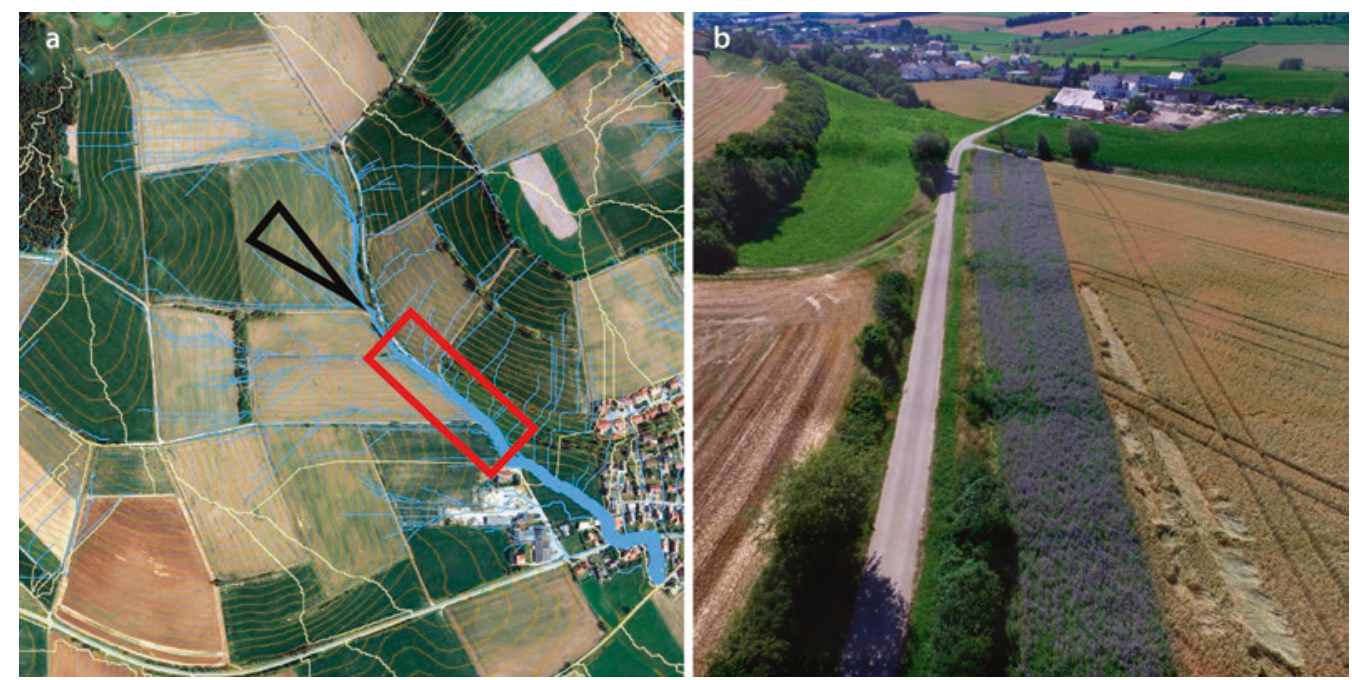

- Abb. 6.23 Dargestellt sind die Fließpfade des Oberflächenabflusses in einem Teileinzugsgebiet der Gemeinde Teugn (a). Die Pfade wurden aus einem hochauflösenden Geländemodell (Rasterweite $1 \mathrm{~m}$ ) mit einem Fließpfadalgorithmus extrahiert. Die Breite der Linie ist relativ zu ihrer Einzugsgebietsgröße skaliert. Die rote Box markiert die Lage der Grabenaufweitung. Das Schrägluftbild (b) zeigt die umgesetzte Maßnahme mit Blick auf die Ortschaft; es wurde von einer Drohne von der Stelle aus aufgenommen, die im Bild links mit dem schwarzen Dreieck markiert ist. (Quelle: [71])

Zur Geschwindigkeitsminderung wurde die Sohle des bestehenden Grabens um $2 \mathrm{~m}$ verbreitert und durch Tolerieren von Bewuchs eine raue Oberfläche geschaffen. Zusätzlich konnte im unteren Drittel des Grabens ein $150 \mathrm{~m}$ langer, $20 \mathrm{~m}$ breiter Ackerrandstreifen als Ausuferungsmöglichkeit angelegt werden. Um die Ausuferung zu fördern, wurden innerhalb des Ackerrandstreifens flache (bewirtschaftbare) Querdämme modelliert (• Abb.6.23, rechts). Während der Ackerrandstreifen Privateigentum blieb, wurde für die Grabenverbreiterung Grund erworben. Durch die erhöhte Rauheit (Annahme: $\mathrm{k}=25 \mathrm{~m}^{1 / 3} \mathrm{~s}^{-1}$ ) und den breiteren Fließquerschnitt reduzierte sich die Fließgeschwindigkeit im Graben rechnerisch auf etwa 2,6 $\mathrm{m} \mathrm{s}^{-1}$, wodurch die Fließzeit im Graben um rund $30 \%$ auf 3,2 min steigt. Da der Grabenabschnitt - ausgehend von der Wasserscheide - nur einen kleinen Teil des gesamten Fließwegs einnimmt, ist die
Wirkung auf die Gesamtfließzeit und damit auch auf die Reduktion des Abflussscheitels gering, aber in Kombination mit weiteren abflussmindernden Maßnahmen (nicht dargestellt) wurde für das betrachtete Teileinzugsgebiet von einer Scheitelreduktion von $20 \%$ ausgegangen [71].

\subsection{Wege- und Wasserführung}

Wege sind Bestandteil der technischen Infrastruktur mit grundlegender Funktion für den ländlichen Raum. Sie prägen die Kulturlandschaft und lassen sich nicht vermeiden. Verlauf und konstruktive Gestaltung des Wegenetzes sowie die Anlage und Ausführung von Wegseitengräben beeinflussen den Landschaftswasserhaushalt oft tiefgreifend und - durch ihre hohe Lebensdauer - über sehr lange Zeiträume. Die Konzeption und Anlage ländlicher Wege ist daher nicht nur eine bedeutsame Aufgabe der ländlichen 
Entwicklung, die rund drei Viertel aller ländlichen Wege, oft in Zusammenhang mit Flurneuordnungen anlegt [64], sie beeinflusst auch dauerhaft den Wasser- und Stoffhaushalt der Landschaft. Die Einflüsse des Wegebaus auf den Wasserhaushalt erfordern daher ein besonderes Augenmerk. Wesentliche Einflussgrößen sind die konstruktive Bauausführung von Wegen und Wegseitengräben und die Trassenwahl. Die Bauausführung beeinflusst vor allem, wie viel Abfluss auf befestigten Flächen entsteht, der Wegverlauf prägt die Ableitung von Wasser durch die Landschaft. Das gilt insbesondere für Gebiete mit hoher Dichte an Wegen und Wegseitengräben und für Oberflächenabfluss bei Starkregen.
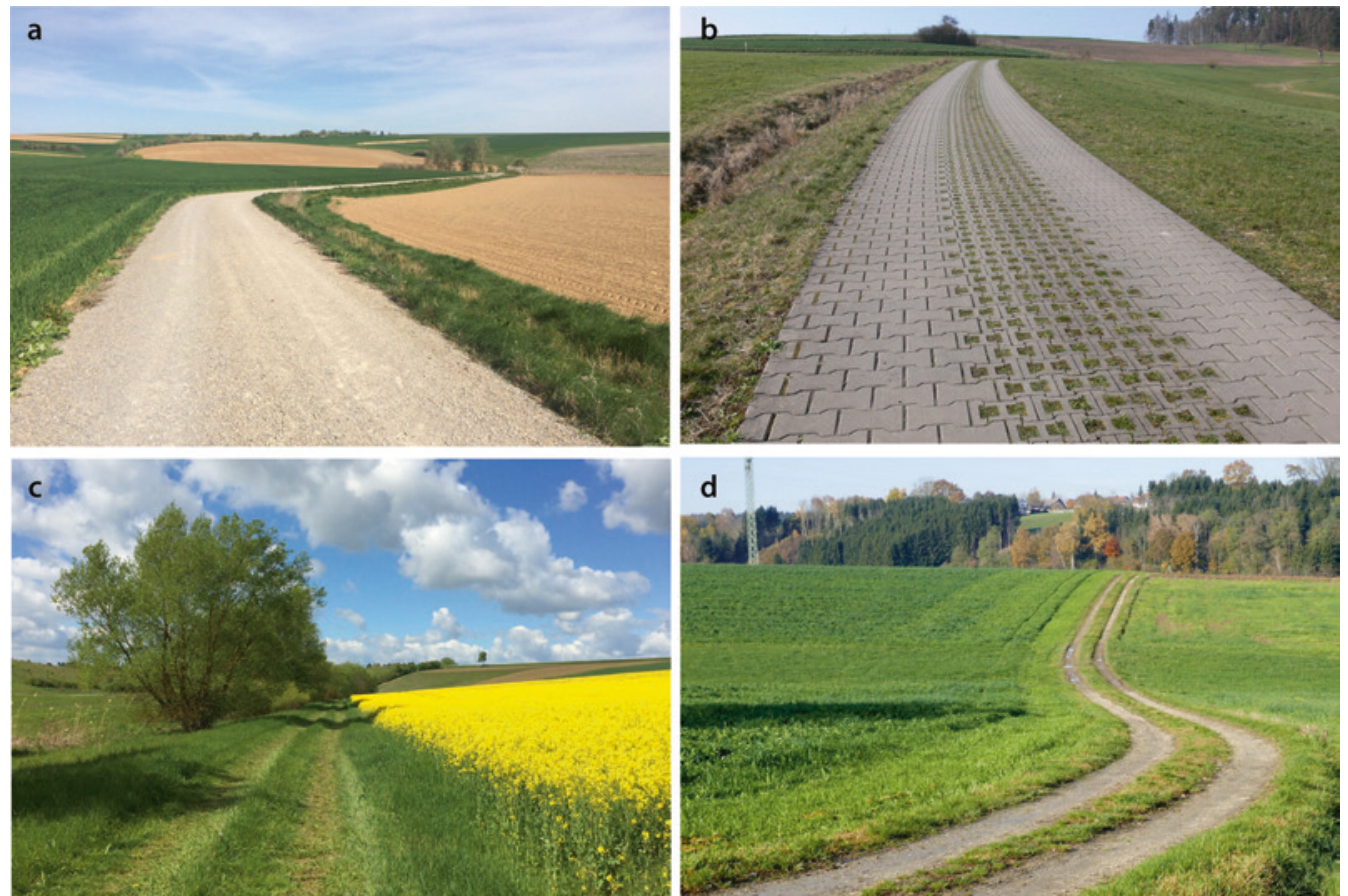

- Abb. 6.24 Zu den Wegtypen, die sich günstiger auf den Wasserhaushalt auswirken als durchgehend asphaltierte Fahrbahnen, zählen Wege mit wassergebundener Tragdeckschicht (Schotterwege) (a), Pflasterspurwege (b) und Grünwege (c). Bei wenig befahrenen Schotterwegen (d) „begrünt" sich der Mittelstreifen oft von selbst. Das Bild zeigt deutlich die Vernässung in der Hangmulde, die häufig als Begründung für eine Wegbefestigung genannt wird. Die Vernässung ließe sich einfach vermeiden, indem der Weg auf einem kleinen Damm geführt und hinter dem Damm ein Retentionsbecken geschaffen würde. (Bildquellen: $a, b$ und c: Peter Pfarr, d: Karl Auerswald) 
- Tab. 6.10 Mittlere Abflussbeiwerte für unterschiedliche Wegoberflächen

\begin{tabular}{|l|l|l|}
\hline Befestigungsart & $\begin{array}{l}\text { Mittlerer Abflussbeiwert } \\
{[\text { nach 45] }}\end{array}$ & $\begin{array}{l}\text { Abflussbeiwert } \\
\text { bei Starkregen }\end{array}$ \\
\hline Asphalt, fugenloser Beton & 0,90 & 0,98 \\
\hline Pflaster mit dichten Fugen & 0,75 & 0,95 \\
\hline fester Kiesbelag (wassergebundene Decken) & 0,60 & 0,92 \\
\hline Pflaster mit offenen Fugen & 0,50 & 0,90 \\
\hline lockerer Kiesbelag, Schotterrasen & 0,30 & 0,86 \\
\hline Verbundsteine mit Fugen, Sickersteine & 0,25 & 0,85 \\
\hline Rasengittersteine & 0,15 & 0,83 (Bodengruppe D: 0,88) \\
\hline
\end{tabular}

Regen, sind aber auf Starkregen nicht anwendbar, da sie deutlich niedriger sind als die Endabflussbeiwerte selbst von Wald (vgl. - Tab. 8.12). Für Starkregen wurden daher die Werte um den Betrag $(1-$ Mittel $) \times 0,8$ erhöht. Rasengittersteine entsprechen dann etwa Reihenkulturen, was ihre Abflussneigung bei Starkregen vermutlich immer noch unterschätzt.

Mögliche Ansatzpunkte zur Förderung des Wasserrückhalts bestehen daher einerseits darin, eine Fahrbahndecke mit kleinem Abflussbeiwert $\mathrm{zu}$ wählen - der Effekt bei Starkregen ist aber klein. Die zweite Maßnahme ist, die versiegelte Fläche zu vermindern, indem nur Spurwege angelegt werden. Bei den für Wirtschaftswege üblichen Dimensionen (Fahrbahnbreite $3 \mathrm{~m}$ bzw. Zwischenstreifenbreite bei Spurwegen 0,9 m) [62] reduziert sich die versiegelte Fläche durch die Beschränkung des Weges auf die Fahrspuren um $30 \%$ und etwa ebenso das Abflussvolumen. Für ein Einzugsgebiet mit einer Fläche von 100 ha ließe sich durch die konsequente Anlage von Spurwegen mit Verbundsteinen bei einer mittleren Wegenetzdichte von rund $60 \mathrm{~m} \mathrm{ha}^{-1}$ [73] bei einer Niederschlagshöhe von $50 \mathrm{~mm}$ ein Abflussvolumen von rund $70 \mathrm{~m}^{3}$ in der Fläche zurückhalten. Etwa ebenso groß wäre die Abflussminderung, wenn statt der Verbund- steine eine Kiesdecke verwendet würde. Kombiniert man Spurweg und Kies, steigt die Verminderung auf $120 \mathrm{~m}^{3}$.

Um den Wasserrückhalt in der Fläche zu fördern und den Abfluss zu verzögern, gelten für das Wegenetz folgende allgemeine Empfehlungen. Eine detailliertere (qualitative) Beschreibung von Ansatzpunkten für unterschiedliche Wegverläufe kann - Anhang 8.7 entnommen werden:

- Die Länge (Dichte) des Wegenetzes und die Wegbreite sollten so gering wie möglich sein, da sich der Oberflächenabfluss proportional zur Vergrößerung des versiegelten Flächenanteils erhöht [74]. Dieser Effekt ist auch für Waldgebiete nachgewiesen und dort von größerer Bedeutung als die Bestandszusammensetzung [67].

- Natürliche, topographisch bedingte Entwässerungswege dürfen durch die Anlage von Wegen und Wegseitengräben nicht verkürzt (z. B. durch Verrohrungen oder Begradigung) oder in ihrer abflussabführenden Wirkung verstärkt werden (z. B. durch die Anlage von Wegen oder Gräben in der Tiefenlinie).

- Das Sammeln und konzentrierte Ableiten von Abfluss erfordert Sicherungsmaßnahmen unterhalb, z. B. begrünte Abflussmulden. 
Wege und Wegseitengräben können auch als Abflusshindernis eingesetzt werden. Dazu sollten Wege möglichst senkrecht zur Hauptgefällerichtung angelegt werden, da hierdurch die hydraulisch wirksame Hanglänge verkürzt wird. Je größer die Anzahl hanggliedernder Strukturen, d. h. je kürzer der Hang, desto mehr Möglichkeiten gibt es, die Fließgeschwindigkeit $\mathrm{zu}$ reduzieren und die Fließstrecke $\mathrm{zu}$ verlängern bzw. hochwassermindernde Abflusswege in der Fläche zu etablieren. Wege, die parallel zu den Höhenlinien verlaufende Wege verbinden, sollten auf Höhenrücken (d. h. entlang der topographischen Wasserscheide) liegen, da das Einzugsgebiet dann klein und die Bedeutung des Weges für die Gebietsentwässerung gering ist $[9,75]$. Bei Umsetzung dieser Prinzipien resultieren lange, hangparallele und arbeits- wie betriebswirtschaftlich günstig geschnittene Flurstücke [62], die in der Landschaft jedoch bis heute wenig verbreitet sind.

Da Hänge immer gemuldet sind, die Wege aber gerade geführt werden, um eine gerade Bewirtschaftung $\mathrm{zu}$ ermöglichen, durchschneiden diese Wege die Hangmulden. Das schafft die Möglichkeit, viele kleine Retentionsbecken mit gedrosseltem Auslauf anzulegen. Dazu werden die Wege in den Hangmulden etwas angehoben, wodurch dahinter ein Retentionsbecken entsteht (- Abb. 6.25, Abb. 8.19). Das erleichtert und verbessert auch die Befahrbarkeit, da weniger Neigungen entlang des Weges auftreten und da der Weg oberhalb der nassen Hangmulde bleibt und damit rasch abtrocknet. Der gedrosselte Auslauf stellt sicher, dass der Weg nicht durchweicht und die landwirtschaftliche Nutzung im Becken weiterhin möglich bleibt, weil es innerhalb von wenigen Tagen wieder auslaufen kann. Da Abfluss spätestens am Auslauf konzentriert wird, muss er idealerweise in einer begrünten Abflussmulde weitergeführt werden (linke Becken in • Abb. 6.25), oder - weit ungünstiger - durch Verrohrung (siehe gestrichelte Linie der rechten Becken in - Abb. 6.25).

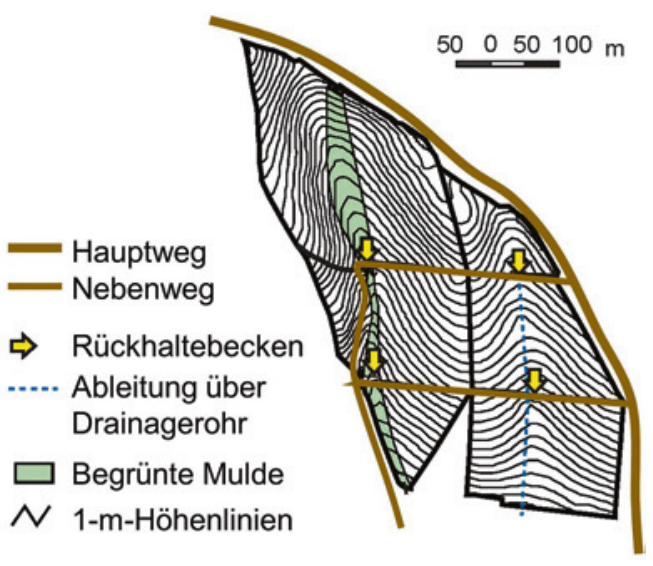

- Abb. 6.25 Die Anlage von Wirtschaftswegen quer zum Hauptgefälle (höchster Punkt ist in der Zeichnung oben) verkürzt die Abflusswege und erlaubt durch Erhöhung des Fahrwegs in den Tiefenlinien, die Befahrbarkeit bei nassen Verhältnissen zu verbessern und gleichzeitig dahinter Retentionsbecken zu schaffen. (Nach [49], verändert)

\section{Literatur}

1. Brandhuber R, Treisch M, Fischer F et al (2017) Starkregen, Bodenerosion, Sturzfluten. Schriftenr Bayer Landesanst Landwirtsch 2: Freising

2. Kainz M (1989) Runoff, erosion and sugar beet yields in conventional and mulched cultivation. Soil Technol Ser 1:103-114

3. Renard KG, Yoder DC, Lightle DT, Dabney SM (2011) Universal soil loss equation and revised universal soil loss equation. In: Morgan RPC, Nearing MA (Hrsg) 137-167, Blackwell, Oxford

4. Fröba N, Brunotte J, Mosimann T et al (2015) Gute fachliche Praxis. Bodenbewirtschaftung und Bodenschutz, aid Infodienst Ernährung, Landwirtschaft, Verbraucherschutz, Bonn

5. Auerswald K, Albrecht H, Kainz M, Pfadenhauer J (2000) Principles of sustainable land-use systems developed and evaluated by the Munich Research Alliance on Agro-Ecosystems (FAM). Petermanns Geogr Mitt 144:16-25

6. Natural Resources Conservation Service (2004) Estimation of direct runoff from storm rainfall. In: National Engineering Handbook. Part 630 Hydrology, chapter 10. United States Department of Agriculture, Washington

7. Fiener P, Wilken F, Auerswald K (2019) Filling the gap between plot and landscape scale - eight years of soil erosion monitoring in 14 adjacent watersheds under soil conservation at Scheyern, 
Southern Germany. Adv Geosci 48:31-48. - https://doi.org/10.5194/adgeo-48-31-2019

8. Mosimann T, Sanders S, Brunotte J (2007) Erosionsminderung in Fahrgassen - Wirkung der Intervallbegrünung in Weizen und Zuckerrüben bei verschiedenen Bodenbearbeitungsverfahren. Pflanzenbauwissenschaften 11:57-66

9. Bronstert A, Seiert S, Oberholzer G (1993) Maßnahmen der Flurbereinigung und ihre Wirkung auf das Abflussverhalten ländlicher Gebiete. Schriftenr Landesamt Flurneuord Landent Baden-Württemberg 3: Kornwestheim

10. Natural Resources Conservation Service (2018) Contour farming (Code 330). Conservation Practice Standard. US Department of Agriculture, Washington

11. Auerswald K (1992) Verfeinerte Bewertung von Erosionsschutzmaßnahmen unter deutschen Anbaubedingungen mit dem P-Faktor der Allgemeinen Bodenabtragsgleichung (ABAG). Z Kulturtechnik Landentwick 33:137-144

12. Demmel $M$, Kirchmeier $H$, Blumenthal $B$ et al (2016) Streifenbodenbearbeitung vor Zuckerrüben und Körnermais. Schriftenr Bayer Landesanst Landwirtsch 3: Freising

13. Kornmann M, Schmidt W, Müller E (2006) Umsetzung erosionsmindernder und hochwasserreduzierender Maßnahmen auf Einzugsgebietsebene am Beispiel des Stausees Baderitz. In: Landwirtschaftlicher Bodenschutz. Schriftenr Sächs Landesanst Landwirtsch 10:79-86, Dresden

14. Tomer MD, Meek DW, Kramer LA (2005) Agricultural practices influence flow regimes of headwater streams in Western lowa. J Environ Qual 34:1547. > https://doi.org/10.2134/jeq2004.0199

15. Wang X, Gassman PW, Williams JR et al (2008) Modeling the impacts of soil management practices on runoff, sediment yield, maize productivity, and soil organic carbon using APEX. Soil Tillage Res 101:78-88

16. Dabney SM, Moore MT, Locke MA (2006) Integrated management of in-field, edge-of-field, and after-field buffers. J Am Water Resour Assoc 42:15-24. > https://doi. org/10.1111/j.1752-1688.2006.tb03819.x

17. Chen B, Krajewski WF, Helmers MJ, Zhang Z (2019) Spatial variability and temporal persistence of event runoff coefficients for cropland hillslopes. Water Resour Res 55:1583-1597. https://doi. org/10.1029/2018WR023576

18. Atkins DM, Coyle JJ (1977) Grass Waterways in Soil Conservation. US Department of Agriculture, Leaflet 477: Washington

19. Berg NA, Gray RJ (1984) Soil conservation: "The search for solutions". J Soil Water Conserv 39:18-22
20. Natural Resources Conservation Service (1999) CORE4 Conservation Practices Training Guide. US Department of Agriculture, Washington

21. Fiener P, Auerswald K (2005) Measurement and modeling of concentrated runoff in grassed waterways. J Hydrol 301:198-215. https://doi. org/10.1016/j.jhydrol.2004.06.030

22. Fiener P, Auerswald K (2003) Concept and effects of a multi-purpose grassed waterway. Soil Use Manag 19:65-72. > https://doi.org/10.1079/ SUM2002170

23. Fiener P, Auerswald K (2018) Grassed waterways. In: Delgado J, Sassenrath G, Mueller T (Hrsg) Precision Conservation: Geospatial Techniques for Agricultural and Natural Resources Conservation. Agronomy Monographs 59:131-150, Madison

24. Neufang L, Auerswald K, Flacke W (1989) Automatisierte Erosionsprognose- und Gewässerverschmutzungskarten mit Hilfe der dABAG - ein Beitrag zur standortgerechten Bodennutzung. Bayer Landwirtsch Jahrb 66:1-19

25. Sächsisches Landesamt für Umwelt, Landwirtschaft und Geologie (2015) Begrünung von erosionsgefährdeten Abflussbahnen. Dresden

26. Sächsisches Landesamt für Umwelt, Landwirtschaft und Geologie (2010) Erosionsschutz in reliefbedingten Abflussbahnen. Schriftenr 13: Dresden

27. Flacke W, Auerswald K, Neufang L (1990) Combining a modified Universal Soil Loss Equation with a digital terrain model for computing high resolution maps of soil loss resulting from rain wash. Catena 17:383-397

28. Kagerer J, Auerswald K (1997) ErosionsprognoseKarten im Maßstab 1:5000 für Flurbereinigungsverfahren und Landwirtschaftsberatung. Schriftenr Bayer Landesanst Bodenkultur Pflanzenbau 2: Freising

29. Fiener P, Auerswald K (2006) Influence of scale and land use pattern on the efficacy of grassed waterways to control runoff. Ecol Eng 27:208-218. - https://doi.org/10.1016/j.ecoleng.2006.02.005

30. Fiener P, Auerswald K (2006) Seasonal variation of grassed waterway effectiveness in reducing runoff and sediment delivery from agricultural watersheds in temperate Europe. Soil Tillage Res 87:48-58. > https://doi.org/10.1016/j.still.2005. 02.035

31. Sieker F, Wilcke D, Reich M, et al (2007) Vorbeugender Hochwasserschutz durch Wasserrückhalt in der Fläche unter besonderer Berücksichtigung naturschutzfachlicher Aspekte am Beispiel des Flusseinzugsgebietes der Mulde in Sachsen. Abschlussbericht, Institut für Wasserwirtschaft, Hydrologie und landwirtschaftlichen Wasserbau der Leibniz Universität Hannover. 
Deutsche Bundesstiftung Umwelt (Projekt AZ 214679), Hannover

32. Bracmort KS, Engel BA, Frankenberger JR (2004) Evaluation of structural best management practice 20 years after installation. J Soil Water Conserv 59:191-196

33. Lenz A, Karlstetter M, Knogler F (2006) Sanierung des ländlichen Stoffhaushalts durch Ländliche Entwicklung. Teil B: Fallbeispiel Schwimmbach. Ingenieurbüro Lenz, Ringelai

34. Reichert E, Achtziger R, Seidler C et al (2007) Maßnahmensteckbriefe zur Broschüre Wasser + Landschaft. Arbeitsgrundlage zur Optimierung einer nachhaltigen Landnutzung aus Sicht des Hochwasserschutzes und des Natur- und Landschaftsschutzes. Deutsche Bundesstiftung Umwelt, Interdisziplinäres Ökologisches Zentrum, Technische Universität Bergakademie, Freiberg

35. Auerswald K (2019) Grünlandverlust - Ursachen und Wirkungen. Schriftenr Bayer Landesanst Landwirtsch 6:17-20, Freising

36. Kreiter T (2007) Dezentrale und naturnahe Retentionsmaßnahmen als Beitrag zum Hochwasserschutz in mesoskaligen Einzugsgebieten der Mittelgebirge. Dissertation, Universität, Trier

37. Schepers JS, Francis DD, Mielke LN (1985) Water quality from erosion control structures in Nebraska. J Environ Qual 14:186-190. https:// doi.org/10.2134/jeq1985.00472425001400020007x

38. Natural Resources Conservation Service (1997) Ponds - Planning, Design, Construction. Agric Handbook 590: US Department of Agriculture, Washington

39. Natural Resources Conservation Service (2011) Terraces. In: Engineering Field Handbook. Part 650, chapter 8. US Department of Agriculture, Washington

40. Natural Resources Conservation Service (2019) Earth Dams and Reservoirs. Technical Release 210-60: US Department of Agriculture, Washington

41. Deutschen Institut für Normung (2004) Stauanlagen - Teil 12: Hochwasserrückhaltebecken. DIN 19700: Beuth Verlag, Berlin

42. Zanke U (2012) Hydraulik für den Wasserbau. Springer, Berlin

43. Schröder W, Euler G, Schneider F, Knauf D (1994) Grundlagen des Wasserbaus. Werner, Düsseldorf

44. Patt H, Jüpner R (2013) Hochwasser-Handbuch. Auswirkungen und Schutz. Springer, Berlin

45. Deutsche Vereinigung für Wasserwirtschaft, Abwasser und Abfall (2013) Bemessung von Regenrückhaltebecken. Arbeitsbl DWA-A 117: Hennef

46. Teschemacher S, Rieger W (2018) Ereignisabhängige Optimierung dezentraler Kleinrückhaltebecken unter Berücksichtigung von
Standort, Retentionsvolumen und Drosselweite. Hydrol und Wasserbewirtsch 62:297-311. > https://doi.org/10.5675/HyWa

47. McLemore AJ, Tyner JS, Yoder DC, Buchanan JR (2013) Discharge coefficients for orifices cut into round pipes. J Irrig Drain Eng 139:947-954. - https://doi.org/10.1061/(ASCE)IR.19434774.0000641

48. Wanielista MP, Kersten R, Eaglin R (1996) Hydrology: water quantity and quality control. Wiley, New York

49. Fiener P, Auerswald K, Weigand S (2005) Managing erosion and water quality in agricultural watersheds by small detention ponds. Agric Ecosyst Environ 110:132-142. $>$ https://doi. org/10.1016/j.agee.2005.03.012

50. Harrell LJ, Ranjithan SR (2003) Detention pond design and land use planning for watershed management. J Water Resour Plan Manag 129:98106. https://doi.org/10.1061/(ASCE)0733-9496 (2003)129:2(98)

51. Heitz LF, Khosrowpanah S, Nelson J (2000) Sizing of surface water runoff detention ponds for water quality improvement. J Am Water Resour Assoc 36:541-548. https://doi. org/10.1111/j.1752-1688.2000.tb04285.x

52. Hong Y-M, Yeh N, Chen J-Y (2006) The simplified methods of evaluating detention storage volume for small catchment. Ecol Eng 26:355-364. > https://doi.org/10.1016/J.ECOLENG.2005.12.006

53. Lukas A (2003) Wasserrückhaltung durch Ländliche Entwicklung - Evaluierung von dezentralen Wasserrückhaltemaßnahmen. Diplomarbeit, Lehrstuhl für Bodenordnung und Landentwicklung, Technische Universität München

54. Ankenbrand E, Schwertmann U (1989) The land consolidation project of Freinhausen, Bavaria. Soil Technol Ser 1:167-173

55. Schwertmann U, Vogl W, Kainz M (1987) Bodenerosion durch Wasser - Vorhersage des Bodenabtrags und Bewertung von Gegenmaßnahmen. Ulmer, Stuttgart

56. Kistler M, Brandhuber R, Maier H (2013) Wirksamkeit von Erosionsschutzmaßnahmen, Ergebnisse einer Feldstudie. Schriftenr Bayer Landesanst Landwirtsch 8: Freising

57. Petit S, Stuart RC, Gillespie MK, Barr CJ (2003) Field boundaries in Great Britain: stock and change between 1984, 1990 and 1998. J Environ Manag 67:229-238. > https://doi.org/10.1016/S03014797(02)00176-7

58. Müller G (2013) Europas Feldeinfriedungen: Wallhecken (Knicks), Hecken, Feldmauern (Steinwälle), Trockenstrauchhecken, Biegehecken, Flechthecken, Flechtzäune und traditionelle Holzzäune. Neuer Kunstverlag, Stuttgart 
59. Merot P (1999) The influence of hedgerow systems on the hydrology of agricultural catchments in a temperate climate. Agronomie 19:655-669. > https://doi.org/10.1051/ agro:19990801

60. Seidler M (2018) Verringerung von Sturzfluten nach Starkregenereignissen - Möglichkeiten und Potentiale der Flurneuordnung durch abflussbremsende Flurgestaltung. Masterarbeit, Lehrstuhl für Bodenordnung und Landentwicklung, Technische Universität München

61. Gamperl H (1967) Ländliche Neuordnung (Flurbereinigung). In: Jordan W, Eggert O, Kneissl M (Hrsg) Handbuch der Vermessungskunde 4b: Metzler, Stuttgart

62. Deutsche Vereinigung für Wasserwirtschaft, Abwasser und Abfall (2016) Richtlinien für den Ländlichen Wegebau (RLW) Teil 1: Richtlinien für die Anlage und Dimensionierung ländlicher Wege. Arbeitsbl DWA-A 904-1: Hennef

63. Bäuml N, Aulig G, Overland H, Krüger G-M (2006) Vorbeugender Hochwasserschutz in der ländlichen Entwicklung - aufgezeigt an der Studie zum vorbeugenden und dezentralen Hochwasserschutz in der Regionalen Landentwicklung Auerbergland. LWF Wissen 55: 67-72 Bayer Landesanst Wald und Forstwirt. Freising

64. Bronstert A, Vollmer S, Ihringer J (1995) Die Bedeutung von Flurbereinigungsmaßnahmen für das Abflussverhalten von Starkniederschlägen in ländlichen Gebieten. Wasser Boden 47:29-46

65. Moussa R, Voltz M, Andrieux P (2002) Effects of the spatial organization of agricultural management on the hydrological behaviour of a farmed catchment during flood events. Hydrol Process 16:393-412. > https://doi.org/10.1002/hyp.333

66. Fiener P, Auerswald K, Van Oost K (2011) Spatio-temporal patterns in land use and management affecting surface runoff response of agricultural catchments-A review. Earth-Sci Rev 106:92-104. > https://doi.org/10.1016/j. earscirev.2011.01.004
67. Tempel M (2006) Abflussverhalten kleiner, forstlich genutzter Bacheinzugsgebiete am Beispiel des Einzugsgebietes des Oberen Gräfenbaches im Soonwald/Hunsrück. Dissertation, JohannesGutenberg-Universität, Mainz

68. Binder F, Macher C, Klöcking B (2006) Integrale Planung von Erstaufforstungen am Beispiel der Paar in der Gemeinde Geltendorf. LWF Wissen 55:73-82 Bayer Landesanst Wald und Forstwirt. Freising

69. Deutsche Vereinigung für Wasserwirtschaft, Abwasser und Abfall (2016) Richtlinien für den Ländlichen Wegebau (RLW) Teil 1: Richtlinien für die Anlage und Dimensionierung ländlicher Wege. Arbeitsbl DWA-A 904-1: Hennef

70. Steppich J (2014) Wasserabfluss und Stoffausträge von Ackerflächen und die Auswirkung von Straßengräben. Digitale Berechnungsmodelle und Hinweise für die Planung in der Ländlichen Entwicklung. Masterarbeit, Institut für Geodäsie, GIS und Landmanagement, Technische Universität, München

71. H\&S Ingenieure (2018) Arbeitspapier Roithbauernbächlein. Bericht zur Empfehlung und Umsetzung von Maßnahmen im Rahmen des boden:ständig-Projektes Teugn - Roitbauernbächlein. Freising

72. Landesamt für Flurneuordnung (2008) Naturnaher Wegebau im ländlichen Raum. Regierungspräsidium Stuttgart, Kornwestheim

73. Machl T, Ewald W, Donaubauer A, Kolbe TH (2016) Entwicklung eines Werkzeugs zur landesweit flächendeckenden Analyse landwirtschaftlicher Transportbeziehungen in Bayern. Z für Geodäsie, Geoinf und Landmanagement 3:197-205

74. Luft G, Vogelbacher A (1985) Modellrechnungen zum Einfluß von Großterrassierungen auf den Abflußprozeß. Z für Kulturtech und Flurberein 26:1-12

75. Hach G, Höltl W (1989) Maßnahmen zur Erhaltung und Verbesserung der Wasserrückhalte-, Wasserreinhalte- und Speicherfähigkeit in der Landwirtschaft. Z Kulturtech Landentwickl 30:8-21 
Open Access Dieses Kapitel wird unter der Creative Commons Namensnennung 4.0 International Lizenz ( $\triangleright$ http://creativecommons.org/licenses/by/4.0/deed.de) veröffentlicht, welche die Nutzung, Vervielfältigung, Bearbeitung, Verbreitung und Wiedergabe in jeglichem Medium und Format erlaubt, sofern Sie den/ die ursprünglichen Autor(en) und die Quelle ordnungsgemäß nennen, einen Link zur Creative Commons Lizenz beifügen und angeben, ob Änderungen vorgenommen wurden.

Die in diesem Kapitel enthaltenen Bilder und sonstiges Drittmaterial unterliegen ebenfalls der genannten Creative Commons Lizenz, sofern sich aus der Abbildungslegende nichts anderes ergibt. Sofern das betreffende Material nicht unter der genannten Creative Commons Lizenz steht und die betreffende Handlung nicht nach gesetzlichen Vorschriften erlaubt ist, ist für die oben aufgeführten Weiterverwendungen des Materials die Einwilligung des jeweiligen Rechteinhabers einzuholen. 